Portland State University

PDXScholar

$11-30-2021$

\title{
Community College Geoscience Faculty Perspectives on Critical Thinking Instructional Tools
}

Mariela Salas Bao

Portland State University

Follow this and additional works at: https://pdxscholar.library.pdx.edu/open_access_etds

Part of the Community College Leadership Commons, Curriculum and Instruction Commons, and the Geology Commons

Let us know how access to this document benefits you.

\section{Recommended Citation}

Bao, Mariela Salas, "Community College Geoscience Faculty Perspectives on Critical Thinking Instructional Tools" (2021). Dissertations and Theses. Paper 5859.

https://doi.org/10.15760/etd.7730

This Dissertation is brought to you for free and open access. It has been accepted for inclusion in Dissertations and Theses by an authorized administrator of PDXScholar. Please contact us if we can make this document more accessible: pdxscholar@pdx.edu. 
Community College Geoscience Faculty Perspectives on Critical Thinking Instructional Tools

by

Mariela Salas Bao

A dissertation submitted in partial fulfillment of the requirements for the degree of

\author{
Doctor of Education \\ in \\ Educational Leadership: Curriculum and Instruction
}

\author{
Dissertation Committee: \\ Micki M. Caskey, Chair \\ Anita Bright \\ Amanda Sugimoto \\ Erin Shortlidge
}

Portland State University

2021 


\begin{abstract}
Research has shown that modern courses and programs designed to foster critical thinking vary in both content and delivery, in turn leading to differences in their effectiveness. Few studies have investigated critical thinking among nontraditional students at community colleges taking STEM courses, especially within the geosciences. Furthermore, such research has focused primarily on the students with few if any studies involving faculty. This study examined the perceptions held by community college geoscience faculty regarding critical thinking and how such perceptions influenced their choice of instructional strategies. This study used a basic qualitative methodology and a maximum variation sampling to select seven participants. The data collected included one survey, two semi-structured interviews, documents, and the researcher's field notes for each of the seven participants. The analysis of the data used two coding cycles. The first cycle used in vivo coding (i.e., open coding) and values coding. The second cycle used pattern coding. The study findings centered around five themes: (a) critical thinking has a hierarchical order, (b) the misalignment of how faculty, departments and institutions understand critical thinking, (c) critical thinking is embedded in scientific literacy, (d) critical thinking takes time, and (e) the pedagogy of hope. Ultimately, the perception and use of critical thinking instructional strategies among community college geoscience faculty was implicit. This characteristic of implicitness permeated the epistemological stances and held belief systems of faculty. It also seemed to influence the pedagogy of critical thinking at the departmental and institutional level. Recognizing the implicit
\end{abstract}


characteristic of critical thinking could offer opportunities for faculty, departments, and institutions to develop critical thinking instruction. 


\section{Dedication}

I would like to dedicate this work to my family: my dear husband, Dr. Brian Aoqi Bao and our beloved son, Brandon Andrés Habuer Bao. Your unwavering support throughout this journey was the key of getting this work done successfully.

To my husband, Brian, the love of my life, thank you for always listening, providing ideas, asking big questions, your incredible pep talks, and always believing in me without any reservations. Your steadfast support even during this pandemic where your work changed our entire lives was incredible and quite honestly it was what inspired me to give it my all. Thank you for caring for Brandon while I worked and for making us smile despite the challenges. Love you to infinity.

To my beloved son, Brandon Andrés, life is an incredible journey filled with millions of paths. Never be afraid to try despite the challenges. Sometimes you may feel self-doubt when things do not turn out like you envisioned, but it is from those challenging times that we learn the most about ourselves. Try again anyways, failures are merely opportunities. Like Yamada said in his book, Trying, "When we make it safe to fail, we make it safe to succeed." I will always be there with you; I love you so much buddy. 


\section{Acknowledgements}

This dissertation would have not been possible without the immense support of a series of important people in my life.

First, I would like to thank my family. A mi mamá, Lcda. Luz M de la Cruz y mi papá, Ing. Catalino Salas Quintana gracias por darme alas para volar y descubrir el mundo a mi manera. Gracias por el apoyo y amor incondicional durante todo este proceso. Por enseñarme que la vida esta llena de oportunidades para crecer, que no hay experiencias malas y buenas. Sin embargo, todas las experiencias son oportunidades que nos da la vida para mejorarse a uno mismo, solo toca reconocer y estar dispuesto a seguir el camino no importa la adversidad. A mi hermano, Dr. David Salas de la Cruz y mi hermana Arq. Mara Salas Chance les doy las gracias por su amor, el apoyo, por escucharme, darme consejos, y por siempre estar allí a mi lado. Los amo.

I would like to thank my committee members, Dr. Bright, Dr. Sugimoto, and Dr. Shortlidge. Thank you for lifting me up throughout this entire process. For taking the time and patience while providing intellectual contributions to my development as education scholar. Thank you for challenging me to continue pushing the boundaries and for reminding me to persevere despite of the challenges.

Most importantly, I would like to express my deepest gratitude to my incredible advisor, Dr. Micki Caskey. Thank you for really “seeing” me, for knowing precisely when to challenge me, when I needed guidance, and knowing the times when I needed nurturing. Thank you for creating a safe-to-fail environment so that I could build a strong confidence in my thinking and development as a scholar. Your unwavering support and 
undoubted belief in me have been crucial throughout this entire journey. And lastly, thank you for providing a supporting environment where we lifted each other. Thank you for being the advisor I always dreamed of having but did not know was possible.

To my EdD Curriculum and Instruction cohort friends, thank you for teaching me so much, for always sharing your thoughts and experiences. Learning alongside from every single one of you was one of the best experiences for me in this program. A special thanks to Dr. Brea Cardiel, my dearest friend, my study buddy, and the one person whose advice always lifted me in ways I do not have enough words to express. Thank you for being such an amazing friend and inspiration.

A very special thanks to my writing tutor, Dr. Jacinta Galea’i. Thank you for teaching me how to become a better writer. Our tutoring sessions during this program were invaluable.

Lastly, I would like to thank my longtime mentor and the one person who inspired me to pursue and experience academia outside of Puerto Rico, Dr. Michael Plater. Thank you for believing in me especially during the times I doubted myself the most. Thanks for all your advice and your unwavering support throughout all these years. 
Table of Contents

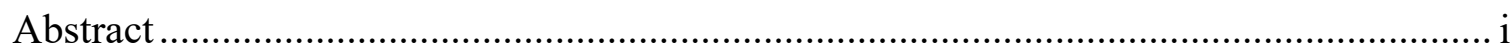

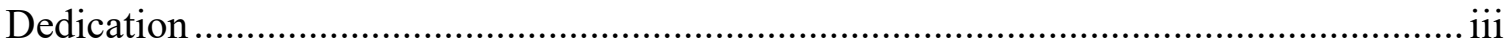

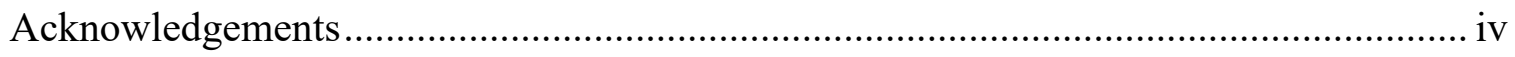

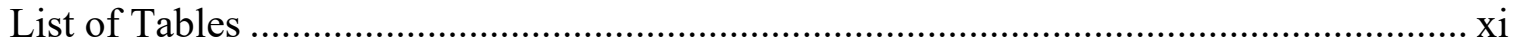

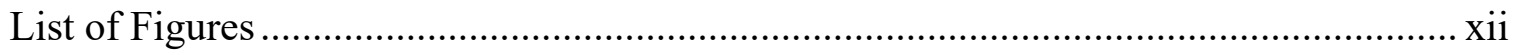

Chapter 1: Problem Statement ........................................................................................ 1

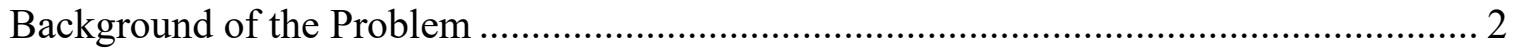

Statement of the Research Problem ........................................................................... 9

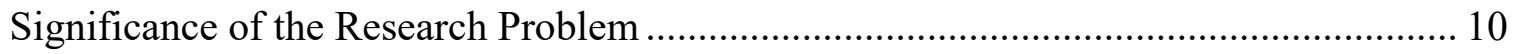

Presentation of Methods and Research Questions .................................................. 11

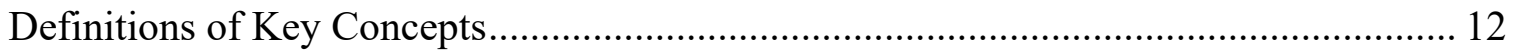

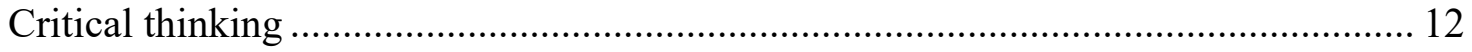

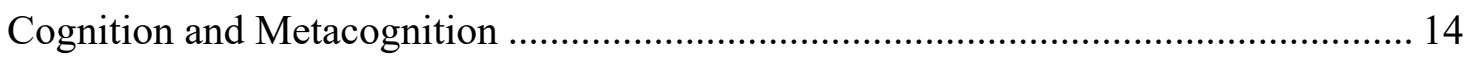

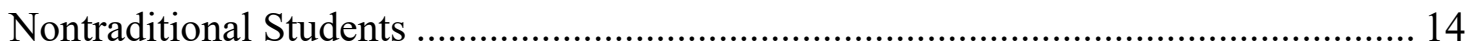

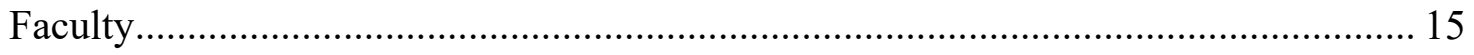

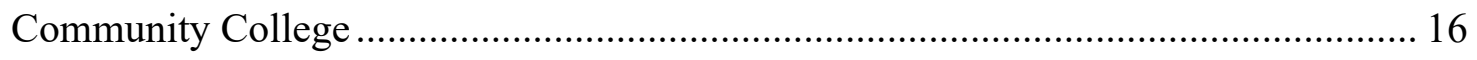

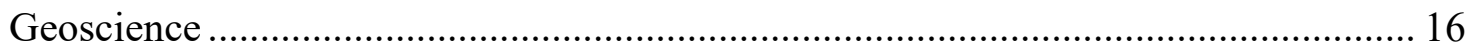

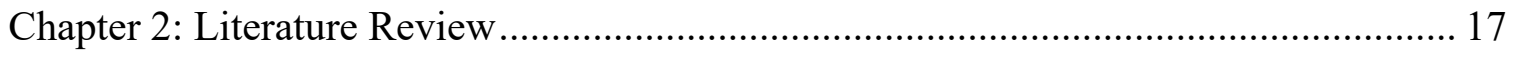


Theoretical Framework: Sociocultural Theory ……………..................................... 18

Analyzing the Problem using Sociocultural Theory ................................................... 21

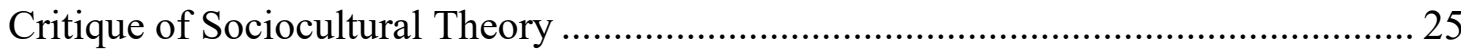

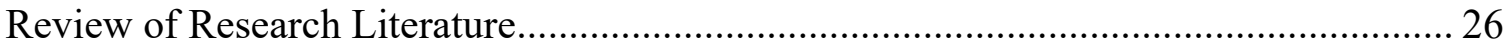

Epistemological Beliefs around Critical Thinking ………........................................ 30

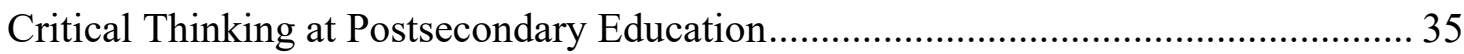

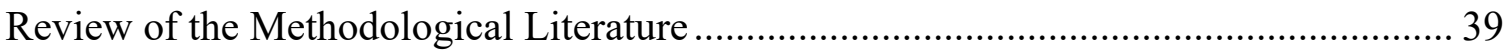

Summary of the Research Literature and Application of the Study .................................. 45

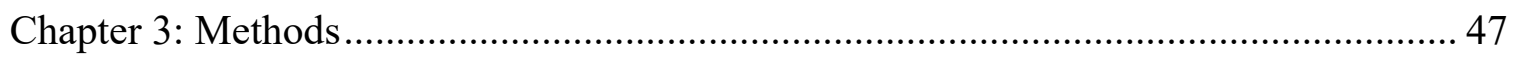

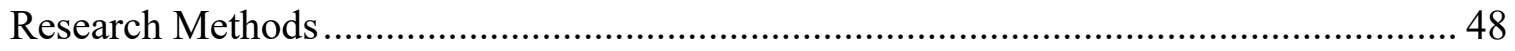

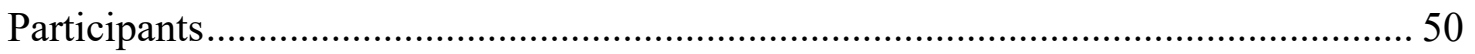

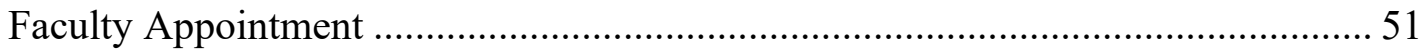

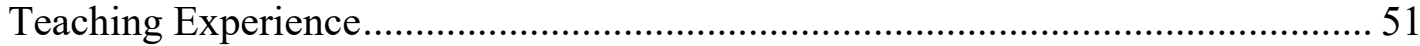

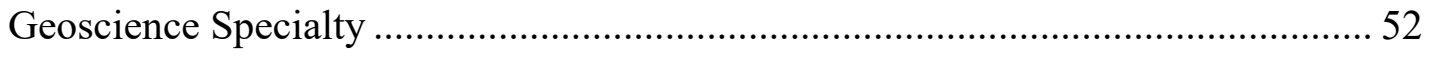

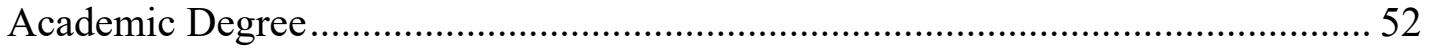

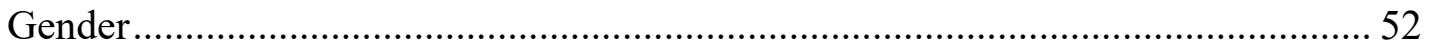

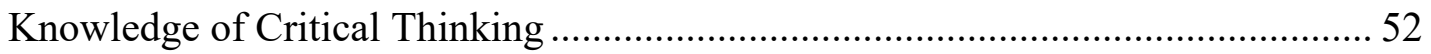

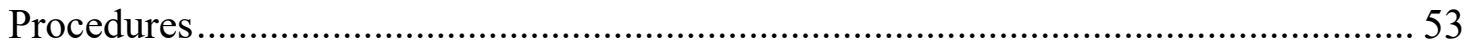

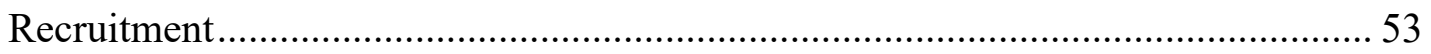

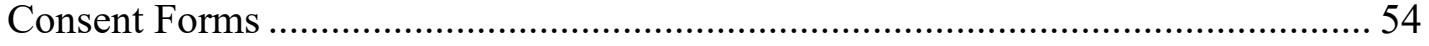




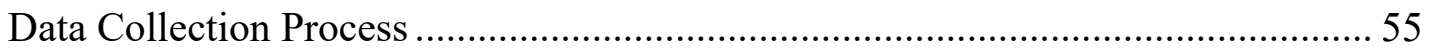

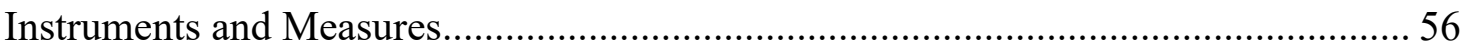

Critical Thinking Survey for Geoscience Faculty ……………………….............. 57

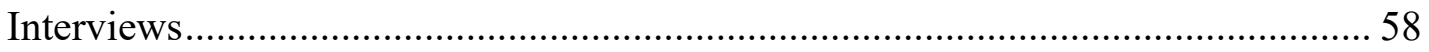

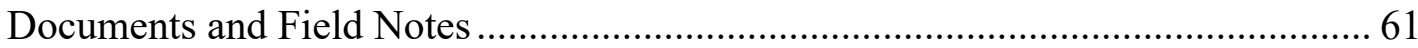

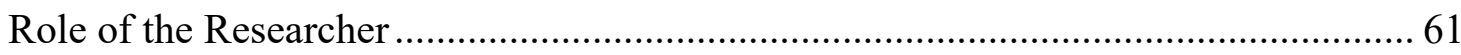

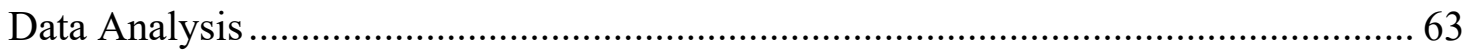

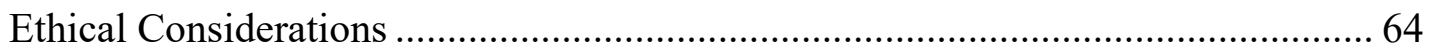

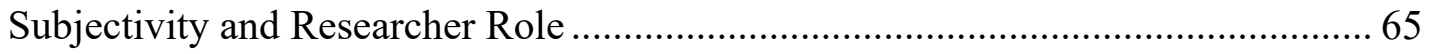

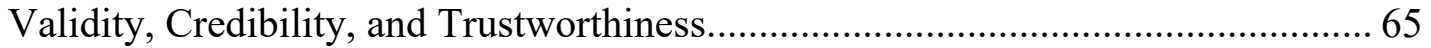

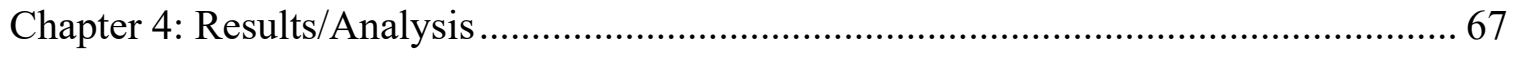

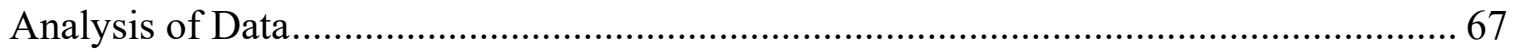

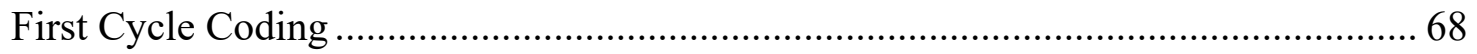

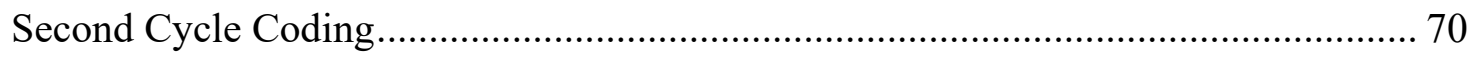

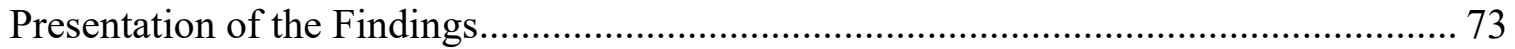

Critical Thinking has a Hierarchal Order.................................................................. 73

Misalignment of How Faculty, Department, and Institutions Understand Critical

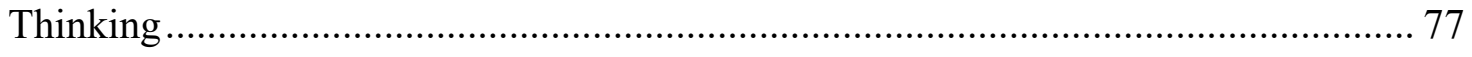

Critical Thinking is an Abstract Concept............................................................... 77

Role of Critical Thinking within Departments and Institutions................................. 80 


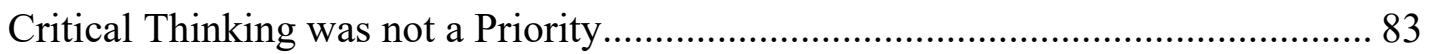

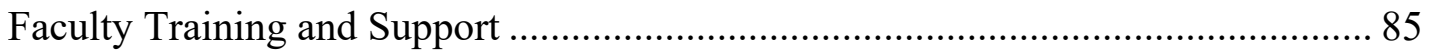

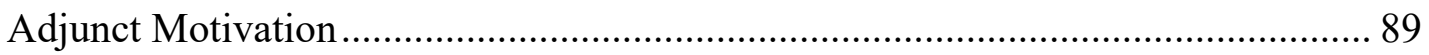

Critical Thinking Embedded in Scientific Literacy ................................................ 93

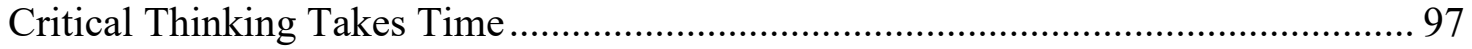

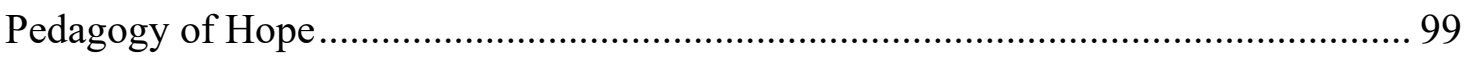

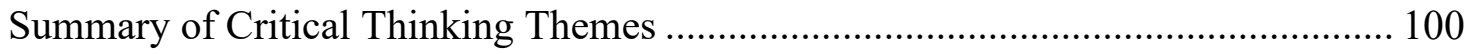

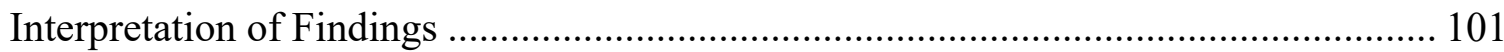

What are the Geoscience Community College Faculty Members' Perceptions of

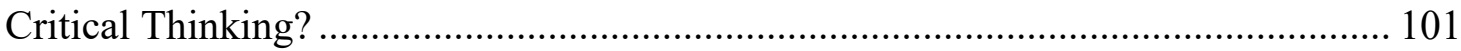

How do Geoscience Faculty Members’ Perceptions Influence their use of Critical

Thinking Instructional Strategies? ................................................................ 112

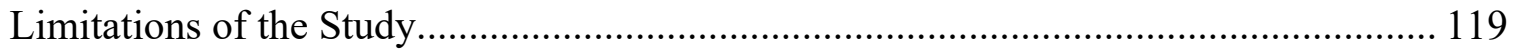

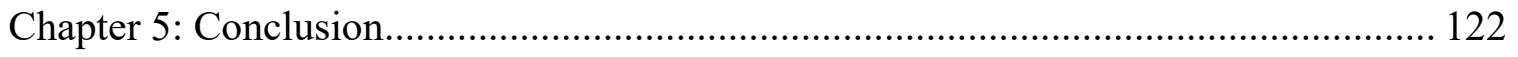

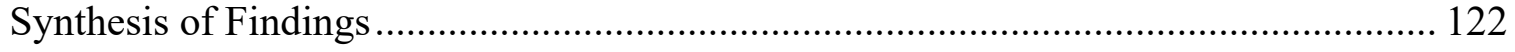

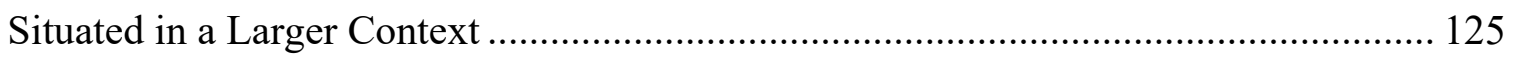

Situating Findings within Theoretical and Conceptual Frameworks....................... 126

Situating Findings within the Research Literature............................................... 131

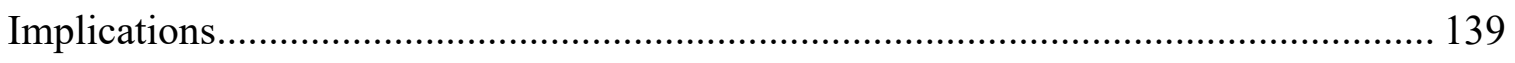


Recommendations for Community Colleges ........................................................ 140

Recommendations for Geoscience Undergraduate and Graduate School Programs .. 142

Recommendations for K-12 Education and Policy Makers..................................... 143

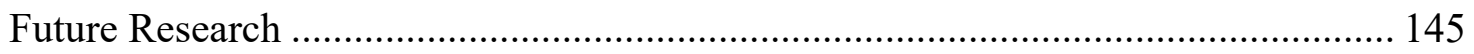

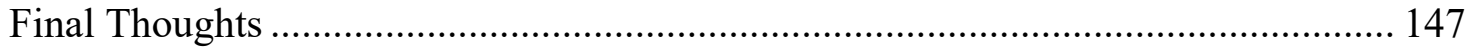

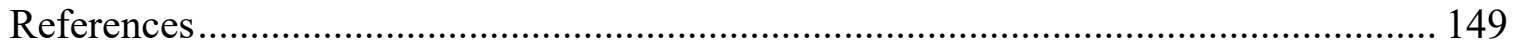

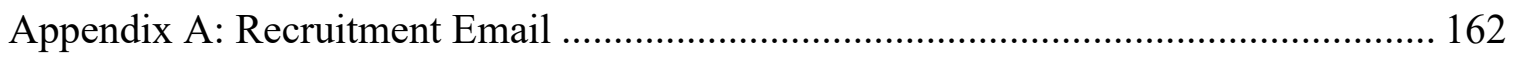

Appendix B: Participant Consent Form ............................................................... 163

Appendix C: Critical Thinking Survey for Geoscience Faculty ...................................... 166

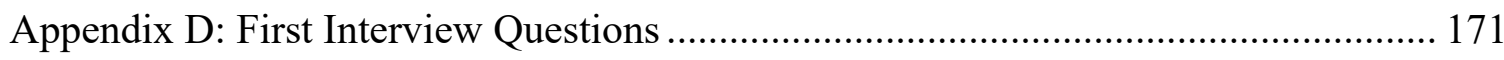

Appendix E: Second Interview Questions ............................................................... 173 
List of Tables

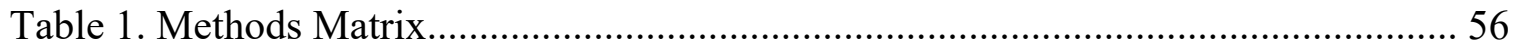

Table 2. First Cycle Coding using In Vivo and Values Coding Strategies...................... 70

Table 3. Refinement of Cluster Categories and Identification of Themes ...................... 70

Table 4. Examples of Confidence/Engagement Condition for Critical Thinking ............ 74

Table 5. Examples of Active Learning/Foundation Condition for Critical Thinking ...... 75

Table 6. Examples of Higher Level Thinking Condition ............................................. 76

Table 7. Examples of Participants' Abstraction of Critical Thinking …........................ 77

Table 8. Training and Support of Critical Thinking: Excerpts from Participants’

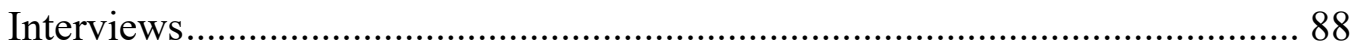

Table 9. Motivation to use Critical Thinking: Excerpts from Participants' Interviews.... 91

Table 10. Personalization of Learning: Excerpts from Participants' Interviews and

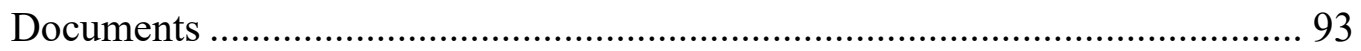

Table 11. Critical Thinking Embedded When Teaching Science as a Process:Excerpts

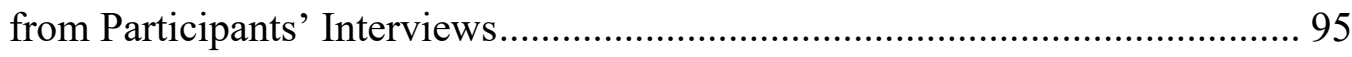

Table 12. Excerpts from Participants' Interviews about Critical Thinking in the Classroom 97

Table 13. Excerpts from Participants' Interviews about the Concept of Time..... 98 


\section{List of Figures}

Figure 1. Conceptual Critical Thinking Instructional Model .................................... 20

Figure 2 . Procedures for Recruitment and Data Collection ...................................... 53

Figure 3. Critical Thinking Terms Selected by Participants ....................................... 79

Figure 4. Participant's Familiarity and Comfort Level with Bloom's Taxonomy, Critical Thinking VALUE Rubrics, and Paul-Elder Critical Thinking Framework ....... 82

Figure 5. Participants' Responses to Teaching Critical Thinking in the Classroom ........ 85

Figure 6. Participants' Responses to Assessing Critical Thinking in the Classroom ....... 86

Figure 7. Revised Conceptual Critical Thinking Instructional Model......................... 130 


\section{Chapter 1: Problem Statement}

Geoscience is an inherently interdisciplinary field that involves an understanding of the Earth and planetary systems. Geoscience draws on concepts of physics, chemistry, biology, and mathematics to explain the Earth and planetary systems' processes and evolution through time (Anderson, 2006; Manduca \& Kastens, 2012). The students in my introductory undergraduate geoscience course come to the classroom with excitement, high expectations, and uncertainties. Most of these students are non-science majors either at the early stages of their community college academic degree or at the end of their associates/certificate. These students are hardworking, dedicated, and ready to learn. As a faculty member, one of my main instructional goals is for students to learn how to use critical thinking within the geosciences; more importantly, how they can apply this type of thinking in their own discipline. However, once I begin to talk about the complexity of the Earth and planetary systems, the students realize quickly that making sense of how our planet works requires real effort and serious thinking. The students also realize that the memorization type of studying that they became accustomed to using in high school is not going to help them make meaning and unify information in a college geoscience class.

Critical thinking is an important requirement for a successful postsecondary education as it involves strengthening, deepening, and enhancing the student's capacity to reason, evaluate evidence, detect mistakes, and ascertain bias and manipulation (Facione, 2015; Kim et al., 2013; National Research Council, 2011; Rowe et al., 2015). For this dissertation, I define critical thinking as "thinking which perceives reality as process, as 
transformation, rather than as a static entity" (Freire, 2000; p. 1311). In other words, when using critical thinking, an individual uses cognitive skills (acquisition and understanding of knowledge), reflects on their thinking/decisions (metacognition), and uses effective strategies directed towards the achievement of a goal in a continuous way. In this first chapter, I describe the background of the problem, statement of the problem, significance of the problem, methodology, and definitions of key concepts.

\section{Background of the Problem}

An individual who can integrate the knowledge and skills of multiple disciplines is arguably the most poised to innovate and lead within the current landscape of education. Yet, even though postsecondary institutions proclaim a successful teaching of critical thinking, a large body of research shows evidence that the achievement of critical thinking is not as straightforward. The literature shows gaps of understanding around the use of critical thinking among students and gaps of understanding around the instruction of critical thinking from faculty members (Arum \& Roska, 2011; Chirgwin \& Huijser, 2015). Moreover, research investigating this exact skill within the STEM fields (not including health sciences) is scarce. Broadly speaking, body of research investigates various forms of critical thinking (i.e., as a skill, discipline or general, as a process, as entity that varies with content) within post-secondary education (Abrami et al., 2015; Bailin, 2002; Behar-Horenstein \& Niu, 2011; Facione, 2015; Kim et al., 2013; McConnell et al., 2003; National Research Council, 2011; Rowe et al., 2015). There are numerous studies investigating discipline-specific critical thinking within STEM (Bailin, 2002; Behar-Horenstein \& Niu, 2011, Kim et al., 2013; National Research Council, 2011; 
Nicholas \& Raider-Roth, 2016; Rowe et al., 2015). For each, the focus is primarily on students and strengthening students' critical thinking by faculty members use of active learning and engagement strategies (Crowe et al., 2008). Additionally, the existing standardized tools measuring critical thinking within the STEM fields are quantitative in nature and limited to course content achievement assessments (Behar-Horenstein \& Niu, 2011). On the other hand, the qualitative research on students' critical thinking focuses on students' dispositions toward using critical thinking. Nevertheless, the overall message highlights the value of building critical thinking skills into STEM courses. When educators transition their paradigm from focusing on individual disciplines into the metadisciplines that embody "interdisciplinary" work, there seems to be an absence of similar research. Most of the research available focuses on the joint disciplines of medicine, biology, and nursing (Bailin, 2002) primarily at the student level. Researchers have yet to explore the intersection of mathematics, physics, geology, and chemistry not only from students' perspective but also, from faculty. Lastly, explicit critical thinking frameworks discussing how to strengthen, deepen, and enhance critical thinking when integrating multiple STEM fields more specifically in the geosciences seem to also be missing in the literature.

In an online seminar from the American Geoscience Institute (AGI), Keane (2018) offered his insight into the current state of geoscience programs. He reviewed the recent geoscience industry data from various AGI surveys about the workforce and described the state of geoscience programs, students, and emerging trends. Keane argued that to fulfill industry needs, geoscience programs need to increase their expectations to 
attract better quality students. Although his presentation provided an important overview of the state of geoscience programs and employment opportunities, the information on pedagogical tools was primarily content based.

In fact, when reflecting on Keane's message, it seems that the field of geoscience is moving towards an individual's ability to use their knowledge from different disciplines to solve problems. This interdisciplinary way of learning shifts the traditional teaching approach which focus was on memorization of facts to a systems thinking approach—disciplines fuse together to understand multiple processes with complex interactions. This approach challenges learners to address issues by making connections among the different disciplines (Cai \& Sankaran, 2015; Ivanitskaya et al., 2010). According to Lloyd and Bahr (2010), when students make connections among different disciplines to address world issues, they are developing, strengthening, and enhancing their critical thinking. Thus, the requirement of discussing and developing critical thinking explicitly in context is imperative within geosciences.

However, there has been little to no explicit conversation around faculty development and instruction. When Keane argued that increasing program demands would allow programs to attract better quality students, he did not elaborate on what this entails. Did he mean to say that geoscience program requirements need to be more challenging? For example, the math requirement in certain courses needed to be higher. Or did he mean providing more faculty support so that instruction quality increases and thus, enhancing student learning?

To fulfill market demands, I believe strongly that the strength of geoscience 
programs may consider supporting both faculty and students. Critical thinking begins with faculty (Burroughs, 1999; Hobaugh, 2010).

I recalled many teaching moments when my students dealt with understanding the material in a meaningful way. A vivid example encountered in my teaching showed how strengthening, deepening, and enhancing critical thinking was a process that involves both students and faculty. Upon learning about rock formation and their identification process during lecture, I gave my students a series of rocks to identify. My intention with this activity was for the students to apply immediately the concepts that we discussed in lecture. Before identifying the different type of rocks, I divided students into groups and each group had the opportunity to plan their own rock identification process. Some of the methodology applied was rock matching and memory. For the students that applied rock matching approach, I noticed these students were trying to match the rocks in front of them with images of similar rocks in the textbook. I was curious about my students' choice of this approach, so I asked them to explain to me how they were using the rock matching process to correctly identify the rocks they had in front of them. A few students defended their answers by showing that the rock looked exactly like one of the textbook images. Interestingly, for the students that used memory to identify the rocks, their explanation was simply that they have seen the rock before, and they remembered the information from their high school earth science class. In addition, what was fascinating to me was their explanations of the chosen process to identify rocks: (a) no student verbalized their own observations of the rocks they were holding in their hands, and (b) no student connected material covered in lecture with their rock identification activity, 
even though we had discussions about the uniqueness of each rock in previous activities. While Halpern (2014) argued that people do not easily forget images, people's memories are often incomplete. It seemed that most of my students were primarily trying to match the rocks to something they have seen, heard, or remembered from the past. Although these were important cognitive process to the comprehension of new material, these approaches were only the initial steps to take before using higher-level thinking.

Recognizing that my students were using different techniques to comprehend the material, I was curious to see if my students could go further and find connections between the activity and what they are learning during lecture (i.e., use higher order thinking skills). In that moment, I decided to try two approaches. First, I indicated explicitly that the following activity would be challenging, and for some uncomfortable, to help students be open to the experience. Second, I provided a series of scaffolding questions that would encourage my students to explore deeply the process of rock identification, the process of rock formation (i.e., presented in the lecture), and their own confusion or misconceptions of the material. After I applied these instructional techniques, students felt excited about their understanding of the material, which allowed them not only to identify key features within each rock on their own, but also to understand how to use rock identification process in general. For example, when I presented these same students with a different scenario, they were comfortable applying a more comprehensive rock identification approach. From this small intervention, students were able to both identify the rocks and to understand which processes make each rock different. In addition, the students were able to experience an alternative and deeper way 
to apply knowledge. Reflecting on my interactions with students provided me with an immense insight about the importance of how instructional approaches can affect students thinking positively or negatively.

Bezuijen et. al. (2010) argued that when instructors set challenging, yet appropriate, clear, and structured goals they provide focus to the intention of the work. When students accomplish these goals, the teachers can influence their students to set goals for themselves and to engage in their learning. When a teacher-student can discuss, evaluate, and analyze areas of success and improvement there use of critical thinking is higher (Bezuijen et.al., 2010). Lastly, reflecting on my interactions with students also led me to conclude that when we, as faculty, understand the different pedagogical tools available and a deeper understanding of how to use such tools, we can be more effectively at providing a positive learning environment for students.

As a teacher, I work to create a safe environment where students trust me enough to take risks and to explore their thinking. Interactions such as the one mentioned earlier are monumental for me. When students as well as faculty, strengthen their critical thinking by communicating, analyzing, evaluating the evidence, detecting errors, and making thoughtful conclusion is a crucial step in finding solutions to the complexities of our planet. Critical thinking is a process that is self-directed involving the use of cognitive skills (acquisition and understanding of knowledge) and metacognitive skills (thinking about our thinking). Students need these types of higher order thinking skills to understand complex science information within a geoscience class and in also, within their own discipline. At the same time, it challenges faculty to reflect how they are 
facilitating critical thinking processes and by how they use critical thinking process themselves.

If the aim of college instructors is to support students' thinking by creating classrooms where the teacher is the only holder of meaning to ones where the student is the maker of meaning (Perry, 1981), instructors must be aware of all possible barriers and tailor the learning to meet the needs of students. Transforming a classroom to students as the makers of meaning requires the instructor to recognize that the ways in which institutions defined critical thinking is not universal nor equitable. Current definitions of critical thinking as well as their assessment come from the dominant culture. Chirgwin and Huijser (2015) argued, "Critical thinking is considered to drive not only knowledge production but also innovation and development, while it is intimately linked to a colonial history in which "progress" has been the key focus and driving force" (p. 335). Instructors might be at risk of misjudging their students' development of critical thinking. For example, Lloyd and Bahr (2010) small-scale study about faculty and students' definition and understanding of critical thinking in an Australian university showed that students understand and have the capacity to think critically at a higher level; however, the students' emphasis of critical thinking was on product, whereas faculty members emphasis on critical thinking was on process.

I argue that for instructors to avoid possible misjudgment of students' development of critical thinking, they must challenge their way of defining critical thinking and be open to other ways of defining it. Also, instructors must make this process explicit in the classroom. Thus, fostering critical thinking in the classroom is a 
process that involves both the student and the teacher. For teachers to move toward supporting their students to be the makers of meaning, teachers themselves must continue practicing their critical thinking as well as make this thinking explicit in the classroom.

\section{Statement of the Research Problem}

Because the scope of this challenge is so large, I have chosen to limit my discussion to the faculty perspective around instructional tools that focus on the teaching of critical thinking within introductory geoscience courses at community colleges. The geosciences represent the prototypical interdisciplinary endeavor. Geosciences combine an understanding of the Earth and planetary systems and draw on concepts of physics, chemistry, biology, and mathematics (Manduca \& Kastens, 2012). I have chosen the community college setting not only because this is where the wealth of my own personal teaching experience lies, but also, because community colleges often involve smaller student-teacher ratio. Additionally, the student population is non-traditional. Thus, community colleges require the development of a conceptual model that is simultaneously comprehensive and adaptable.

Recent research showed that despite institutions' statements regarding their achievement of teaching critical thinking, when evaluating critical thinking through existent critical thinking skills assessment frameworks, it appears that nontraditional students at community college taking STEM courses (i.e., geosciences) have few opportunities to use critical thinking skills (Arum \& Roksa, 2011). Even though there is a large body of research about this topic, scholars have yet to explore the other part of this narrative, faculty (Choy \& Cheah, 2009; Ennis, 2015; Haas \& Keeley, 1998; Hobaugh, 
2005). Burroughs (1999) argued that when evaluating critical thinking, we must begin with faculty to fill the gap that is missing in the current body of research regarding critical thinking. The purpose of my study was to describe and examine the perceptions of community college geoscience faculty regarding critical thinking and how such perceptions influence their chosen instructional strategies

\section{Significance of the Research Problem}

Scholars consider critical thinking a lifelong journey (Perry, 1981; Van Gelder, 2005) yet most students rarely experience school-based instruction dedicated specifically to the development of critical thinking (Graff, 2003). Therefore, making critical thinking an explicit part of science curriculum (Van Gelder, 2005), especially at introductory classes, will expose students to the importance of independent thinking. Changes in geoscience policy and postsecondary education are viewed using one narrative: the quality of students within geoscience programs (i.e., what they have and what they do not) rather than viewing the narrative as an intertwined relationship between student and faculty. Are we really capturing the whole story by only looking only at the student? Expecting a student to develop their critical thinking is a process that involves both the student and the teacher. Therefore, if a goal is to make critical thinking an explicit part of the curriculum and to prepare our students to be successful professionals, exploring faculty members' reflections around instructional practices that focus on strengthening their students' independent thinking is just as important as the exploration and transformation of student's critical thinking.

Analyzing body of research on critical thinking, I found the focus has been on 
defining critical thinking as a process, or, set of skills or dispositions and the settings in which most research studies lie is mostly at the K-12 level and four-year postsecondary institutions. In fact, very few research studies are at community colleges classrooms (Arum \& Roksa, 2011; Bers, 2005). Moreover, research studies about critical thinking at community college geoscience programs have been even more scarce. Due to many community colleges' open-door policy, the population of students in these institutions have been quite diverse. In addition, the interdisciplinary approach that the field of geosciences has taken involves the use of critical thinking to understand Earth and planetary processes and evolution through time to mostly students might not necessarily be STEM related majors.

Thus, the geosciences provide an interesting platform to observe the critical thinking interventions faculty use to support their students. The significance that this study is the opportunity to evaluate the current ways in which educators define, use, and assess critical thinking at postsecondary institutions, as a single definition may not fit or encompass everything (Lloyd \& Bahr, 2010). Moreover, practical implications of my research study may provide adaptable and culturally responsive instructional tools that can accommodate for diverse student populations.

\section{Presentation of Methods and Research Questions}

For this research study, I used a basic qualitative methodology. The purpose of this study was to identify: (a) the perceptions of community college faculty teaching introductory geoscience courses regarding critical thinking, and (b) the instructional tools that influence, improve, or augment their students' use of critical thinking skills in the 
classroom. The data collected for this study came from a survey, two interviews, and documents from geoscience faculty members working at several community colleges within the Pacific Northwest.

Research questions for this problem of practice were:

1. What are geoscience community college faculty members' perceptions of critical thinking?

2. How do geoscience faculty members' perceptions influence their use of critical thinking instructional strategies?

\section{Definitions of Key Concepts}

In this section, I provide definitions for terminology I used while exploring my research problem. While many of the terminologies have a variety of definitions, I identify the definitions that pertain to my problem of practice.

\section{Critical thinking}

Although Max Black, a philosopher was the first to use the words critical thinking in an academic setting, it was John Dewey who introduced the term critical thinking within the education field in 1910 (Ennis, 2015). Dewey (1910) defined critical thinking as reflective thought. In How we think, Dewey defined reflective thought as "active, persistent, and careful consideration of any belief or supposed form of knowledge" (p. 6). Although recent definitions of critical thinking seemed to be an extension of philosophers stated in the past, recent understanding of human brain development has shifted the definition. Four scholars may shine a light of the modern variations of critical thinking definitions, and even though these definitions may appear to be different, they are 
complementary to one another. First, Halpern (2014) defined critical thinking as the use of cognitive skills and metacognitive skills to evaluate, plan, persist, and reflect towards the achievement of a goal. In other words, when using critical thinking, an individual accesses their cognitive skills (acquisition and understanding of knowledge), they reflect on our thinking/decisions (metacognition), and they use effective strategies directed towards the achievement of a goal. Second, Ennis (2015) defined critical thinking as a "reasonable reflective thinking focused on deciding what to believe or do" (p. 32). Interestingly, Ennis' definition challenged students to evaluate through reflection all reasonable definitions and reasoning behind an idea first before deciding which one to believe or do. Third, Freire (2000) defined critical thinking as thinking that perceives reality as process, as transformation, rather than as a static entity" (p. 1311). Seeing reality as dynamic may be challenging, yet this is such a powerful statement. Something that is constantly transforming implies a constant reworking of one's understanding. Lastly, Bailin and Battersby (2015) defined critical thinking as inquiry, something applied in everyday contexts and disciplines. In 2002, Bailin argued that critical thinking is contextual; therefore, the focus could be on looking at the "question of what one needs to understand in order to meet the criteria of good thinking in particular contexts" ( $p$. 368). Evaluating the definitions offered by these scholars, I noted a commonality: active reflection is fundamental for critical thought and the recognition that our thoughts are constantly changing because we, as humans, are constantly changing. To me, these scholars were advocating that when faculty teach critical thinking, they must not only be aware of the constant adjustment of how they define critical thinking, but also of how 
they applied it and how the students are interpreting it. Thus, highlighting what scholars have said multiple times, a standard definition of critical thinking might not be the goalas this type of thinking is and will always be in constant flux.

\section{Cognition and Metacognition}

Because I describe critical thinking as a cognitive and metacognitive process, it is important define what is meant when using the terms, cognition, and metacognition. Whereas cognition is the process by which individuals acquire and understand knowledge. According to Winne (2011), the acquisition of knowledge occurs in two ways: declarative (i.e., facts, metaphors, definitions) and procedural (task oriented). For example, while reading the definition of convergent plate boundaries (declarative knowledge) the learner decides to test his/her understanding by identifying where this process is occurring (procedural knowledge). Metacognition as defined by Flavell (1979) is the awareness of one's own knowledge; metacognition influences cognitive experiences that can direct the learning (Bandura, 1986; Piaget, 1968; Vygotsky, 1978).

\section{Nontraditional Students}

Although factors that define a nontraditional student vary, in this dissertation, I use the definition published by the National Center of Education Statistics (Choy, 2002). Choy (2002) defined nontraditional students as someone who does not attend college as soon as they graduate from high school, someone who is financially independent, someone who works full time, someone who has dependents (i.e., children), and someone that attends part time for at least some part of the academic year. 


\section{Faculty}

Community college faculty and instructional staff differ in varied ways. Unlike faculty at four-year institutions, the majority of faculty at community colleges hold parttime appointments (Provasnik \& Planty, 2008). However, according to Conley et al. (2002) faculty appointments available at community colleges consist of full professor, associate professor, assistant professor, instructor/lecturer, and part-time/adjunct positions. The full professor, associate professor, and assistant professor are typically tenured appointments, whereas the instructor/lecturer and part-time/adjunct positions are non-tenured (Antonio et al., 2000). Additionally, the promotion of full-time faculty in community colleges varies by years of experience: (a) early career with 0 to 1 year of experience are often assistant professor, (b) mid-career faculty with 3 years or more of experience are often associate professor, (c) if granted tenure, faculty with 5 years or more of experience often move to full professor. As noted by Conley et al., contrary to full-time faculty appointments, the part-time faculty appointments are temporary positions that offer no benefit and most part-time faculty appointments depend on the community college or department needs (i.e., course student enrollment). Lastly, the primary focus of faculty members at community colleges is teaching, not research. In terms of demographics, a large percentage of faculty members at community college have a master's degree (Provasnik \& Planty, 2008). However, in terms of diversity, 77\% of full-time faculty at community college self-report as White, whereas $74 \%$ of faculty at community college self-report as non-White (i.e., Black, Hispanic, Asian, and other) (American Association of Community Colleges, 2018) 


\section{Community College}

Using the definition published by the National Center of Education Statistics (NCES) in the U.S. Department of Education, community colleges are regionally accredited public postsecondary institutions in which their highest degree offered is an associate degree (Horn \& Radwin, 2012; Vaughan, 2006). Community colleges distinguish themselves by their "commitment of open access, comprehensiveness in course and program offerings, and community building" (Vaughan, 2006, p. 1). Most community colleges are public and receive financial support from government (Vaughan, 2006). Community colleges do not have residential housing available; therefore, they primarily serve commuter students (Vaughan, 2006). In addition, at community colleges, the student-teacher ratio tends to be smaller in all disciplines. Most classrooms have no more than 30 students per faculty member. According to the Oregon Higher Education Coordinating Commission (n.d.), Oregon has 17 community colleges with more than 60 campuses and centers. Whereas according to Green (2018) from Washington State Board for Community and Technical Colleges, Washington has 24 community colleges.

\section{Geoscience}

According to the American Geoscience Institute (2018), geoscience is a field that addresses critical issues such as energy, meteorology, water and mineral resources, stewardship of the environment, oceanography, reducing natural hazards for society, planetary science and more. Geoscience courses at community colleges are part of the general education program. Most courses in geoscience programs at community colleges are introductory (i.e., classes at the 100 to 200 levels). 


\section{Chapter 2: Literature Review}

Critical thinking is currently one of the most important outcomes in postsecondary education (Facione, 2015; Kim et al., 2013; National Research Council, 2011; Rowe et al., 2015) as it involves developing the student's capacity to reason, to evaluate evidence, detect mistakes, and to ascertain bias and manipulation. Current assessments of student learning done at the high school level focuses on students' achievement in factual knowledge (National Research Council, 2011) rather than students' achievement in critical thinking. In addition, most research done of critical thinking development is either at the K-12 level or at four-year postsecondary education. More importantly, scarcer studies focus on geosciences faculty members at community colleges. Especially studies that explore faculty members' perceptions and use of instructional tools to strengthen, deepen, and enhance their students' critical thinking.

Recent research showed that despite institutions' statements regarding their achievement of teaching critical thinking, when evaluating critical thinking through existent critical thinking skills assessment frameworks, it appears that nontraditional students at community college taking STEM (i.e., geosciences) have few opportunities to use critical thinking skills (Arum \& Roksa, 2011). Even though large body of research focuses on this topic, researchers have yet to explore another side of this narrative, the faculty (Choy \& Cheah, 2009; Ennis, 2015; Haas \& Keeley, 1998; Hobaugh, 2005).

In this chapter, I begin with my theoretical framework followed by an overview of history of critical thinking, epistemological beliefs around critical thinking, and critical thinking strategies used by faculty within the geosciences. The goal of this section is to 
unveil the importance of exploring the perceptions of community college geoscience faculty regarding critical thinking and how such perceptions influenced their chosen instructional strategies.

\section{Theoretical Framework: Sociocultural Theory}

In sociocultural theory, Vygotsky (1978) emphasized that the development of a learner's cognition is a social process involving interactions with other capable peers (Shute \& Slee, 2015; Tudge \& Winterhoff, 1993). He asserted that these interactions play a fundamental role in the learner's cognitive development individually, as well as socially. Each interaction with other capable peers enhanced the learner's sense of wonder and could provide an understanding of how the world around them works. Vygotsky (1978) argued that development occurs in stages_ - "every function in the child's cultural development appears twice: first, on the social level, and later, on the individual level; first, between people (interpsychological) and then inside the child (intrapsychological)” (p. 57). He also argued, “All higher functions originate as actual relations between human individuals" (p. 57). In other words, sociocultural theory focused on the passing of culture (i.e., values, beliefs, customs, skills of a social group) to the next generation. This social interaction generated an environment of cooperative dialogues with more knowledgeable members (Vygotsky, 1978) which in turn, other members could attain the ways of thinking and behaviors that make up a community's culture (Berk, 2018).

Subsequent to cognitive development occurring socially and individually is the development of cognition that exists in two zones: the zone of actual development and 
the zone of proximal development (Vygotsky, 1978). The zone of actual development is the learner's present cognitive development whereas the zone of proximal development (ZPD) is "the distance between the actual developmental level as determined by independent problem solving and the level of potential development as determined through problem solving under adult guidance or in collaboration with more capable peers" (p. 86). To put it in another way, in a given task a learner may be able to problemsolve independently, but to deepen their analysis it may require help and social interaction. This is the precise moment where the faculty member or a more capable learner can provide support via scaffolding to develop, strengthen, and deepen the learner's understanding.

Vygotsky's (1978) sociocultural theory plays a fundamental part of my framework. I view critical thinking as something that is developed, strengthened, and deepened initially at the social level, and later, at the individual level once the learner has integrated and personalized knowledge. In the literature about critical thinking, few frameworks lend themselves to the adaptation of critical thinking in the classroom. Some frameworks are complex, yet not very well understood unless faculty has received some level of professional training.

After reading the literature on critical thinking, I created a model of what critical thinking means to me. This conceptual model would provide a framework for analyzing my problem of practice. Therefore, I developed this intuitive model in which faculty can continually reflect on how they are using critical thinking in their classrooms. To advance understanding of critical thinking and highlight the key phases that could potentially 
develop, strengthen, and deepen their use of critical thinking, I created a visual representation shown in Figure 1.

\section{Figure 1}

\section{Conceptual Critical Thinking Instructional Model}
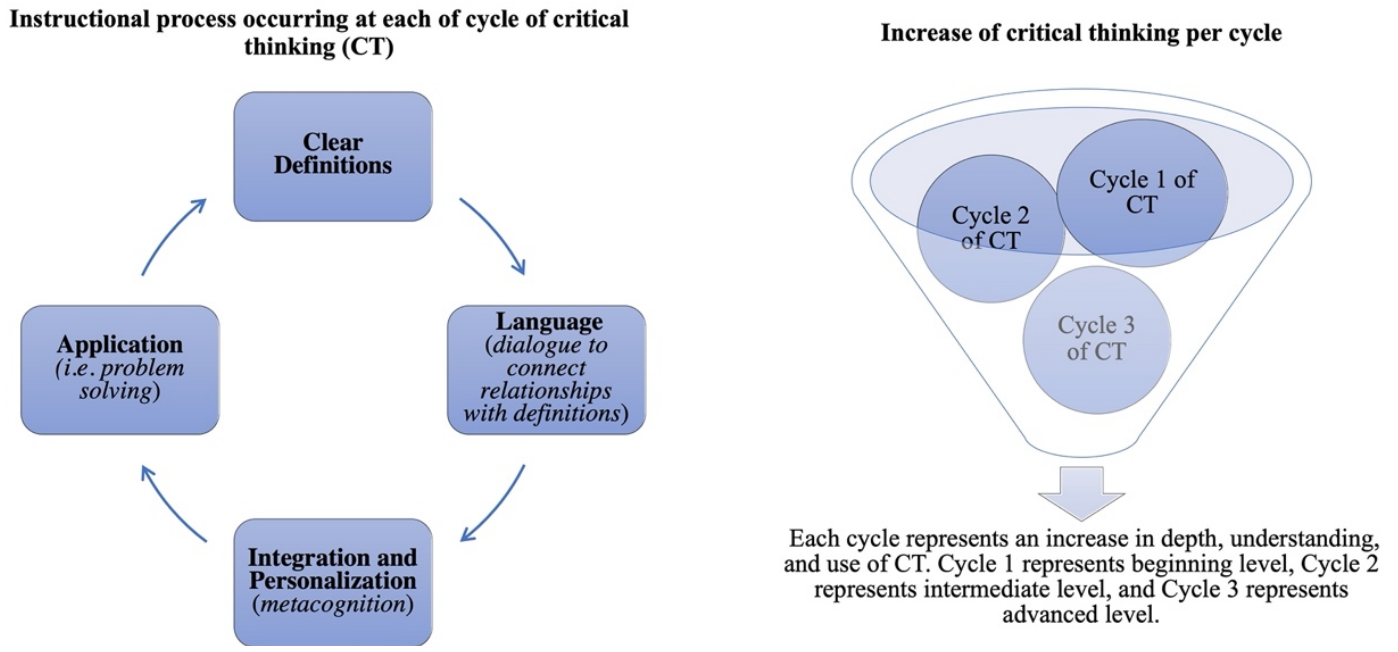

In my Conceptual Critical Thinking Instructional Model, the image on the left represents the process of how critical thinking occurs at each cycle. The image on the left has two important distinctions. First, most instructors start the cycle at the clear definitions stage. However, they may also choose to start at one of the later stages (i.e., language, integration and personalization, application), and potentially start at the application stage as a way to set up dialogue regarding the necessity for clear definitions. Second, although the arrows are unidirectional, in practice, instructors may need to return to a prior stage if they encounter significant challenges in the current stage. The image on the right shows how critical thinking is evolving. The funnel represents the relationship between the use of critical thinking cycles and the overall depth of critical thinking. Each time a faculty member and student complete a cycle, the depth increases, though, the 
critical thinking process remains the same.

\section{Analyzing the Problem using Sociocultural Theory}

In the literature, some scholars view critical thinking as a skill, while others view it a as a process or something that varies in context (Bailin, 2002). Within postsecondary institutions, faculty members often consider the definition and assessment of critical thinking as a skill. When considering critical thinking as a skill, it can potentially be something that can be taught, developed, and transferred (Ennis, 2015). Within the geosciences, one of the most frequently used assessment and definition of critical thinking comes from Bloom's Taxonomy (Bloom et al., 1956). Blooms taxonomy is a framework that divides cognitive learning into six categories (i.e., remembering, understanding, applying, analyzing, evaluating, creating) that range from lower-level thinking skills (i.e., remembering) to higher-order thinking skills (i.e., evaluation). Bloom's taxonomy provides a framework to categorize learning goals, objectives, and standards (Krathwohl, 2002) than can used widely within institutions.

However, when the application of Bloom's Taxonomy is across disciplines, Crowe et al. (2008) argued that still each discipline must define their own classifications within the context of their field. Geoscience faculty have used Bloom's Taxonomy as a guide to develop questions that strengthen critical thinking skills yet at most, few faculty members have properly received an introductory training via professional development on how to use this tool. From my experience, faculty introduced this tool as guide for course planning and during instruction, however, a dialogue or reflection as to the importance of implementing this tool was often missing. 
The conceptual model of critical thinking that I present is a way for faculty members to reflect on their own perceptions of critical thinking and experiment how they are applying critical thinking their classrooms. In a way, it is a step back from using assessment tools. This model provides a fluid structure in which a faculty member can use to build a learning community with their students. With this model, a faculty member can reflect not only on how to teach the material, but also on how to tailor the learning to their specific students.

Using my Conceptual Critical Thinking Instructional Model (see Figure 1), faculty can gather both content and pedagogical approaches that may fit more appropriately to their students' needs. Critical thinking in this model, viewed as cyclical, indicating that there is no beginning or end because the start or ending and that it is adaptable to the needs of students in the classroom. I offer the following example of using Vygotsky's (1978) development stages: social level and individual level. At the social level, the faculty member starts the discussion of a new concept. The introduction of a new concept involves the use of clear definitions as an essential part of building knowledge. Due to this introduction of new concepts the faculty then chooses to start the critical thinking process at the clear definitions stage. A language between facultystudents and student-student created to bind the definitions and material together (language stage). Afterwards, faculty may move to Vygotsky’s second developmental stage, the individual level. At an individual development level, faculty allows time for metacognitive activities with the goal of student individualization and personalization of the material content (integration and personalization stage). By giving students time to 
think about what and how they understand the material, the students make meaning more personal. When meaning becomes personal, the application of critical thinking comes into play. For example, the action of problem solving can be more personal. Once students understand what they know and do not know, they can add the tasks needed to create solutions to solve problems uniquely to their experience and need (application stage).

The Conceptual Critical Thinking Instructional Model (see Figure 1) focuses on critical thinking in context. It provides faculty with an explicit tool they can use for the teaching of content and pedagogical approach at two developmental stages, social and individual, without overwhelming students. This model allows faculty to be more explicit with their students in a step-by-step process of how to use critical thinking. They can use this model with the understanding that some students may choose to try different starting and ending points, granting an opportunity for students and faculty to define critical thinking in the classroom together rather than just by faculty. This collaboration, in turn, shifts the learning from only faculty as the makers of meaning to now students being the makers of meaning.

Additionally, when considering Vygotsky’s (1978) development zones (i.e., actual development and proximal development), a faculty member can measure their students critical thinking in the same way. For example, in postsecondary education when planning a course curriculum and instruction, geoscience faculty members can use the K12 science standards as the actual development of critical thinking and then design the critical thinking course expectations for their students in their geoscience courses 
(proximal development). For geoscience faculty member, the ZPD becomes the area in which they need to provide support to the students, so they can reach the course outcomes that involve the development of higher order cognitive processes.

Research has shown that students can further develop their learning when the teacher provides support while students are learning class material and then moves away when the students are making progress (Shute \& Slee, 2015). Wass et al. (2011) investigated the use of scaffolding of critical thinking in a zoology program. Their study showed that scaffolding critical thinking throughout students first three years in the program improved the use of critical thinking. While learning the facts and theories during the first year, the zoology students perceived their learning as an extension of high school. For these students, the learning involved memorization of facts and theories. When asked about critical thinking, the students had difficulty defining what it meant to be a critical thinker (Wass, et al., 2011). Moreover, Wass et al. showed that the degree to which students started to "develop new attitudes to knowledge congruent with the broad aims of critical thinking" were not present until the students' second to third year in the program (p. 326). The reasoning behind the increased use of critical thinking among students was due to an increased familiarity of the class structure, trust of others (i.e., faculty and classmates), and the use of research articles in advance courses. Therefore, the implication for instructors was that using sociocultural theory to track the students' development of critical thinking could provide a deeper understanding of how their students were developing their critical thinking. Understanding the process of how, when, and where students were using critical thinking might allow instructors to provide 
realistic outcomes that could more effectively guide their students' critical thinking deeper.

\section{Critique of Sociocultural Theory}

Although there are benefits of applying sociocultural theory to understanding the development of critical thinking, Vygotsky (1978) did not provide detailed explanations of what he means by capable learner (Wass et al., 2011). Thus, I argue that Vygotsky's lack of explanation can lead the researcher to decide then who she or he considers capable and to what effect. For example, Wass et al. (2011) concluded that although teachers are capable peers who have a positive impact in their student learning, considering advanced students as capable peers during peer interactions had a different impact. In their study, Wass et al. observed that during peer interaction, the capable peers within the group "who seemed more knowledgeable could irritate those who were not up to their level" (p. 325) and students in their early years of the program did not trust the knowledge of other peers. My second critique focuses on scaffolding. Van Der Stuyf (2002) argued that although the idea of scaffolding the material to the students can both engage and provide immense support, this may involve the teacher individualizing the way in which he or she can support his or her students' critical thinking, a daunting task for a class of 24-30 students. Third critique, Vygotsky's sociocultural theory emphasis on culture and social interaction often neglects the biological side of development, specifically how exactly the cognitive change happens in the brain development (Berk, 2018). Lastly, due to Vygotsky's emphasis of knowledge transmitted socially he did not provide more information about the individuals' capacity of their own cognitive 
development (Berk, 2018).

\section{Review of Research Literature}

The concept of critical thinking is not new, in fact the focus of higher education during the 17 to $18^{\text {th }}$ century was on "inculcation, memorization, repetition, and forensic display" (Paul, 1992, p. 4). During this time, education was only available for the upper class; however, everything changed during the $20^{\text {th }}$ century when higher education was open to more individuals of all classes. Although the history of critical thinking stretches back to $17^{\text {th }}$ and $18^{\text {th }}$ centuries, for this dissertation, I start with the influential work of the $20^{\text {th }}$ century from Dewey (1910), Glaser (1941), Black (1946), and Paul (1992) that

illuminated the stages in which critical thinking evolved over time. In his work, Dewey defined critical thinking as reflective thinking. He argued that when people engage in reflective thinking they are "overcoming the inertia that inclines one to accept suggestions at their face value" (p. 11). This active and self-directed process involves persistent search for inquiry before judgement. As Bandura (2001) emphasized, "Through reflective self-consciousness, people evaluate their motivation, values, and the meaning of their life pursuits" (p. 10). Although Dewey pioneered critical thinking in the $20^{\text {th }}$ century, it was Max Black in 1946 who within the title of his college textbook used the words "critical thinking" (Ennis, 2015). Meanwhile, Abrami et al. (2015) contended that contemporary research interest in critical thinking gained momentum from Glaser's dissertation on critical thinking. In his work, Glaser argued critical thinking needs persistent examination and evaluation of knowledge or belief as well as the evidence that supports it. Like Dewey, Glaser advocated the idea of suspending judgment until the 
examination of all inquiry and the testing of conclusions to connect with allegations. Like many others, Paul thought knowledge and learning must involve critical reflection, otherwise there would be prejudices. He emphasized that an individual mind is not a blank slate and argued that thinking happens constantly and moves in a direction. Evidence of an individual's thinking is shown by the formulation of new ideas, beliefs, and patterns of thoughts; therefore, such individual's mind is already actively thinking, he or she is experiencing a world of competing ideas (Paul, 1992). In a world of competing ideas, an individual's intellectual and personal growth, compassion, acceptance, and humility urges a need to learn how to think critically to build a more socially just world. If the purpose of education is to enhance a more democratic society, it demands a critical and emancipatory view of instruction that reframes the object of critique from our students to the oppressive system (Paris \& Alim, 2017).

Where historically does the concept of critical thinking lie, and what is currently happening to critical thinking in education? More specifically, what is happening with critical thinking in the field of geosciences? Past and recent research shows a significant increase in the need to incur the practice of critical thinking. As a start, many have pondered on what it means to be a critical thinker, especially within education. According to Facione (1990), the Delphi Method can help experts reach a consensus about the definition and assessment of critical thinking. The Delphi method is a process in which international experts engaged in several rounds of questioning and thoughtful discussions; in this case, the focus was to define the ideal critical thinker. After a consensus, the experts identify certain characteristics of what it meant by the ideal critical 
thinker, then the experts offered recommendations on how to teach and assess critical thinking (Facione, 1990).

Paul et al. (1997) conducted a study to determine the emphasis faculty from Education and the Arts and Sciences used to teach critical thinking in their courses. They observed that although most faculty considered critical thinking as an essential part of their instructions, many did not clearly articulate a concept of critical thinking. For example, Paul et al. found that faculty in the Arts and Sciences articulated the basics skills of critical thinking more than the Education faculty; however, Education faculty articulated more clearly how they use critical thinking in the instruction than the faculty in the Arts and Sciences. Their finding was important because it confirmed Paul's (1992) earlier position on critical thinking. In his book, Critical Thinking: What Every Person Needs to Survive in a Rapidly Changing World, Paul argued that defining critical thinking is very complex and one definition may not encapsulate the entire understanding of the concept. Furthermore, Bailin (2002) noted that many of the current assumptions of critical thinking conceptualized it terms of skills or process. She reported that within science education faculty viewed critical thinking as a mental process or a procedural move, allowing critical thinking to be something that can improved with practice. To examine this complexity, Nicholas and Raider-Ross (2016) conducted a study about faculty teaching general education courses. They concluded that the concept or definition of critical thinking varied by faculty's disciplinary field. Nicholas and Raider-Ross's finding was important because they realized that institutions in which these faculty members taught used a more general definition of critical thinking. If faculty and the 
institution defined the concept of critical thinking differently, how could faculty accurately measure student's use of critical thinking? If most of the literature in education views critical thinking as a process or skill, did faculty, or in this case, did all geoscience faculty by default also view critical thinking the same way?

In recent educational political trends, critical thinking gained immense momentum especially within many initiatives from educators. In 2008, the Association of American Colleges and Universities (AAC\&U) reported that more educators and employers have reached consensus on students' essential skills students needed for the workforce. One of these essentials skills was critical thinking. According to Nicholas and Labig (2013), these recent policy trends are pushing higher education to shift towards an outcomes-based approach when granting their degrees. This means that for institutions to evaluate the accomplishment of critical thinking skill learning outcomes, institutions may implement standardized assessment practices. If institutions are starting to move to an outcomes-based learning and standardized assessment practices, then there is a need for an urgent exploration behind the conceptualization of critical thinking by the faculty members and how such conceptualization influence the critical thinking strategies faculty members use to support their students. Presently geoscience education research is starting to have these important conversations as a field within the academic system. I, however, argue that expanding the conversation not only from students' perspective but also, from faculty's perspective can provide a deeper dialogue within the department and institutions. 


\section{Epistemological Beliefs around Critical Thinking}

According to Nicholas and Raider-Roth (2016), recent research advocates for understanding the role epistemology plays in critical thinking. Thus, challenging the notion that a one size fits all definition of critical thinking is not realistic. Epistemology is the study of knowledge and justified belief, and at root, that one gathers knowledge empirically because it is perceived through our senses. As noted by Sainn and Ugwuegbu (1980), perception, a central component of epistemology, is the process of information meaning making from physical stimulation (sensorial response), individual's experience, intention, and social needs. As faculty members, we are actively observing, selecting information, reflecting, and forming hypotheses to understand what is taking place in our classrooms. In fact, many would argue that faculty members' perceptions of the course content knowledge, their students, and teaching effectiveness influence faculty member's behavior in the classroom (Aragón et al., 2018; Choy \& Cheah, 2009; Gronlund, 1955;

Rowles et al., 2014; Stedman \& Adams, 2012). Several studies from past to present shine a light on the importance of understanding faculty members 's perceptions of critical thinking may influence students' classroom experience.

In 2009, Choy and Cheah studied 30 postsecondary faculty members of various disciplines in Malaysia about their perceptions of critical thinking while teaching introductory courses. Using an open-ended questionnaire to gather their data, they found that faculty members' perception of themselves played a role in how they developed, strengthened, and deepened the use of critical thinking in the classroom. For example, if faculty perceived themselves as the disseminator of knowledge, faculty were in control 
and there was little regard for student input and meaningful learning (Choy \& Cheah, 2009), which hinders the development of critical thinking. However, if faculty perceived themselves as the mediators of learning, they empowered their students to take ownership of their own learning, therefore, developing a student-faculty relationship (Choy \& Cheah, 2009). Thus, the enhancement of critical thinking was possible. Choy and Cheah (2009) concluded that for most faculty the main teaching focus during introductory courses was for students to understand the material. Therefore, the use of higher levels of critical thinking was not something on which the faculty members focused.

Interestingly, in a qualitative research study on faculty's preparation to teach critical thinking, Paul et al. (1997) interviewed 140 faculty members (i.e., 101 Education faculty members and 39 Arts and Sciences faculty members) in California. They found that even though a few faculty members had in-depth exposure about the concept of critical thinking, most faculty members had a vague understanding of critical thinking. This in turn, created a challenge for faculty to successfully infuse or embed critical thinking in their instruction. Moreover, 16 years later the research of Nicholas and Labig (2013) appeared to expand upon the findings from Paul et al. (1997). In their study, Nicholas and Labig, explored the perceptions of 19 faculty members who taught humanities, natural and social sciences at two large public universities. They collected data from these 19 faculty members via one-hour semi-structured interviews and focus groups. Their findings showed that although faculty had approaches for assessing embedded critical thinking in their disciplinary content, critical thinking content was still implicit to the students in the classroom (Nicholas \& Labig, 2013). Therefore, this 
begged the question that if students are not aware of the use of critical thinking in the material, how does a faculty member know when students are using it and thus, assess critical thinking? In addition, discipline-specific epistemologies (i.e., natural sciences: positivism and rationalistic; social science: positivism and post-positivism; humanities: relativism constructivism, and critical lens) determined what skills of critical thinking each faculty assessed. Nicholas and Labig highlighted that when faculty's knowledge of critical thinking is present, they see the incredible value of teaching it. However, when it comes to pedagogical approaches to critical thinking among faculty members, each faculty member's assessment of critical thinking varied per discipline due to disciplinespecific epistemologies whereas institutions assessment of critical thinking used a universal epistemology (discipline-general). In their implications, Nicholas and Labig urged institutions to reexamine the way in which critical thinking is assessed. Earlier, Tsui (1999) noted that courses and programs designed to foster critical thinking vary in both content and delivery hence the differences in their effectiveness. While many have argued that students either lack critical thinking or do not move beyond a certain stage and that faculty members hold varied definitions of critical thinking and used pedagogical approaches, how could faculty members accurately evaluate their students' achievement of critical thinking?

In a study on humanities, natural and social sciences faculty, Nicholas and RaiderRoth (2016) found three important findings that may provide some answers. In their study, they explored the approach, assessment, and effectiveness of teaching critical thinking from faculty lecturing general education requirement courses such as 
humanities, natural sciences, and social science at two large public universities in the Midwest. To make visible the participants' voice and construction of meaning, Nicholas and Raider-Roth gathered their data by conducting individual semi-structured interviews (9 faculty members three of each discipline). In addition, they conducted focus groups (each focus group had eight faculty members) to facilitate understanding of multiple views among the faculty members. They used grounded theory to synthesize data from the interviews and focus groups. Nicholas and Raider-Roth identified three important findings from this study. First, there was a disconnect between faculty and the institution's approach, assessment, and effectiveness of the teaching of critical thinking. Second, faculty's definition of critical thinking varied depending on their respective disciplines whereas institution's policy and assessment evaluations used a standard definition of critical thinking. Lastly, upon the faculty member's frustration with their students' level of critical thinking (i.e., although students can acquire reasoning skills and content knowledge, students were unable to apply critical thinking), most faculty developed a hopeful rather than a confident approach to teaching critical thinking.

The debate about a universal definition of critical thinking and its assessment has remained present, especially because the learning goals of the National Research Council (1996), National Research Council (2011), and even Obama's State of the Union Address (2014) include teaching critical thinking. Within the sciences, scholars promoted teaching critical thinking as inquiry. Bailin (2002) argued that the problem with teaching critical thinking stem from the conceptions and assumptions used to define critical thinking. Many debated whether critical thinking is an ability, skill, process, or is something that 
varies with context. In many institutions as well as within the medical, health and natural sciences disciplines, define critical thinking as an ability, skill, and even as process (Ennis, 2015; Facione, 1990; Halpern, 1999, 2014; Kim et al., 2013; McConnell et al., 2003; Rowles et al., 2014). Bailin (2002) noted that within the science literature when definitions of critical thinking label it as a process or skill, critical thinking becomes either a mental process or a series of procedural moves. She argued that when viewing critical thinking as a mental process or as a series of procedural moves, is unobservable. Leading faculty to the misinterpretation of critical thinking development, strengthening, or deepening within their students. In fact, she proposed the idea of viewing critical thinking as contextual. Thus, using critical thinking as a response to a particular task, question, and/or challenge. However, how we respond to each task, question, and/or challenge requires critical thought involving understanding, evaluation of concepts and particular resources needed within their context (Bailin, 2002). Bailin articulated:

The question is not whether a certain mental ability transfers to a variety of domains. It is, rather, what constellation of resources is required in particular contexts in response to particular challenges and what the range of application is for particular resources. (pp. 368-369)

In other words, critical thinking has been based on understanding of what one knows, what one does not know, and what does one need to know to answer questions. Although Bailin's (2002) conception of critical thinking seemed agreeable, I wondered whether individuals to use critical thought would depend on their disposition to do so. Ennis (2015) proposed an interesting view of the relationship of critical 
thinking and disposition. In his view, he defined critical thinking as "a reasonable reflective thinking focused and deciding what to believe or do" (p. 31). With this conception of critical thinking, he proposed 12 dispositions and 18 abilities in which students can show their use of critical thinking (see Ennis, 2015, pp. 32-33). Abiding to Bailin's conception of critical thinking as understanding, I found that Ennis's (2015) proposed disposition and abilities list matched with Bailin's conception of critical thinking. Although I could see how Ennis used a list of "abilities," I argue that it is not necessarily a list of mental process or series of procedural moves. Instead, it offers a small flexible guiding structure that faculty members can use, if needed, to guide students in their critical thinking.

\section{Critical Thinking at Postsecondary Education}

Critical thinking has become one of the most important learning outcomes within higher education. Due to accountability measures, pressure at institutions to measure and report the student learning gains is increasing (Stassen et al., 2011). In fact, agencies such as Voluntary Systems of Accountability (VSA) required institutions to use standardized tests to measure student learning outcome gains (Stassen et al., 2011). However, the results of Stassen et al.'s (2011) study on critical thinking definitions used across institutions showed that critical thinking definitions from the standardized test vary from the institutions' definitions. In their study, they did a quantitative analysis of two internal definitions of critical thinking generated by a group of general education instructors at University of Massachusetts-Amherst and three external definitions of critical thinking generated by three different agencies: Collegiate Assessment of Academic Proficiency, 
Collegiate Learning Assessment, and Educational Testing Service. Findings from Stassen et al. showed that the standardized tests used a narrower definition of critical thinking than the institution' definition of critical thinking thus, leaving certain aspects of critical thinking unmeasured. Similarly, Nicolas and Labig (2013) and Nicolas and Raider-Roth (2016) found comparable results. Both studies focused on identifying critical thinking definitions and perceptions however, rather than comparing the how standardized tests and institutions define critical thinking, their study focused on how general education faculty members and institutions define critical thinking. Their findings also showed that the definitions around critical thinking vary. In this case, the institutions tend to define critical thinking in general terms whereas the faculty members' definition of critical thinking vary due to discipline-specific learning goals. However, across all these studies, the scholars argued the importance of an understanding of critical thinking among faculty members, institutions, and policy makers critical thinking epistemologies which in turn, could potentially allow the space to create frameworks that could lead to a more realistic as well as adaptable assessment tool. In addition, the scholars among these studies noted the need of professional development that focuses on embedded and explicit teaching of critical thinking.

Although past and recent research indicated the need for clarity about definitions of critical thinking, postsecondary institutions actively use a few dominant frameworks at different levels (i.e., institution, program, department level). These frameworks have been the root of many assessment tools available. However, for this dissertation, I have chosen the Bloom's Taxonomy (Bloom et al., 1956). My reason of using this framework it was it 
is the most popular framework used by most geoscience faculty for curriculum design and for student assessment (Fuhrman, 1996; Nuhfer, 1996). Bloom's Taxonomy was created to categorize thinking skills (Bloom et al., 1956) and used three domains and six subcategories. Bloom (1965) defined the three domains as cognitive (i.e., intellectual abilities and skills), affective (i.e., attitudes and values), and psychomotor (i.e., motor skills). Please note that although the scope of Bloom's is quite large, for this dissertation I focused only on Bloom's cognitive domain. In the cognitive domain, Bloom proposed subdividing these thinking skills into six categories: knowledge, comprehension, application, analysis, synthesis, and evaluation (Bloom, 1965; Bloom et al., 1956). These categories range from lower-level cognitive skill (i.e., knowledge) to higher-level cognitive skills (i.e., synthesis).

Two examples of how faculty used Bloom's Taxonomy for geoscience curriculum design (McConnell et al., 2003) and for assessment (Nunn \& Braud, 2013) elucidated how Bloom's framework has been the tool to assess levels of critical thinking within the geosciences. In their study, McConnell et al. (2003) used Bloom's cognitive domain and inquiry questions from King (1995) to transform introductory geoscience course for nonmajors from passive to active learning environments. In their study, McConnell et al. (2003) compared four large (140-180 students) undergraduate sections where faculty used a traditional lecture format in two sections and an inquiry-based learning format in the other two sections. In the inquiry-based section, faculty used active learning methods such as group work, image analysis, questions, Venn diagrams, and concept tests as well as quantitative (student evaluations) and qualitative (classroom observations and student 
interviews) methods. Findings of this study showed that even though content knowledge was comparable in both methods (traditional and inquiry-based), when faculty used inquiry-based learning it increased student retention, increased a deeper understanding of material, and increased logical thinking skills (McConnell et al., 2003). Moreover, students preferred when a faculty member used inquiry-based learning teaching methods. While McConnell et al. showed a way to use Bloom's Taxonomy for curriculum design, Nunn and Braud (2013) used Bloom's Taxonomy to assess critical thinking and earth science literacy in a service-learning project. In this study, assessment of the students' critical thinking and literacy occurred by assigning the students oral and written communication activities (i.e., research paper, PowerPoint presentation, poster) on the topic of volcanoes. Each of these assignments focused on different parts of the Bloom's taxonomy. For example, the research paper measured two lower-level cognitive skills (i.e., remembering, understanding) and one higher-level cognitive skill (i.e., application). Whereas both the presentation and poster focused measured only higher-level cognitive skills (i.e., applying, analyzing, evaluating, creating). Although many introductory courses focus on lower-level thinking skills, the findings of this study showed that service-learning environments do promote the use of higher-order thinking skills (Nunn \& Braud, 2013).

Interestingly, although McConnell et al. (2003) and Nunn and Braud's (2013) studies showed instructional tools that promote critical thinking, upon further investigation of these studies, it seems that the researchers defined critical thinking implicitly as Bloom's six categories: knowledge, comprehension, application, analysis, 
synthesis, and evaluation. There are few studies around faculty's perception and assessment of critical thinking instructional practices especially at community colleges (BoarerPitchford, 2010; Hobaugh, 2005). For this reason, I argue that faculty members need to consider in their reflective practice what it means to be a critical thinker so that a deeper understanding around the impact of different instructional tools to support critical thinking among students.

\section{Review of the Methodological Literature}

Critical thinking research studies have been complex and have extended for more than two decades. What initially started as a method to improve faculty's pedagogical approach in their courses has become a focus of what students need to be successful professionals in the field. In fact, much of the critical thinking research came from feedback given by employers that hired many STEM employees (Arum \& Roksa, 2011; Paul, 1992). Most of employers' feedback relied on the fact that students' skills did not match with the demands in the workplace. For example, in Keane's (2018) recent review of geoscience industry data from various AGI surveys on workforce, employers expressed the need for students who know how to apply their discipline-specific (i.e., geosciences) problem solving to a spectrum of science and engineering topics with the goal of developing new data. Meaning that employers were seeking someone who could use problem solving in the context of open and dynamic systems, someone who could apply their skills to new scenarios, and for someone comfortable with uncertainty. These industry demands have been what tends to shift most of the curriculum development and instruction within geoscience departments at postsecondary institutions. Interestingly, 
most research regarding students' acquisition of critical thinking focused on (a) the skill of critical thinking, and (b) the pedagogical tools that develop, strengthen, and deepen their thinking.

To elaborate on the research on critical thinking curriculum and instruction at postsecondary education, I identified three specific examples: Rowe et al. (2015), Richardson and Ice (2010), and LaDue and Clark (2012). First, Rowe et al. noted that recent studies challenged the claims about the effectiveness of traditional college curriculum in the development of critical thinking skills. In their work, Rowe et al. developed an introductory general science for non-major's course that incorporated the teaching of critical thinking by focusing on the nature of science. The course also had the students reflect and analyze science versus pseudoscience, learn about basics of an argument, fallacies, and psychological factors that can influence the rejection and acceptance of scientific ideas (Rowe et al., 2015). The aim of the study was to examine whether a redesigned curriculum to teach the nature of science in non-science major's general science courses could promote the use critical thinking (Rowe et al., 2015). Rowe et al. assessed 475 undergraduate students, where 203 were students taking traditional general education courses (i.e., chemistry, geology, geography, physics, environmental studies) and 272 were students taking the new course called Foundations of Science (FoS), between fall 2008 and fall 2012. Rowe et al.'s experimental approach involved comparing their new course, FoS, with other general science courses using two pretests and post-tests: Critical Assessment Test and Measure of Acceptance of the Theory for Evolution. The results of their study indicated that when focusing on the nature of science 
rather than only the facts, students increased the usage of their critical thinking (Rowe et al., 2015) in one single semester. In fact, their study showed that students increased the use of critical thinking in one single course by almost $28 \%$ compared with the national average improvement in critical thinking over a typical four-year undergraduate curriculum, which is $26 \%$. Their findings demonstrated that when a faculty member teaches a course with a focus on the nature of science, students improve their use of critical thinking. In addition, although there was still much to learn about the exact factors that influence students in accepting or rejecting a theory, their robust results showed that when a course focuses on the nature of science and uses social judgement theory students are more engaged (Rowe et al., 2015).

Rather than curricular changes, the second study by Richardson and Ice (2010) investigated the impact of students' critical thinking skills through online discussions using three different instructional strategies (i.e., case-based discussion, open-ended discussion, debate discussions). In this study, the researchers assessed a critical thinking using a model called Practical Inquiry Model (PIM) derived from “Dewey's concept of practical inquiry" (Richardson \& Ice, 2010, p. 53). The PIM of critical thinking used four phases: triggering, exploration, integration, and resolution. Participants of this study included students enrolled in a course about fundamentals of technology in the classroom during the fall 2008. Data collection came from two main sources: (a) online discussions (three online discussions using a different instructional strategy for each discussion) and (b) surveys (student responded at the end of the semester a survey about students' perception around online learning and preferred instructional strategy). Findings of 
Richardson and Ice's study showed three important results. First, open-ended discussions were the students preferred instructional strategy (47\%) due to less regulation. However, $36 \%$ of participants chose debate discussion and $17 \%$ chose case-based discussions as preferred instructional strategy. Interestingly, comparing the students' preferred strategy and PIM critical thinking levels, the open-ended discussions scored lower. Second, there was a relationship between online learning comfort level, instructional strategies, and critical thinking. The more comfortable students were in an online environment, the more comfortable they become using different instructional strategies, thus, increasing their opportunity to use higher order thinking skills. Lastly, when comparing the participants' critical thinking level (PIM) by instructional strategy, 78\% of case-based discussion posts, $77 \%$ of debate discussion posts, and $60 \%$ of open-ended discussion posts aligned with the integration phase (i.e., creative solutions). A limitation of this study was that researchers tested each instructional activity only once (Richardson \& Ice, 2010). Thus, making it difficult for them to separate if the choice of students preferred instructional strategy was due to personal relevance of the topic or an understanding of how instructional strategy changed their critical thinking (Richardson \& Ice, 2010).

In the last example study, LaDue and Clark (2012) focused on survey analysis on K-12 teachers and undergraduate geoscience faculty's perception of important concepts and challenges needed to improve Earth science literacy. The first survey gathered perceptions regarding Earth science literacy among the public. Results from the first survey indicated that Earth science literacy supported decision-making due to its personal and local relevancy (LaDue \& Clark, 2012). However, result also showed that Earth 
science was not only underrepresented at the K-12 level but it was also, it was not considered a rigorous science thus leading to a poorly informed public (LaDue \& Clark, 2012). On the contrary, the second survey, which gathered the perceptions on essential learning goals for non-science undergraduate majors enrolled in geoscience courses (LaDue \& Clark, 2012), indicated that for postsecondary geoscience educators the instruction on systems concepts was more important than specific topics. This finding was important because systems concepts offer a deeper scientific understanding of Earth's and planetary processes.

Although two of these research studies focused on students and the other focused on faculty perceptions about geoscience instruction, they showed the use of different methodologies by scholars to investigate perceptions and instruction of critical thinking. As my research topic focused on understanding the use of critical thinking instructional tools with geoscience community college non-science majors taking introductory geoscience courses, my review of these exemplars was invaluable. Research methodologies that focused on understanding faculty members' perceptions of what they consider to be important or challenging, as well as the different instructional tools they use to assess critical thinking were important to investigate. These methods played a role in identifying what ways that faculty members may use, enhance, or define critical thinking. Additionally, except for the study from Richardson and Ice (2010), the dominant methodology used to explore critical thinking was quantitative. In addition, research in the past has shown that content and delivery designed to foster critical thinking might vary (Tsui, 1999); little research has investigated what faculty’s 
epistemologies are regarding critical thinking.

The question of epistemology is important as it may play a role on how content and delivery vary, and therefore, why we see the levels of students' efficacy in critical thinking being so diverse. Examples of why investigating faculty members perceptions and instructional tools is important to understand can be seen in LaDue and Clark's (2012) study, where a distinction of values between K-12 teachers and undergraduate geoscience faculty was evident in both surveys given at conference. For example, whereas the K-12 teachers value the connection between Earth and humanity more, the undergraduate geoscience faculty put greater value on a deeper understanding and application of scientific phenomena.

I proposed a qualitative study that focused on learning about individual thinking via a survey, interviews, and documents to uncover important understanding within the students' development of critical thinking from the perspective of the faculty member. Allowing faculty members from postsecondary education time to reflect and discuss their own practice was often expected but not necessarily enforced among postsecondary education faculty members. While I have not suggested that all faculty be required to reflect on their own practice, it appeared that many already engage in reflective practice.

I think that faculty at postsecondary institutions rarely have time to speak to other colleagues about their classroom ideas and learning experiences. Creating an environment that facilitates faculty member's voices regarding the intentionality behind the use of an instructional tool designed to foster critical thinking is not only significant but, it may also provide a bigger perspective of the use and assessment of critical thinking 
in the classroom.

\section{Summary of the Research Literature and Application of the Study}

According to Forawi (2016), as the world grows more complex at an increasing rate the use of critical thinking skills becomes imperative. The quest for postsecondary education to shift the instruction from simple memorization to systems thinking approach prepares graduating students to tackle the complexities of the world. Thus, I want to challenge the academic community to reflect on what it means to be a critical thinker and to reflect on one's epistemological beliefs around critical thinking. Such reflections can facilitate faculty members the confidence to learn how they can explicitly embed critical thinking in their discipline-specific curriculum and instruction. Although a universal definition of critical thinking may never be possible, faculty members can use several strategies to deepen their students thinking. Bringing back Dewey's 1910 argument: when we are practicing reflective thinking, we overcome the inertia of accepting all information at their face value. Therefore, rather than aiming for a one-size fits all definition, looking at the commonalities shared among definitions can allow educators to create adaptable frameworks that can facilitate the understanding of how, when, and where critical thinking is happening in the classroom. Giving the opportunity for faculty members to reflect on their own epistemologies around critical thinking can be the first step to connect the pieces of the understanding, use, and assessment of critical thinking the classroom. In addition, assessment practices can be more adaptable to the student population rather than generalizing the learning and development of critical thinking. Past and recent research indicates that students are not using higher levels of critical thinking 
(Arum \& Roska, 2011) and few of the available research studies show that when faculty members are using critical thinking in the classroom, it varies per discipline (Nicholas \& Labig 2013; Nicolas \& Raider-Roth, 2016; Tsui, 1999). As stated previously, there are few studies on community colleges, especially within geoscience programs. The field of geoscience education in comparison to other STEM disciplines is young and therefore, there is a need for more studies featuring faculty members' voices regarding perceptions around critical thinking and the instructional methods used in their classroom. Featuring faculty voices via qualitative studies using surveys, interviews, and documents can potentially be a first step towards a more complete understanding of the learning happening within the classrooms. My aim is to shift the focus to one with a more positive lens. Rather than viewing research findings as a lack of critical thinking among students, I contend that we can shift the perspective to how the environments created by faculty and students describe the development, strengthening, and deepening of critical thinking within their classroom. My qualitative study with community college geoscience faculty as the sole participants may unveil some of the many areas missing in the understanding, use, and development of critical thinking in the classroom. 


\section{Chapter 3: Methods}

Critical thinking is one of the most important outcomes in postsecondary education (Facione, 2015; Kim et al., 2013; National Research Council, 2011; Rowe et al., 2015) as it involves developing the student's capacity to reason, to evaluate evidence, detect mistakes, and to ascertain bias and manipulation. However most non-science majors taking an introductory geoscience course at a community college arrive with the knowledge they remember from their high school science courses. Also, assessments of student learning at the high school level focus on students' achievement in factual knowledge (National Research Council, 2011) rather than students' achievement specifically in critical thinking. In addition, most research on critical thinking development focuses either at the K-12 level or at four-year postsecondary education. In fact, very few of the studies focus on the geosciences at community colleges. More importantly, few studies explore the critical thinking instructional tools geoscience faculty members use to strengthen, deepen, and enhance their students' critical thinking. The purpose of my study is to describe and examine the perceptions of community college geoscience faculty regarding critical thinking and how such perceptions influence their chosen instructional strategies

In this chapter, I define and describe the methodology, discussing data collection procedures and analysis used to examine my research questions. Data resulting from this study may provide knowledge and understanding of the state in which community college faculty members teach critical thinking within their introductory geosciences classroom. For example, data may advance understanding of (a) how faculty define critical thinking 
to themselves and to their students, (b) the role of critical thinking in the classroomimplicit or explicit, and (c) the instructional tools frequently used for critical thinking in the classroom. Lastly, the data from this work may lead to a better understanding of the role of critical thinking within community college institutions and faculty members so that institutions can provide more direct support that eventually enhances learning for both faculty and students.

\section{Research Methods}

With the understanding that educators and researchers are only at the very beginning of developing a comprehensive conceptual framework for teaching critical thinking within interdisciplinary STEM fields, the decision of which type of initial qualitative study to use is an important one. According to sociocultural theorists, individuals construct meaning and view of their world through social interactions (Jaramillo, 1996; Vygotsky, 1978). Interestingly, the central goal of qualitative research is to learn how an individual constructs reality while interacting in a social world. Recognizing that qualitative research has certain affordances and constraints, often sacrificing depth for breadth, I use basic qualitative research for my study.

Caelli et al. (2003) defined basic qualitative research as "not guided by an explicit or established set of philosophic assumptions in the form of the known qualitative methodologies" (p. 9) (e.g., phenomenology, grounded theory, case studies, ethnography). In fact, Kahlke (2014, p. 39) noted that basic qualitative studies "draw on the strengths of established methodologies while maintaining flexibility," especially when the research studies do not align perfectly within a well-established methodology. 
Merriam and Tisdell (2016) suggested that basic qualitative study seeks to understand “(1) how people interpret their experiences, (2) how they construct their worlds, and (3) what meaning they attribute to their experiences" (p. 24). Thus, researchers contended that basic qualitative research studies at its roots are epistemologically social constructivist and theoretically interpretive studies that focus on how participants interpret, construct, and make meaning of their world and experiences (Kahlke, 2014).

Postsecondary institutions and certain community colleges specifically are considering a variety of critical thinking frameworks, instructional tools, and assessments. Although institutions consider critical thinking as a necessary skill for success, the reality is that the conceptualization of critical thinking is still in debate. This debate often leads to misalignment between the institutions' administration, faculty and students on the use and assessment of critical thinking in the classroom (Nicholas \& Raider-Roth, 2016). Therefore, in this investigation, I am interested in understanding how faculty members (a) interpret institutional demands, (b) make sense of the concept of critical thinking in their own classrooms, and (c) the ways in which their conception of critical thinking is playing (or not) a role in the selection of the classroom instructional tools.

Using basic qualitative research has its affordances and constraints. The affordances of conducting a basic qualitative research lie in its flexibility of using multiple data collection methods. Thus, basic qualitative research allows my use of multiple data collection methods including surveys, interviews, and documents to uncover and interpret meaning without compromising a specific qualitative design. In 
addition, basic qualitative methodology is a good fit for a first foray into an undiscovered terrain. The constraints of using basic qualitative research are evident in the review of the methodological literature.

Kahlke (2014) asserted that when researchers do not construct basic qualitative studies in a well-established methodology these studies are at risk of being incoherent or inadequately acknowledging epistemological origins and its assumptions. However, Caelli et al. (2003) argued that researchers can avoid such risks by making declarations within their researcher's role, showing alignment between their methodology and method, articulating their specific approach to rigor, and explaining clearly the analytic lens used in the study.

\section{Participants}

To capture multiple perspectives of community college geoscience faculty members perceptions of critical thinking and how their perceptions influence the critical thinking instructions tools they used in the classroom, I used maximum variation sampling to select my participants (Creswell, 2014). Glesne (2016) defined maximum variation sampling as a purposive sampling technique used to capture a wide range of perspectives relating to scope of a study. Affordances of this type of sampling have had strong generalizability whereas the constraints of this sampling have been the lack of specific in-depth characteristics. For example, in my study, I had a variation of perspectives due to career experience but not an in-depth perspective within a specific career group.

The participants of this study were seven geoscience faculty members currently 
teaching geology courses at community colleges in the Pacific Northwest. However, to maintain the scope of the study within the maximum variation sampling, each participant had three common characteristics: location (Oregon and Washington), type of institution (community college), and discipline (geoscience). What differed for each participant that in fact maximized the sampling was (a) the type of community college faculty appointment, (b) the teaching experience, (c) the specialty within the geoscience

discipline, (d) the academic degree, (e) the gender identification, and (f) the knowledge of critical thinking.

\section{Faculty Appointment}

Community college faculty appointments have included multiple positions: instructor, assistant professor, associate professor, and full professor. These positions have varied from whether they are full-time or part-time to their teaching experience and rank. Depending on the institution, geoscience departments could have one full-time faculty and three or more part-time faculty. Of the seven participants in this study, four were full-time faculty and three were part-time faculty. Although four of the participants were full-time, their faculty appointment varied (i.e., instructor, assistant professor, associate professor, professor).

\section{Teaching Experience}

Not only did the participants vary in faculty appointment, but each participant also varied in their years of experience teaching at community college. Classification of years of experience were early career (i.e., 1-4 years), mid-career (i.e., 5-10 years), and late career (i.e., 10+ years). Using this distinction, three of the participants were in their 
early career faculty stage, two participants were in their mid-career faculty stage, and two participants were in their late career faculty stage.

\section{Geoscience Specialty}

Geoscience is a vast discipline drawing on concepts of physics, chemistry, biology, and mathematics to explain the Earth and planetary systems' processes and evolution through time (Manduca \& Kastens, 2012). Depending on the focus within geoscience, many subject areas are covered by the field of geoscience. In this study, two of the participants were geoscience educators, two participants were geomorphologists (i.e., study the Earth's landforms and surface processes), two participants were volcanologists (i.e., study the formation and processes of volcanic activity), and one participant was an oceanographer (i.e., studies the oceans).

\section{Academic Degree}

Community colleges have hired faculty who hold a master's degree or higher. Thus, the faculty member's academic degree was also a variation factor. Four of the participants held master's degrees, and five of the participants held Ph.D. degrees.

\section{Gender}

Participants gender identification was another variation factor. Four of the participants self-identified their gender as male, and three of the participants selfidentified their gender as female.

\section{Knowledge of Critical Thinking}

Faculty members knowledge of critical thinking was another variation factor among the participants. This meant that each participant's knowledge varied greatly- 
from their definitions of critical thinking to their prior training about critical thinking.

In addition of the variation factors mentioned for each of the participants, ethnicity could have been another variation. However, all the participants in this study self-identified as White or Caucasian; therefore, ethnicity was not a variation among the participants.

\section{Procedures}

In this study, I used procedures for participant recruitment, participant selection, and step-by-step data collection as shown in Figure 2. In this section, I discuss recruitment, participant consent forms (i.e., informed consent), and the data collection process.

Figure 2

Procedures for Recruitment and Data Collection

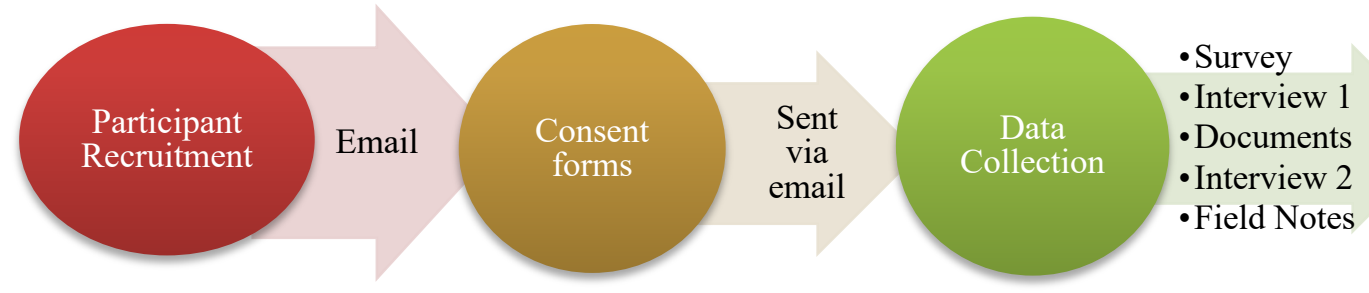

\section{Recruitment}

A formal invitation to participate email (see Appendix A) was sent to community college geoscience faculty members in two ways: an individual email message with an invitation to participate and an announcement via popular geoscience listserv with an invitation to participate. Initially, I contacted faculty members by finding their email information through their institution's website and sent a formal invitation to participate email. Unfortunately, using this method was limiting as it yielded little response. 
Therefore, I reached out to several popular geoscience listserv newsletter editors. After our conversation regarding my research study, they were excited to send an announcement with my invitation to participate via their respective listservs. This announcement with invitation to participate was sent to three popular professional development geoscience listservs currently supporting community college geoscience faculty members. These included (a) National Association of Geoscience Teachers (NAGT) that recently expanded their support to community colleges faculty members by creating a subdivision called Geo2yc; (b) Supporting and Advancing Education for Community College (SAGE2YC), one of the biggest and most popular professional development agencies available to community college faculty; and (c) Ocean Sciences listserv dedicated to all oceanography faculty members at either four-year institutions or community colleges. Using listservs for recruitment yielded more success, and many faculty members expressed their interest in participating.

\section{Consent Forms}

Participants who responded with interest in participating obtained an email with the Participant Consent Form (see Appendix B). The consent forms were signed electronically using HelloSign's digital workflow platform which offered legally binding eSignatures. Each participant received their own link to the documents to revise, ask questions, and finally, to sign. After the participants and researcher signed the Participant Consent Forms, both participant and researcher received copies of the form. The consent form allowed participants to give their consent for participation, provided study's data collection process, and included my contact information in the case participants had 
questions regarding the study.

\section{Data Collection Process}

Data collection proceeded in the following order: survey (see Appendix C), first individual interview (see Appendix D), documents (e.g., syllabi, field notes, faculty member handouts, activity sheets, classroom notes), and second interview (see Appendix F). However, before official data collection occurred during winter 2020 term, I conducted an interview pilot study. I piloted each of the question that I eventually used to collect data. This pilot helped to ensure that the interview protocols were providing data to answer to my research questions.

Data collection began during the months of March, April, May, June, and July. Upon completing their consent forms, each participant received a Qualtrics link to the Critical Thinking Survey for Geoscience Faculty (see Appendix C). The survey contained demographic information and questions to determine participants' initial understanding of their knowledge around critical thinking. In addition, the purpose of the survey was to explore and then narrow the participant pool to acquire a maximum variation participant sample. Using the survey, I narrowed the pool to seven participants that reflected a wide sample variation; then, I contacted participants individually to schedule the two interviews. All participants scheduled both interviews within a period of two weeks and each interview occurred online using the Zoom video conferencing platform. The interviews were semi-structured and had 10 questions. For the individual interviews, each participant received an interview protocol with questions at the start of the interview. Each interview protocol included succinct information regarding the interview process 
and the 10 questions so that each participant could read and hear the questions.

During the entire process of data collection, I took field notes. Before the interviews, I would re-read the participants' survey answers and make additional notes. During interview, I allowed time to introduce myself to participants, time for participants to ask for any questions or to request clarifications before starting interview questions. While conducting the interview, I mostly focused on listening and taking few essential notes, especially if I had a follow-up question. However, after each interview, I took additional notes about my observations and experience conducting the interview. In between interviews, I asked participants to share documents that they considered pertinent to the study. I took additional notes about each document shared with me. If I needed clarifications about the documents, I asked participants for permission to ask them clarifying questions at the end of interview. Lastly, while editing the interview transcripts, I wrote an additional set of notes.

\section{Instruments and Measures}

I used multiple data sources to address my research questions: one survey, two semi-structured interviews, documents (syllabi, faculty handouts of lecture, lesson plan, activity, or assignments), and my own field notes. As shown in Table 1, each data source related to a specific research question.

\section{Table 1}

\section{Methods Matrix}




$\begin{array}{lll}\text { RQ \#1 } & \begin{array}{l}\text { What are geoscience community college faculty } \\ \text { members' is the perceptions of critical thinking? }\end{array} & \begin{array}{l}\text { Survey } \\ \text { First Interview } \\ \text { Field Notes }\end{array} \\ \text { RQ \#2 } & \begin{array}{l}\text { How do geoscience faculty members' perceptions } \\ \text { influence their use of critical thinking instructional } \\ \text { strategies? }\end{array} & \begin{array}{l}\text { Second interview } \\ \text { Instruction } \\ \text { documents } \\ \text { Field Notes }\end{array}\end{array}$

\section{Critical Thinking Survey for Geoscience Faculty}

The first instrument that each participant received after the consent forms was the survey. Kelley-Quon (2018) argued that a survey enabled researchers to obtain information about demographics, perceptions and practice within a given population that may not necessarily captured using other forms of research techniques. In this research study the survey (see Appendix D) usage was twofold first, as tool for selecting participants and second, to understand initial faculty members' perceptions of critical thinking frameworks. The survey took 5-10 minutes for participants to complete. First, to use the survey as a tool for participant selection, I focused on the scope of the study to make sure all participants had these three things in common: location (Oregon and Washington), type of institution (community college), and discipline (geoscience). Second, to ensure maximum variation of faculty members' voices, I selected participants that vary in (a) type of community college faculty appointment, (b) teaching experience, (c) geoscience discipline, (d) academic degree, (e) knowledge of critical thinking, and (f) gender and ethnicity identification — as discussed in the Participants section.

Although the primary usage of the survey was to explore and narrow the 
participant pool, it was also used to assess participant perspectives of critical thinking. As noted in the literature review, researchers have debated the definition of critical thinking and have used a variety of assessment frameworks to measure how critical thinking occurs in the classroom. Therefore, I designed the Critical Thinking Survey for Geoscience Faculty (see Appendix C) to gather initial faculty perceptions regarding research-based definitions and critical thinking frameworks within the field of geoscience and in education in general. Thus, I could obtain actual data on participants' knowledge of different terms used within critical thinking literature, knowledge and use of existing critical thinking frameworks in their classroom, and if they have received any training to teach and/or assess critical thinking.

\section{Interviews}

Seidman (2013) argued that interviewing is a way to learn from other people's stories. Via these stories, the researcher could learn about the meaning-making process of their participants (Seidman, 2013). In this study, the purpose of an individual interview with the participants was to explore in depth their perceptions regarding critical thinking and to explore how their perception toward critical thinking influences their instruction. In the individual interview, I had more control and a closer communication with the participant, which in turn, allowed for depth about the participants experience (Morgan, 1997). Two semi-structured individual interviews (see Appendices E \& F) afforded me with an opportunity to highlight the participant's voice and develop participant-researcher co-construction of meaning (Merriam \& Tisdell, 2016; Nicholas \& Raider-Roth, 2016). The focus of the interviews was (a) how they define critical thinking, (b) pedagogical 
approaches to critical thinking strategies (c) frameworks associated with critical thinking strategies, and (d) attitudes towards teaching/assessment of critical thinking strategies (Nicholas \& Raider-Roth, 2016). Each interview was comprised of 10 questions (see Appendix E and Appendix F for questions).

Each interview participant had a particular focus. The first interview focused on the participant's perception of critical thinking from their own perspectives to all the way to the institution's perspective. As stated in my theoretical framework sociocultural theory, Vygotsky (1978) emphasized that the development of a learner's cognition is a social process involving interactions with other capable peers (Shute \& Slee, 2015; Tudge \& Winterhoff, 1993). These interactions play a fundamental role in the learner's cognitive development individually, as well as socially. Therefore, the purpose of the 10 questions in the first interview was to understand participants cognitive process about critical thinking from an individual perspective (i.e., define critical thinking in your own words) to a social perspective (i.e., how your institution defines critical thinking). Additionally, these questions investigated (a) what language they used to connect relationship between critical thinking with themselves, the field, and their lessons plans; (b) the metacognitive tools they used to learn about the role of critical thinking within geosciences; and (c) the application from their understanding of critical thinking and the application in the classroom. The second interview also had 10 questions that focused on how their perceptions play (or do not play) a role when using critical thinking instructional tools. Ennis (2015) argued that faculty member roles in the classroom classified in two: disseminators of knowledge (faculty is the one with knowledge and 
students listen) and mentors (faculty as facilitator, student construct knowledge). He reasoned that the role of the faculty member in the classroom greatly affects how to support critical thinking in the classroom. Thus, the second interview provided an opportunity to learn more about participants' application of critical thinking cognitive process in their classroom. For example, in this social setting what is the participant' role in learning and applying their understanding of critical thinking in the classroom setting individually and collectively with their students. In addition, the interview questions explored (a) what language they used to connect relationship between critical thinking within their lessons and with their students; (b) the metacognitive tools they used to provide an opportunity to learn, develop, strengthen their students' critical thinking; and (c) the application from their understanding of critical thinking and the application in the classroom.

I conducted two 45-minute semi-structure individual interviews per participant via zoom. All interviews were audio/video recorded and transcribed verbatim using Zoom Transcription software. After conducting interviews with the seven participants, First, I edited seven of the verbatim transcriptions created automatically by the Zoom Transcription software. Second, I used the services of Rev.com to edit remaining seven verbatim transcriptions. Miles et.al. 2020 emphasized that one of the most logical sources of corroboration comes from participants' feedback. Participants' feedback is a way for researchers to do member checking. Therefore, after I edited the 14 verbatim transcripts, I sent each participant their corresponding interview transcripts via email for member checking. Each participant had a week to review and make modifications. 


\section{Documents and Field Notes}

In addition to the survey and interviews, I gathered documents from each participant and took extensive field notes. Example of the documents shared by participants were course syllabus, activity sheets, lecture notes, exams, and posters. Like previous instruments used to gather information about participants critical thinking perspectives and how such perceptions influence their critical thinking instructional goals, I wanted to see how their written documents presented critical thinking language, integration, personalization, and the application used by participants to their students. I also took field notes throughout the data collection process: after reading each participants' surveys, before/after conducting the interviews, and after reading the documents shared by participants. Thus, I used the supplemental material from the data collected (i.e., survey, interviews) as well as my own field notes as data sources. How I made meaning while learning from my participants was an important source of information.

\section{Role of the Researcher}

Maxwell (2002) argued that the "researcher's identity, perspective, and relationship to those studied are an important influence on the results of the research" (p. 12). Therefore, I would like to introduce myself, where am I coming from, the background experiences that influence my work, and finally, my commitment to this work.

First, I was born and raised in Cabo Rojo, Puerto Rico. At the age of 23, I left my beautiful island to pursue my geophysics graduate degree. As an adult Latina living for 
the first time in the United States, I endured many challenges. In my entire geology department, I was one of the very few Latinx graduate students, and in my specific field, I was the only one during my first graduate school year. This transition was quite difficult, because I had a hard time adjusting to the culture, the colloquialisms of the language, the variety of English accents, the social relationships (especially the ones within my field of study), and even the religion/political views. These challenges affected my learning quite heavily and forced me to find alternative ways to communicate effectively about how I understood and applied knowledge. Not only I was struggling in the language, but I was also struggling with my identity. My identity of who I was in Puerto Rico changed; I was in a completely different environment learning new skills and having new experiences. These set of skills played a significant role on who I was as a faculty to my students. I wanted to offer my students what I did not have when I was in school. Someone that understands when to listen, when to give time, when to reach out, when to push, and when to let go. I care deeply about the learning environment that a faculty member creates for their students. Therefore, to me learning happened as a community, we all learned together, and we supported each other through our learning.

Second, before starting my EdD program with a curriculum and instruction specialization at Portland State University, I had an identity as a scientist and instructor. My prior training was in geology and geophysics; I hold a B.S. in Geology and a M.S. in Geophysics. Although my training before this doctoral degree was not formally in the education field, I have taught geology, physics, and environmental science for nine years at various community colleges as both tenured faculty and adjunct faculty. Reflecting on 
my academic background experiences, the key strength that I brought to this research study stemmed from a combination of a post-positivist (from my STEM background) and constructivist (from my educator background) philosophical perspectives. In many ways, I viewed the work of this research study as a bridge between geology, education, and my experiences.

Lastly, I acknowledge that this was my first qualitative research study, so I recognized that there could be room for improvement. Nevertheless, my advisor and my program prepared me well to take on this task. For this dissertation study, I have carefully maintained rigorous data collection procedures, engaged in meaningful interactions with participants, and used well-established data analysis methods.

\section{Data Analysis}

Creswell and Poth (2018) argued that qualitative research data analysis occurs in three main stages: organizing data collected (i.e., survey, interview transcripts, documents), using qualitative research coding methodologies to reduce the data into themes until research has high quality, condensed codes, and representing data findings in figures, tables or in a discussion. For this study, I conducted data analysis of one survey per participant, two interview transcripts per participant, documents shared per participants, and researcher's field notes. I used data analysis strategies from the work of Creswell (2014), Creswell and Poth (2018), Miles et al. (2020), and Merriam and Tisdell (2016). First, I organized the data for each participant in a file that included: survey responses, both interview transcripts, documents shared by participant, and researcher's notes for each document. This organization kept all the data for analysis process in one 
place. Using my theoretical framework (i.e., Vygotsky's [1978] sociocultural theory) and Conceptual Critical Thinking Instructional Model, I looked at data sources individually and then collectively in two coding cycles. In the first cycle, I used in vivo coding (i.e., open coding) and values coding. In vivo coding offered me an opportunity to honor each of my participants' voices. In other words, I started my analysis using my participants' own language and recorded them as codes (Miles et al. 2020). As for values coding, gave me an opportunity to reflect on my participants values, attitudes, and beliefs that further represented their worldview (Miles et al., 2020). During the second coding cycle, I used pattern and eclectic coding from the codes generated from the first cycle coding to categorize (pattern) and redefine (eclectic) the codes further by related categoriestherefore identifying larger themes and concepts of the data.

\section{Ethical Considerations}

To ensure the ethical collection of data, the Institutional Review Board from Portland State University reviewed and approved my research study. I explained how I would maintain confidentiality of all data collection sources during collection, analysis, and reporting. In this study, I did not used the participants' names, the names of their institutions, or any information that would compromise participants' identity. Instead, to maintain anonymity, I assigned pseudonyms (i.e., Garnet, Mica, Slate, Serpentinite, Amphibolite, Eclogite, and Peridotite) for the participants. Furthermore, to eliminate the possibility of one's own personal biases when developing the interview questions, I reviewed the items carefully to avoid subtly leading participants to specific answers (Glesne, 2011; Merriam \& Tisdell, 2016). In addition, I piloted the interview items with a 
colleague not involved in the study to help reduce the possibility of bias when conducting the interviews. Before the interviews, I, (a) reiterated the information from their signed Participant Consent Forms to protect participants, and (b) explained the participant's rights (i.e., declining to answer specific questions, to withdraw at any point from the study).

\section{Subjectivity and Researcher Role}

To address the issue of subjectivity within the data collection process, I wrote reflective memos about (a) personal goals — why does certain data "stand out"?; (b) practical goals - what are themes from the surveys, interviews, and documents and are these themes leading me to address to my research question?; and (c) intellectual goalswhat are the possible causal explanations, when taking into consideration the perspectives of the participants, the context of their actions, unanticipated phenomena? (Maxwell, 2013).

\section{Validity, Credibility, and Trustworthiness}

The development of clear and descriptive protocols for the interviews helped me to bolster the validity, credibility, and trustworthiness of the data. To this end, I assert that the continual process of writing reflective memos, member checking with participants and my advisor, and triangulation added quality and rigor to my study. First, I wrote writing reflective memos during the data collection and analysis, which elicited insight into my own positionality, epistemologies, subjectivity, and bias. In addition, writing such memos provided an opportunity to discuss the data collection and analysis processes. Second, I conducted member checking in two ways: (a) participant member 
checking (Miles et. al., 2020), each participant received their interview transcripts via email to review their responses and make changes that clarify or correct meaning; (b) member checking with advisor, during data analysis I collaborated with my advisor to gain inter-rate reliability; (c) gather participants' feedback after the final analysis (Miles et.al., 2020) to gain inter-rate reliability. Thus, further establishing validation of accuracy and credibility of the data collection and findings (Creswell \& Poth, 2018). 


\section{Chapter 4: Results/Analysis}

Critical thinking is one of the most highly regarded outcomes in education as it involves the "process used to analyze data, solve problems, generate ideas, identify fallacies, locate flaws, etc.” (Pearlman, 2020, p. 13). Yet, assessments on student learning from K-12 environments focus on factual knowledge rather than understanding students' processes or strategies used to achieve critical thinking. Rarer are studies that narrow the research to non-science majors taking introductory geoscience courses at community colleges and their faculty members teaching such courses.

The purpose of my study was to describe and examine the perceptions of community college geoscience faculty regarding critical thinking and how such perceptions influence their chosen instructional strategies. To investigate this study the two research questions were: (a) what are the geoscience community college faculty members' perceptions of critical thinking? and (b) how do geoscience faculty members' perceptions influence their use of critical thinking instructional strategies? My study provided an opportunity to explore the state of critical thinking among geoscience faculty members at community colleges to further the dialogue within these spaces.

In this chapter, I describe the process of data analysis, present the findings, interpret the findings, and note the limitations of the study. To begin, I discuss how I analyzed the three data sources from my data collection: survey, interviews, and participants' documents (i.e., syllabus, handouts, activities).

\section{Analysis of Data}

In this section, for my analysis of the data, I used strategies from Saldaña (2016), 
Creswell (2014), Creswell and Poth (2018), Miles et al. (2020), and Merriam and Tisdell (2016). First, I organized the data for each participant (i.e., geoscience faculty members) in a file that included survey responses, both interview transcripts, documents shared by the participant, and the researcher's notes for each document. This organization kept all the data for the analysis process in one place. Using my theoretical framework (i.e., Vygotsky's [1978] sociocultural theory) and Conceptual Critical Thinking Instructional Model (i.e., a four-step intuitive model for faculty to track and reflect the use of critical thinking in the classroom), I looked at data sources individually, and then collectively in two coding cycles. In the first cycle, I used two types of coding strategies: in vivo coding (i.e., open coding) and values coding. In the second cycle, I used pattern coding. In pattern coding, I used codes generated in the first cycle of coding to cluster the codes further into related categories - therefore, identifying larger themes and concepts in the data.

\section{First Cycle Coding}

First cycle coding guided my initial analysis of the data using in vivo and values coding. In vivo coding afforded me with an opportunity to capture and represent each of my participants' voices. Using participants' language to describe their perceptions on critical thinking and how such perceptions influence their use of critical thinking instructional strategies was important because it "grounds the analysis in their perspectives" (Saldaña, 2016, p. 71). To complete this cycle first, I read each of the participants' interviews entirely; then, I identified excerpts of each participants' language as a code. Once completed, I conducted another first cycle coding strategy: values 
coding.

Given the ontological nature of my questions about critical thinking, values coding was the next logical step for my analysis. I used values coding to focus on viewing the data from the participants' values, attitudes, and beliefs - thus, further representing their worldview (Miles et al., 2020; Saldaña, 2016). My choice of values coding prompted the need for defining or describing the terms: values, attitudes, and beliefs. Daiute (2014) defined values as the assigned importance people give to themselves, another person, or idea based on their worldviews. Saldaña (2016) defined attitudes as "the way we think and feel about ourselves, another person, thing or idea" (p. 131). Wolcott (1999) described belief as a system of values and attitudes created by one's interpretation and point of view of the social world. Nevertheless, Saldaña argued that although values, attitudes, and beliefs as isolated constructs have different meanings, values coding could encompass all three.

I used both coding strategies — in vivo and values coding — during my first cycle of data analysis as shown in a representative example (see Table 2). I wanted to remain close to my participants' voices; therefore, during both in vivo and values coding, I used either a word or short phrase from their statements. I took data analysis memos throughout the first cycle coding process, which allowed me to identify the need for further and deeper analysis of my data. Thus, my first cycle of coding led me to conduct a second cycle of data analysis.

\section{Table 2}

First Cycle Coding using In Vivo and Values Coding Strategies 


\begin{tabular}{|c|c|c|}
\hline $\begin{array}{l}\text { Code } \\
\text { Type }\end{array}$ & Participants' quotations & Coding Name \\
\hline \multirow[t]{2}{*}{ In vivo } & $\begin{array}{l}\text { "So, my definition of critical thinking as } \\
\text { thinking for yourself and using reasoning skills } \\
\text { certainly reflects in my teaching style and what } \\
\text { I expect from the students." (Slate) }\end{array}$ & Thinking for yourself \\
\hline & $\begin{array}{l}\text { "Being able to assess a source, being able to } \\
\text { connect concepts or things that are presented as } \\
\text { facts." (Peridotite) }\end{array}$ & $\begin{array}{l}\text { Critically assessing } \\
\text { information }\end{array}$ \\
\hline \multirow[t]{3}{*}{ Values } & $\begin{array}{l}\text { "...then the other place where I think I struggle } \\
\text { with teaching critical thinking...I don't feel } \\
\text { comfortable with my ability to assess it." } \\
\text { (Mica) }\end{array}$ & Not Comfortable (Attitude) \\
\hline & $\begin{array}{l}\text { "So, the process of science is one of these } \\
\text { things I sort of thread through the quarter, and } \\
\text { so during that stream lab, I asked them to sort } \\
\text { of think about where the greatest challenge is in } \\
\text { doing the process of science." (Serpentinite) }\end{array}$ & Process of science (Values) \\
\hline & $\begin{array}{l}\text { "I think giving them open-ended questions } \\
\text { allows them to use their own tools, or their own } \\
\text { ways of thinking, to come up with an answer. } \\
\text { Justifying it. How they do that. Maybe that's } \\
\text { one way." (Eclogite) }\end{array}$ & $\begin{array}{l}\text { Open-ended questions allow } \\
\text { personalization of knowledge } \\
\text { (Belief) }\end{array}$ \\
\hline
\end{tabular}

\section{Second Cycle Coding}

Second cycle coding was the next step in my data analysis. I agreed with Saldaña (2016) whose assertion that the second cycle of coding allows researchers to reorganize and reanalyze the data coded during the first cycle methods. So, I conducted a second coding cycle using pattern coding. Saldaña defined pattern coding, often used for a second cycle analysis of data, as a way of grouping first cycle coding data into a smaller number of categories, themes, or concepts. This coding process provided me with more meaningful units of analysis. After conducting a second cycle data analysis using my 
research questions and data analysis memos as guidance, I identified 25 cluster categories that I further redefined into 18 categories. I created a spreadsheet with the 18 categories with the respective key interview data (i.e., quotations per participant), survey data, and document information. After redefining the 25 cluster categories as 18 cluster categories, I identified five themes (see Table 3).

\section{Table 3}

Refinement of Cluster Categories and Identification of Themes

\begin{tabular}{|c|c|c|}
\hline Initial cluster categories & Final cluster categories & Themes \\
\hline $\begin{array}{l}\text { Building confidence } \\
\text { Engagement }\end{array}$ & \multirow[t]{2}{*}{ Confidence/engagement } & \multirow{6}{*}{$\begin{array}{l}\text { Critical thinking } \\
\text { has a hierarchy }\end{array}$} \\
\hline Academic pathway & & \\
\hline $\begin{array}{l}\text { Evidence-based } \\
\text { practices }\end{array}$ & Active learning-foundation & \\
\hline Critical thinking tools & \multirow{3}{*}{ Higher level thinking } & \\
\hline $\begin{array}{l}\text { Critical thinking } \\
\text { ability/skills }\end{array}$ & & \\
\hline Deep structure & & \\
\hline $\begin{array}{l}\text { Critical thinking } \\
\text { emotionless } \\
\text { Lack of knowledge }\end{array}$ & \multirow[t]{2}{*}{$\begin{array}{l}\text { Critical thinking is an abstract } \\
\text { concept }\end{array}$} & \multirow{6}{*}{$\begin{array}{l}\text { Misalignment of } \\
\text { how } \\
\text { faculty/department/ } \\
\text { institutions } \\
\text { understand critical } \\
\text { thinking }\end{array}$} \\
\hline Lack of knowledge & & \\
\hline $\begin{array}{l}\text { Faculty training } \\
\text { Faculty learning } \\
\text { community }\end{array}$ & Faculty training \& support & \\
\hline $\begin{array}{l}\text { Lack of knowledge } \\
\text { Teaching and assessing } \\
\text { critical thinking }\end{array}$ & $\begin{array}{l}\text { Role of critical thinking in } \\
\text { Dept/Institutions }\end{array}$ & \\
\hline $\begin{array}{l}\text { Critical thinking not a } \\
\text { priority }\end{array}$ & Critical thinking is not a priority & \\
\hline Adjunct motivation & Adjunct motivation & \\
\hline
\end{tabular}




\begin{tabular}{lll}
\hline $\begin{array}{l}\text { Facilitator/curator } \\
\text { Diverse community of } \\
\text { learning }\end{array}$ & Personalization of learning \\
$\begin{array}{l}\text { Think aloud model } \\
\text { Process of science } \\
\begin{array}{l}\text { Critical thinking is } \\
\text { implicit }\end{array}\end{array}$ & $\begin{array}{l}\text { Think aloud model } \\
\text { Process of science }\end{array}$ & $\begin{array}{l}\text { Critical thinking } \\
\text { embedded in } \\
\text { scientific literacy }\end{array}$ \\
\hline $\begin{array}{l}\text { Time } \\
\text { Content vs breadth }\end{array}$ & Time & \\
Cognitive dissonance & Cognitive dissonance & Critical thinking \\
\hline Hope & Hope & Peding is time \\
\hline
\end{tabular}

I used different techniques to redefine the cluster categories from 25 to 18 . For example, I had initially separated the confidence/engagement category into two categories: building confidence and engagement. However, when analyzed more carefully I noticed that the participants always linked engagement and confidence- - they asserted a relationship between engagement and confidence. Because they rarely separated these categories when talking about critical thinking, I decided to cluster them into one category. Another example was with the active learning-foundation category, which I had initially separated into two categories: academic pathway and evidencebased practices. When re-reading the quotations belonging to these two categories, I noticed that the participants' comments focused on reflecting on their past academic experiences and using current evidence-based classroom practices that support techniques to build student's content foundation, thus leading me to combine these two categories. My third example of refining categories was Critical thinking is an abstract concept. I initially had divided this critical thinking as emotionlessness and lack of knowledge. 
When explored further, I noticed that some participants made comments about critical thinking occurring without emotion ( 2 of 7 participants). However, given the limited number of participants making those statements, I decided to eliminate that category. Lastly, I reviewed all data within the spreadsheet and wrote additional data analysis memos focusing on the relationship between the surveys, interviews, and participants' documents. By triangulating the data from surveys, interviews, and participants' documents, I was able to identify five key themes: (a) critical thinking has a hierarchal order; (b) misalignment between faculty, department, and institutions; (c) critical thinking embedded in scientific literacy; (d) critical thinking takes time, and (e) pedagogy of hope (see Table 3).

\section{Presentation of the Findings}

The findings from my analyses center around five important themes: (a) critical thinking has a hierarchal order, (b) misalignment of how faculty, department, and institutions understand critical thinking, (c) critical thinking is embedded in scientific literacy, (d) critical thinking takes time, and (e) pedagogy of hope. In the next sections, I present details about the findings by theme.

\section{Critical Thinking has a Hierarchal Order}

The first theme was the hierarchical order of critical thinking. According to participants, before students engage in critical thinking, three important conditions had to be in place. These three conditions were (a) confidence/engagement, (b) active learning/foundation, and (c) higher level thinking. These three conditions occurred in a hierarchical order with confidence/engagement preceding active learning/foundation, and 
higher -level thinking.

For the first condition, confidence/engagement, six of the seven participants argued that critical thinking occurs when students are engaged. Three of six participants explained that in addition to being engaged, students must also feel confident and remain curious about their thinking. The condition of confidence/engagement needed for critical thinking was evident in the participants' interviews and documents (see representative excerpts in Table 4).

Table 4

Examples of Confidence/Engagement Condition for Critical Thinking

Interview Excerpts Document Excerpts

"You know, it makes the classes more engaging and it, it helps increase students' confidence in their own abilities in this class to be able to think critically and solve problems right." (Garnet)

"...every time there's curiosity. The way to answer that curiosity is with critical thinking. It just, it happens all the time." (Mica)

"...building of confidence, and then the why we care, or context, and then why we care, so that it's not just in this isolated bubble." (Amphibolite)

For the second condition, active learning/foundation, six of seven participants discussed their use of active learning for student engagement and to build foundational understanding (i.e., content knowledge). Participants mentioned active learning strategies 
used in the classroom including jigsaw puzzles, gallery walks, reflection notebooks, think-pair-share, exam wrappers, concept sketches, real-life data, discussions, and clickers. The condition of active learning/foundation needed for critical thinking was apparent in the participants' interview comments and documents (see representative excerpts in Table 5).

Table 5

Examples of Active Learning/Foundation Condition for Critical Thinking

Interview Excerpts Document Excerpts

“...you can't do the critical thinking, till you have the foundation and the foundation either isn't there, or it is there, but it hasn't been explicitly connected or it's even there, and maybe they're aware of it, but they're not willing to step past that." (Mica)

"...concept maps or concept sketches or both, and I explicitly talk about how these are strategies that can be employed in classes where they might have a lot of vocabulary to help them create a framework upon which to build." (Serpentinite)

"I'm going under the assumption that to critically think, that goes hand in hand with active learning in some ways." (Eclogite)
"Outcomes focus on identify, discuss, describe and explain which mostly focus on building foundation." (Slate's syllabus)

"This is not a lab class, but it is my belief that you cannot learn about the oceans without touching it and experiencing it first-hand. There will be many field and hands-on activities throughout the course." (Peridotite's syllabus)

For the third condition, higher level thinking, all seven participants indicated that once students are engaged, confident, and possess foundational understanding, then higher level thinking (i.e., Bloom's cognitive levels moving from low to high: knowledge, comprehension, application, analysis, synthesis, evaluation) can transpire. Many 
participants argued that written reflections as well as the ability to apply, assess, and synthesize information showed higher levels of thinking. The higher-level thinking condition was evident in many of the participants' interview comments and documents (see representative excerpts in Table 6).

\section{Table 6}

Examples for Higher Level Thinking Condition

Interview Excerpts

“...so, kind of that ability to apply knowledge critically to new situations." (Garnet)

“...bringing information together from different places, so that they can't just memorize a bunch of facts because I think memorizing and critical thinking are definitely two different things." (Slate)

"I'm not placing a burden on the students to just memorize and then say it back to me, but that they're able to see how things are related to one another so that if considering a new problem, they're able to take what they know and apply it to something new, even if we've never talked about it before." (Amphibolite)

"Being able to assess a source, being able to connect concepts or things that are presented as facts." (Peridotite)
Document Excerpts

"Throughout this class, you will be asked to reflect on your learning. Reflections are critical for learning and developing expertise. High performing students have demonstrated that they are more likely to engage in the cycle of selfdirected learning." (Serpentinite's syllabus)

"To develop and improve study skills, and other life-long skills such as problem solving, critical thinking, oral communication, and group work." (Eclogite's syllabus)

When analyzing the data, I found that participants reported how critical thinking has a hierarchical order. According to the participants, critical thinking did not happen right away; they argued that certain conditions needed to happen before students started using critical thinking. They noted that teachers needed to set up an environment where 
students are engaged and feel confident in their thinking process. They explained that teachers could use active learning techniques to engage students, build their confidence, and then strengthen content knowledge (foundational understanding). Lastly, once students were engaged, confident, and had built strong content knowledge, they could exhibit characteristics of critical thinking by using higher levels of thinking (e.g., application, analysis, synthesis, evaluation).

\section{Misalignment of How Faculty, Department, and Institutions Understand Critical Thinking}

The second theme was the misalignment of how faculty, department, and institutions understand critical thinking due to varied definitions, faculty training, faculty support, learning outcomes priorities, and motivation. To highlight and explain this misalignment, I identified five categories: (a) critical thinking is an abstract concept, (b) the role of critical thinking in department/institutions, (c) critical thinking was not a priority, (d) faculty training and support, and (e) adjunct motivation.

\section{Critical Thinking is an Abstract Concept}

All seven participants maintained that critical thinking is an abstract concept whether based on the definitions, instruction, or curriculum development. For example, during the interviews, Mica, Serpentinite, Eclogite, and Peridotite noted the complexity of defining critical thinking; whereas Garnet, Slate, Amphibolite, and Peridotite elaborated on the challenge on implementing critical thinking in the classroom (see representative excerpts in Table 7).

\section{Table 7}

Examples of Participants' Abstraction of Critical Thinking 
$\begin{array}{ll}\text { Excerpts highlighting abstract definitions } & \begin{array}{l}\text { Excerpts highlighting abstract } \\ \text { of critical thinking }\end{array} \\ \text { implementation of critical thinking }\end{array}$

"I guess there's a lot of different ways to define it by one way that occurs to me." (Mica)

"So, I feel like critical thinking is a little bit of a loaded term in that there are a lot of things that can mean to a lot of people. And so, depending on who I'm with and what their interpretation is kind of also been sometimes how I think about critical thinking." (Serpentinite)

"It is a term that is bounced around with the assumption that everyone has the same definition." (Eclogite)

"I was like, oh, I don't have a definition or a conceptual model." (Peridotite)
"I can't ever remember specifically being taught how to think critically." (Garnet)

“...lack of experience as even having instructed for seven years, nobody's ever kind of told me or guided me to that sort of in that direction." (Slate)

"I just it feels very abstract. I think if there was like an example of like here's, here's a tool that you use to assess critical thinking in a classroom, and I was to look at it." (Amphibolite)

"...even though I looked, and it is in my syllabus's of course objective. It is in there twice actually, in my course objectives. I was like, I actually don't really know what I mean there." (Peridotite)

When looking at the survey data, the participants selected choices for critical thinking terms they had seen in research literature and used in their documents. Participants could select more than one preferred term. As displayed in Figure 3, participants did identify their preferred specific terms for critical thinking. Higher-order learning and problem solving were the preferred terms by eight participants. The next favored terms were reflective thinking and metacognition by six participants. The least preferred terms were self-regulation and Bloom's Taxonomy. However, in their interview responses, some participants used these critical thinking terms:

- “...in terms of my own practices. I guess I then I start to look at it through the 
lens of sort of self-regulation." (Serpentinite)

- "I think to critical thinking it requires using higher levels of thinking. I'm thinking of like, higher levels in Bloom's Taxonomy." (Eclogite)

\section{Figure 3}

Critical Thinking Terms Selected by Participants $(n=9)$

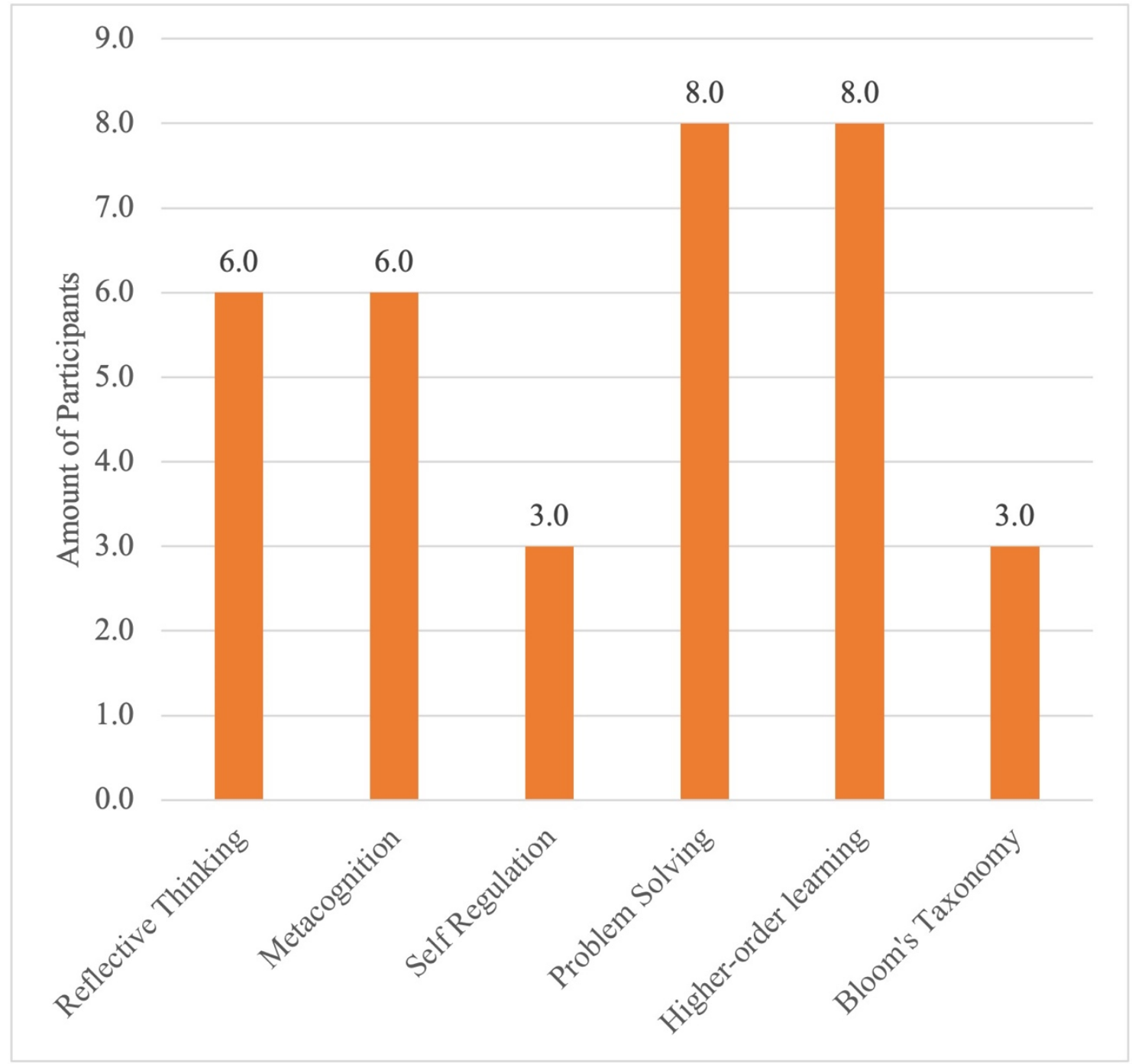

Note: Figure includes data from nine geoscience faculty gathered prior to the selection of seven participants for this study. 
During the interviews, the participants mentioned critical thinking as a learning outcome in their syllabus or as an overall learning theme within the course. Although all the participants' syllabi used critical thinking in the learning outcomes, they were not the original creators of these learning outcomes. All participants stated that they inherited the learning outcomes from previous faculty members working at their institutions. The participants also used critical thinking research literature terms when responding to the interview questions (i.e., higher-order learning, metacognition, self-regulation). Yet, aside of one participant, six participants seemed to be unsure about how exactly critical thinking happened in the classroom. Even though participants had their own definitions of critical thinking, critical thinking remained an abstract concept among the participants due to the lack of discussions among faculty members, departments, and even within their own institutions. Findings derived from the survey, interviews, and documents showed the misalignment of how faculty, department, and institutions understand critical thinking. Thus, leading to the next category: the role of critical thinking within departments and institutions.

\section{Role of Critical Thinking within Departments and Institutions}

All seven participants stated that their departments had no formal definition of critical thinking; they were unsure about whether their institutions had a standard definition of critical thinking as well. A search of participants' department websites showed that one of seven had a formal and easily accessible definition of critical thinking. Although I found no easily accessible definitions via participants' institutions websites, their institutions used the words critical thinking in individual course learning 
outcome statements and within the institutions' vision statements. Moreover, two of seven participants stated that their institutions used the Analytical Reasoning VALUE rubrics to define critical thinking.

- "No, I am not aware, but I do not think we do. At some point, I would have seen that, like we have got learning at General Science Learning Outcomes. That's the closest I can think of where you would find something like that." (Mica)

- "Yeah, they do. I think it is the AACU value rubrics. I think there is a critical thinking one.” (Serpentinite)

Most participants stated they were unsure about ever learning about their institutions' definition of critical thinking. Examples of their remarks included:

- "Yeah. I don't know if I've ever heard that exact term used at the institutional level, but I think the analogous concept is analytical reasoning, is what they call it." (Garnet)

- "Yeah, that's kind of that's kind of a tough question to answer because I don't know that I've had a lot of conversations with my college about what critical thinking is as a skill to be taught or otherwise." (Slate)

- "I do not think there is a standard definition, not that I'm aware of." (Eclogite)

- "I have no idea" (Amphibolite and Peridotite)

Interview data revealed that most participants were not aware of departmental and/or institutional stances on critical thinking. 
Survey data showed that among the three most prevalent frameworks used at the community colleges (i.e., Bloom's Taxonomy, Critical Thinking VALUE Rubrics, PaulElder Critical thinking framework) most participants were familiar and comfortable using one: Bloom’s Taxonomy. Six participants stated that they were familiar with Bloom's Taxonomy and used it as a framework for critical thinking in the classroom; whereas two participants indicated they are familiar with the taxonomy but did not use it in the classroom, and one participant was not familiar at all. Five participants were not familiar with Critical Thinking VALUE rubric, though two participants were either familiar and did use it in the classroom or were familiar but did not use it in the classroom. The lack of familiarity with the Critical Thinking VALUE rubric was unexpected given that more than 3,300 U.S. colleges and universities used this framework (Association of American Colleges and Universities, n.d.). Lastly, participants' responses about the Paul-Elder Critical Thinking Framework showed that eight participants were not familiar with this framework, whereas one participant was familiar but did not use it in the classroom. The participant who was familiar with this framework was an early career faculty member.

\section{Figure 4}

Participant's Familiarity and Comfort Level with Bloom's Taxonomy, Critical Thinking VALUE Rubrics, and Paul-Elder Critical Thinking Framework 


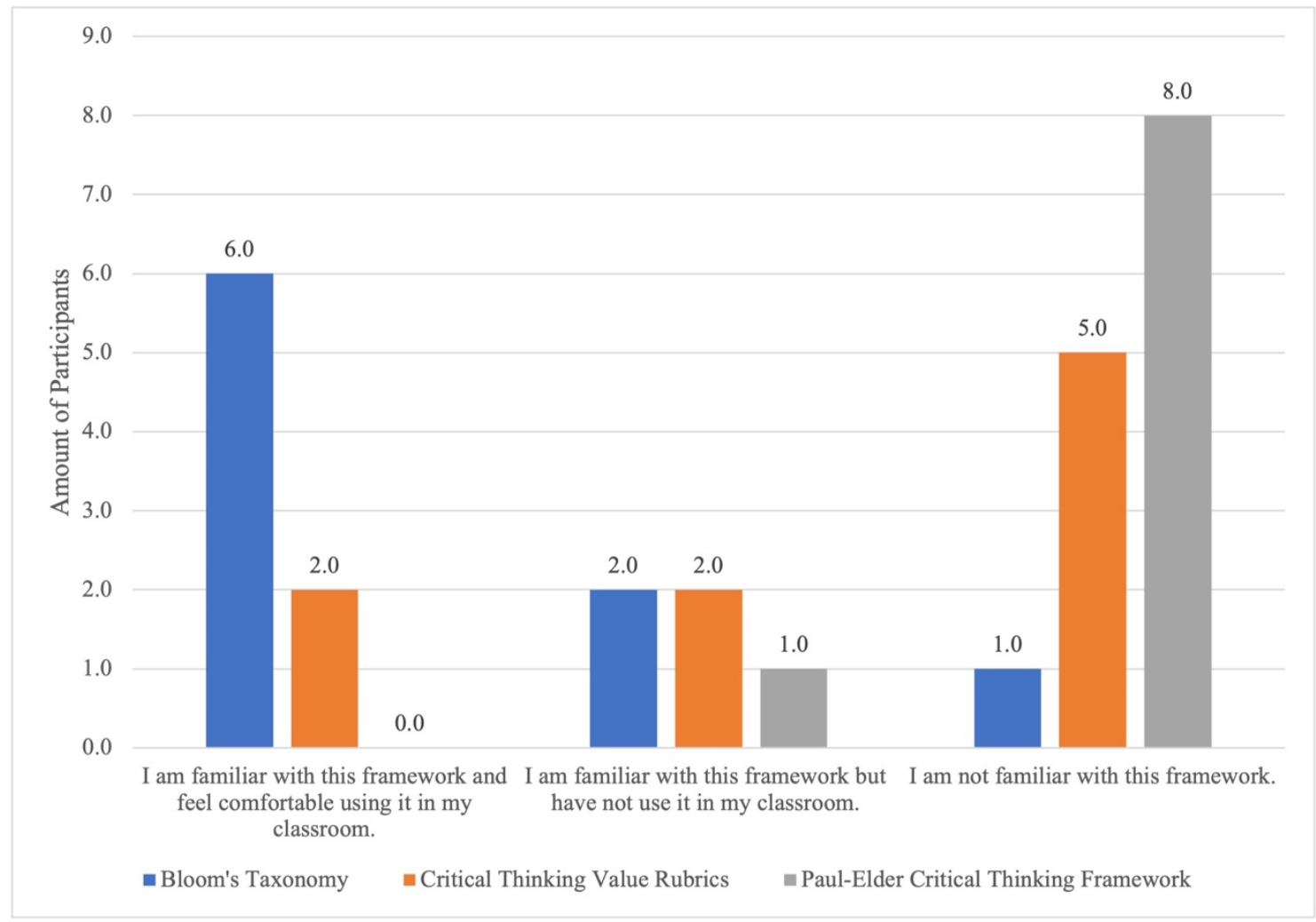

Note: Figure includes data from nine geoscience faculty gathered prior to the selection of seven participants for this study.

Though participants were not necessarily aware of the role of critical thinking in their departments and institutions, the majority used Bloom's framework in their classroom. The data showed that faculty members individually selected a critical thinking framework that fit their needs in the classroom regardless of the departmental or institutional preferred frameworks, which further demonstrated a misalignment among faculty, departments, and institutions. This finding about faculty members not being aware of the role critical thinking plays within their faculty members, departments, and institutions prompted the question: Is critical thinking a primary priority?

\section{Critical Thinking was not a Priority}


Nonexistence of discussions about the role of critical thinking in the classroom, departments, and institutions implied that it was not a priority. Four of the seven participants argued that the lack of discussions about the role of critical thinking made it challenging to know how to implement critical thinking in the classroom. They offered the following thoughts:

- "But I guess that would probably go back to just the fact that we don't talk about it in the college a lot. I do not think a lot comes down from above. Encouraging or pushing us even necessarily requiring us to teach critical thinking." (Slate)

- "If someone at our institution was to say, hey, we are now all about critical thinking, and we are going to focus on that, and we are going to do it in all our classes, and ideally, they also say: Hey, here's how you do it. Here's our standards that you have to try to accomplish, then I would put more emphasis on it, probably." (Peridotite)

- "I have not had enough interactions with administrators or my dean, who's my supervisor to really say that they support or discouraged me from using those tools." (Garnet)

- "I think it's hard sometimes to employ critical thinking skills" (Amphibolite) The participants' responses showed that when critical thinking was not a priority within institutions and departments, it affected the implementation of critical thinking instructional tools in the classroom by geoscience faculty members in their departments and institutions. Not only did participants note the need for departments and institutions 
to prioritize critical thinking, but they also elaborated on the need for training and support.

\section{Faculty Training and Support}

All participants asserted the need for training and support when it comes to the implementation of critical thinking instructional tools. Survey results about receiving any form of training about teaching critical thinking indicated that six participants occasionally read about how to teach critical thinking; whereas four participants had received formal training on how to teach critical thinking (see Figure 5). Additionally, one participant chose two options: formal training and occasionally reading about how to teach critical thinking from articles and/or books.

\section{Figure 5}

Participants' Responses to Teaching Critical Thinking in the Classroom 


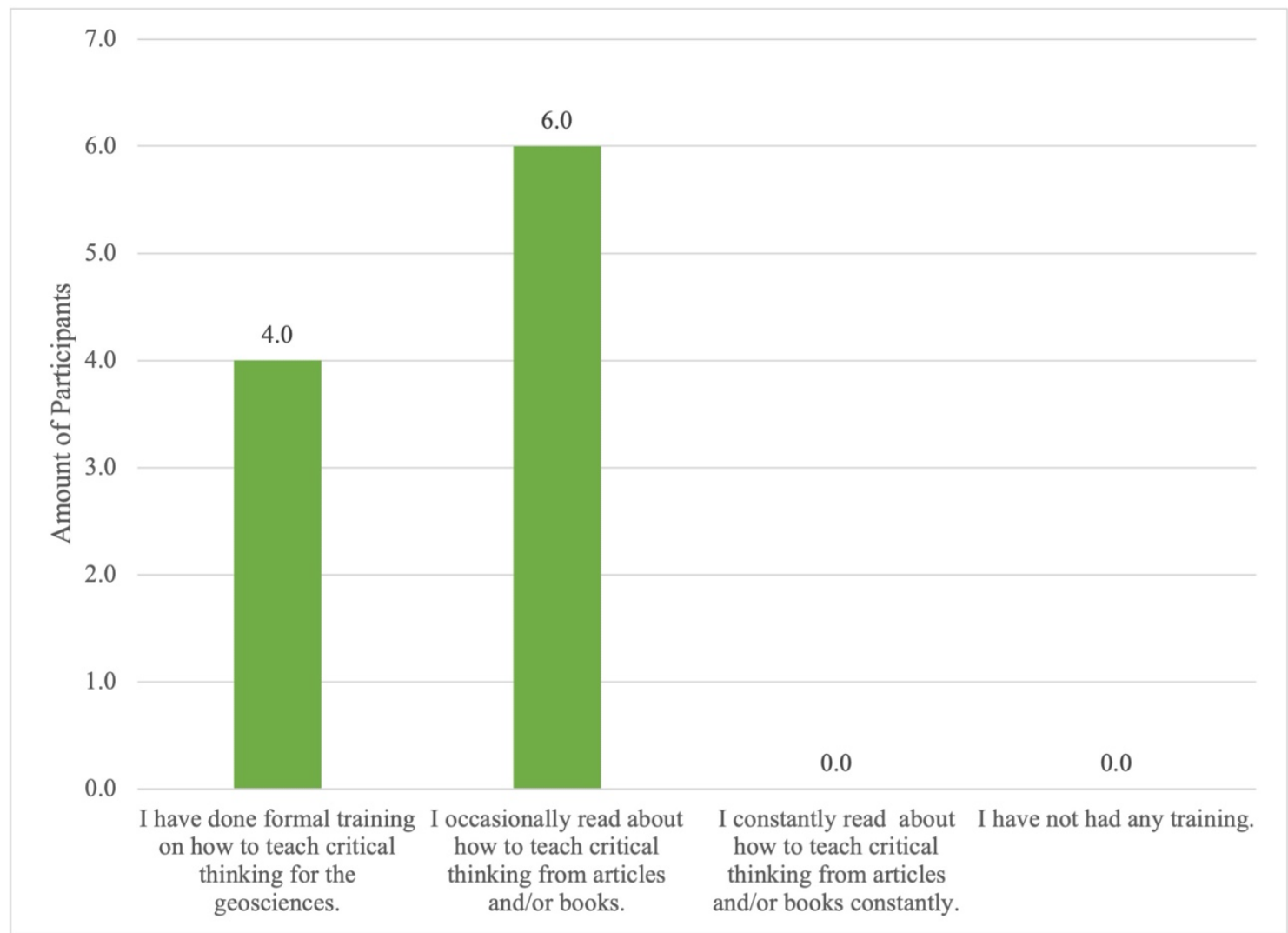

Note: Figure includes data from nine geoscience faculty gathered prior to the selection of seven participants for this study.

Survey data about receiving any form of training in assessing critical thinking showed that five participants had not received any training about assessing critical thinking; whereas two participants received training on how to assess critical thinking, and two participants read occasionally about critical thinking assessment tools (see Figure 6). Participants who had formal training mentioned receiving it via their graduate school program that focused on geoscience education.

\section{Figure 6}

Participants' Responses to Assessing Critical Thinking in the Classroom 
6.0

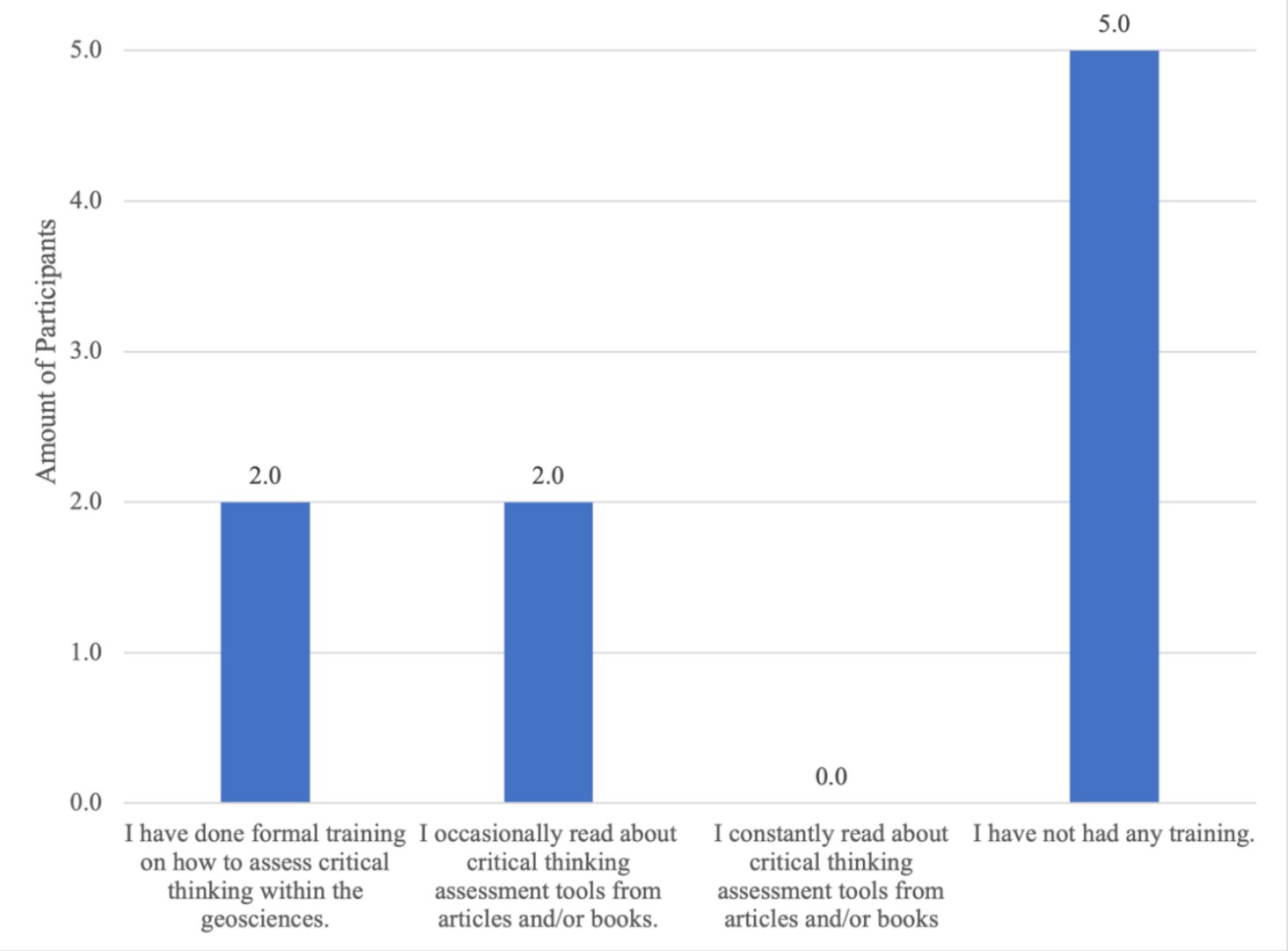

Note: Figure includes data from nine geoscience faculty gathered prior to the selection of seven participants for this study.

Participants' interview data included additional details in relation to training and support. They elaborated as to how: (a) the lack of training affects their ability to know how to improve, (b) assessment is harder to do than teaching critical thinking, and (c) the lack of discipline-specific critical thinking training affects their ability to apply critical thinking instructional tools in their classroom. For the participants who had received some training in critical thinking during their graduate school programs with a focus on geoscience education, they stated that even with formal training the implementation of 
critical thinking was challenging because there was still a need for more diverse tools to assess critical thinking (see Table 8).

In addition, participants' responses about supports from department and institutions highlighted the need to provide opportunities for faculty to engage in learning communities within their own campuses. Among these discussions participants talked about the: (a) effects of having teaching experts observing your class for feedback, (b) need for more learning process discussions at department meetings, and (c) effects of working with faculty at different departments (see Table 8).

\section{Table 8}

Training and Support on Critical Thinking: Excerpts from Participants' Interviews

Interview Excerpts highlighting training of critical thinking
Interview Excerpts highlighting support of critical thinking
"I don't know. Again, I cannot ... I've definitely never received what I would call formal training in critical thinking, so I guess that's a hard question for me to answer, because I'm not quite sure where it all came from or what I could do better." (Garnet)

"It is like teaching is an intuitive art on a certain level. Obviously, we can inform it with science, which is what you are doing right now, which I, which is why I am participating because I dig that. But assessment is so much harder and less intuitive." (Mica)

"no. I mean, you're talking about things like in most of my trainings that I've gone through for the college. It has been diversity or accessibility or very specific those kinds “...hugely positive because pretty much everybody here is really into teaching. So, you have got teaching experts sitting in on your class, giving you feedback saying you are doing wonderful here's something you can do better. So yeah, that's that is a good example of direct support that I really appreciate it." (Mica)

"I would say more discussions probably happen outside of department meetings department meetings seem to be almost strictly policy related and we very seldom talk about teaching itself." (Slate)

“...we do ourselves a disservice for our students if we're not really getting them to think through some of these 
of trainings... and that lack of knowledge. I think is more a hindrance" (Slate)

"... and, how comfortable I feel about assessing it? It is hard, I will just say that it is one of those things where it is... I am going to go back to the fact that it is primarily in written form. And not everybody is a strong writer, or is... I think it does tend to bias a certain population in terms of who is more likely to express themselves in writing..." (Serpentinite)

"And then through the certificate of teaching we talked about a lot of these things, but it is always kind of like in a workshop, not just geology....and so, it is never in the context of geology. It's always other things." (Amphibolite)

"Do not have real solid thoughts about how to assess it or approaches, how important it should be relative to other teaching objectives, all that kind of stuff. So, I think that all adds up to not super comfortable." (Peridotite) more critical aspects of their learning process." (Serpentinite)

"I would like to have discussions with other faculty members in the community college." (Amphibolite)

"Those across discipline workshops, that help, that can tie into critical thinking. The other thing that comes to mind, more specifically in the geo sciences, is in this last year, I worked with a colleague of mine in biology...we have created a faculty learning community, a mix of biology instructors, mostly geo science instructors and I think we have one physics instructor as well." (Eclogite)

Overall, the participants expressed their discomfort about teaching and assessing critical thinking regardless of their current training and support. These findings indicated training of critical thinking within the context of geoscience and support within each individual institution could potentially make a significant impact in the faculty members confidence when teaching and assessing critical thinking. The lack of training and support at the faculty, department, and institutional level further demonstrated a misalignment among these three areas. 
The last category within the theme of misalignment among faculty, department, and institutions focused on the participants who were adjunct/part-time faculty members. Three of the seven participants were adjunct or part-time faculty members. Of the three participants, two worked at a single community college and one worked at two different community colleges. Data from these three participants showed a common category related to critical thinking: motivation. Although these three participants highlighted their love for teaching and desire to use critical thinking in their classroom, all mentioned how motivation affected their instruction. Their motivation to use critical thinking was challenging due to (a) the possible effect on student enrollment when trying new techniques, (b) low adjunct pay, (c) lack of institution support, and (d) instructional momentum.

First, regarding the effects of motivation and student enrollment, Slate explained that student enrollment affected whether she would have an opportunity to teach the course again. Even though student enrollment did not necessarily dissuade her from trying new techniques, she tended to try them only once if the students push backed or resisted the techniques. Second, as to the effects of motivation and adjunct pay, Amphibolite underscored the cost benefits between compensation vs time dedicated to building lessons. She expressed that the amount of adjunct pay made her feel like she was not a valuable contributing member in her department or institution, which affected her motivation to do more in the course. A full-time participant also mentioned that adjunct/part-time faculty members' low pay impacted the adjunct/part-time faculty attrition rates. Third, considering the effects of motivation and instructional support, Slate 
and Peridotite noted that their low motivation to use more critical thinking stemmed from the lack of instructional support on how to implement critical thinking in their classroom. Lastly, regarding the effects of motivation and instructional momentum, Peridotite shared how teaching the course once a year affected his motivation to make courses changes for the following year. Notable interview excerpts shown in Table 9 help to illustrate what affected the participants' motivation to use critical thinking instructional tools in their classroom.

Table 9

Motivation to use Critical Thinking: Excerpts from Participants' Interviews

Interview Excerpts $\quad$ Effect on Motivation

“...you try new techniques like maybe flipping the classroom or something like that. The students can get very frustrated, and they actually can take it out on the instructor by bad reviews or by saying, you know, I had one instructor told me that their students told him he was a terrible teacher because he wasn't teaching them anything because he expected them to learn it all themselves... But on the other hand, whether your class fills up or not would reflect on whether you get hired back." (Slate)

"If you compare full time to part time yes, I think full time can feel more comfortable trying new techniques because they have tenured and they're not going to lose their job if their students don't like them. It doesn't matter as much to them because they're just going to get the next class." (Slate)

Trying new techniques affects student enrollment

Trying new techniques affects student enrollment 
“...the pay doesn't really... It is not that you do not want to, it is just, the amount of work, the cost benefit there, to spend those extra couple hours preparing each lecture or really coming up with an impactful activity, it is not that like, you do not want to, and it is not that the benefit is not there, you know, it will be. But especially as an adjunct, I cannot justify it. I know that that's a problem." (Amphibolite)

"Downsides of paying our adjunct faculty so little is that we have a lot of turnovers. And, in the six years I have been at this institution, I think I have trained six different adjunct faculty." (Serpentinite)

"Aside from one day of training (not on critical thinking) there is no institutional support." (Peridotite)

"There's not like a lot of support on improving your ability to teach critical thinking." (Slate)

"I guess the biggest challenge for me is every year, when it comes around, time for me to teach my course, I am like, at the end of the last course that I taught a year ago, I had all these ideas and things I wanted to change. But class is starting next week, and I got all this stuff set up. I have run the course a bunch of times. I am not going to change anything. It is just that momentum." (Peridotite)
Adjunct pay does not justify the work

Effects of adjunct pay in attrition rates

No instructional support

No instructional support

Momentum lost since courses taught once a year

Findings in this category demonstrated demotivating factors for adjunct/part time faculty members, which affected their desire to implement more critical thinking in their 
classroom. These findings confirmed the existence of a misalignment of how faculty, department, and institutions understand critical thinking.

\section{Critical Thinking Embedded in Scientific Literacy}

Critical thinking has not been an isolated instructional tool—instead faculty members often embedded critical thinking within scientific literacy. Findings showed that participants applied critical thinking by (a) personalizing content learning, (b) providing think aloud models, (c) teaching science as a process, and (d) applying critical thinking implicitly within their instruction.

All participants argued that personalized learning provided students an opportunity to connect with the content by seeing the impact of understanding geosciences in their lives and in turn, engaging in critical thinking while learning geoscience (see Table 10).

\section{Table 10}

Personalization of Learning: Excerpts from Participants' Interviews and Documents

Interview Excerpts

"... my goal is always the more that I can connect what I am teaching to their lives, the more natural it's going to be for students to engage that critical thinking part of their brain." (Garnet)

"If you are doing earthquakes or flood information. If you are doing you know river processes. So, spending some time talking about things that might matter to them and how the science might help them." (Slate)
Document Excerpts

"Compare your own thinking process during this lab to how scientists like J.Harlan Bretz or Nick Zentner work on geologic problems." (Mica's activity excerpt)

"Write a 350 word or more reflection with your responses to these resources on climate change." (Eclogite's activity excerpt)

"Complete the table in the excel sheet using data we collected in class on 


\begin{tabular}{|c|c|}
\hline $\begin{array}{l}\text { "Why should anybody care about this? } \\
\text { And, I might have an actual discussion } \\
\text { prompt like, "why do anybody care about } \\
\text { this?" so, that it gets them to think a little } \\
\text { bit about why it is something that's worth } \\
\text { caring about. I mean, I try to bring in the } \\
\text { human element as much as I can, and then } \\
\text { I think that that is where a lot of my } \\
\text { students do connect to my content." } \\
\text { (Serpentinite) }\end{array}$ & $\begin{array}{l}\text { Monday...Now, using Google Earth's } \\
\text { distance tool and the depth soundings, } \\
\text { create your own profile of the transect } \\
\text { labeled Juan de Fuca Ridge." } \\
\text { (Peridotite's activity excerpt) }\end{array}$ \\
\hline
\end{tabular}

Five of seven participants stated that they used a form of a think aloud modeling tool to offer an opportunity for students to see how they can apply critical thinking in the geosciences:

- "And then, in some cases, you know, there is something that they're missing. And then I would go back and sort of model, you know, okay, when I look at this." (Garnet)

- 'Um, but also, let us see, what's my spiel on that. Basically, what I say is you try to come up with at least more than one possible explanation for something so multiple hypotheses. And the idea is then you go out and try to find evidence that will disprove as many of them as possible. Winnowing down the range of possibilities.” (Mica)

- "I kind of also talk to this class as a whole like, "Here are some things to think about for both the justifications of why I do them." So, that they sort of part probably buy in...I do not necessary give actual student examples but kind of talk about what it means to be able to reflect more deeply. So, I always try to give them probing questions, and my feedback tends to be in the form of 
questions, because I want them to recognize that they are never done." (Serpentinite)

- "So, I feel like the way that I try to model critical thinking when I teach is to constantly say the words: based on x and y. I can figure out z. And then based on a and b. That's how I know c.” (Amphibolite)

- "When a student asks a question, try to model it there. Try to explain my reasoning/justification for an answer." (Eclogite)

Another way the participants embedded critical thinking during their instruction was when they taught science as a process. All participants stated that one of the biggest outcomes in their courses was for students to be able to filter through misinformation. Therefore, participants stated that they designed their courses to provide students with experiences where students could become scientists as shown in Table 11. In the first example, Garnet's intention was to teach students to think beyond scientific content. The goal of this activity discussion was for students to learn about the importance of scientific literacy and society. In the second example, Mica's intention centered on teaching students the value of evaluating multiple hypotheses to eliminate personal confirmation biases. In the third example, Peridotite's intention centered on students learning scientific facts and recognizing that facts can change as scientific knowledge grows. In all these examples, the participants' use of critical thinking within different scientific activities with their students showed how they infused critical thinking when teaching geoscience concepts and issues.

\section{Table 11}

Critical Thinking Embedded When Teaching Science as a Process: Excerpts from 
Participants' Interviews

Interview Excerpts

Participant's Intention

"...discussion topics of the controversy over the Mauna Kea observatories and sort of how that that land is used and who has the right to determine how that land is used...it's science but you know you're really getting into you know, land management and culture and in all sorts of these different things." (Garnet)

"I really focus that in geology specifically we employ multiple working hypotheses mostly to like protect ourselves or build in a buffer against confirmation bias." (Mica)

“...scientific facts are conceptual models of hypotheses that we're constantly testing. Plate tectonics is a killer example of basically the process of science. And because it has happened so recently, it is a story that we can tell. So, a lot of how I present plate tectonics is about the people that contributed the bits of information that led to this new conceptual model of how the earth works" (Peridotite)

Impact of science to land and humanity

Working with multiple hypothesis to buffer against bias

Meaning of facts in the scientific community

The last category in this theme focused on the implicit nature of critical thinking. Though participants were using critical thinking in their instruction, with six of the seven participants identifying critical thinking in their syllabi's learning outcomes or mentioning it as a theme in their courses, they asserted that in the classroom critical thinking is often implicit to the students (see Table 12). While most of the participants implied that students engaged in critical thinking during classroom instruction and activities, one participant's course curriculum and instruction focused on teaching a 
learning process model. Though this participant was not necessarily using the words

"critical thinking," she did use a self-directed learning cycle process called self-regulation (see Table 12).

Table 12

Excerpts from Participants' Interviews about Critical Thinking in the Classroom

Interview Excerpts showing Critical Thinking Interview Excerpts showing Critical is Implicit Thinking is Explicit

"...if they are trying to predict whether this volcano is going to erupt or not, you know, are they are they drawing on the information from class or from lecture that they need, you know, there is typically concepts or, you know, pieces of knowledge that they need to use in these activities in order to be successful." (Garnet)

“...but where I really focus the class efforts like okay, you know, part one, the last question, how do we, you know, take it up a notch do the critical thinking thing and then that might be a class mini discussion." (Mica)

"Critical thinking is reflected in the way that I write questions for both labs and tests." (Slate)

"I don't know if I explicitly call that out as critical thinking, but it's certainly a theme throughout my class." (Eclogite)

"I think that a lot of this is really implicit in the way... expect students to most osmotically learn about critical thinking" (Peridotite)

\section{Critical Thinking Takes Time}

Developing and implementing higher levels of critical thinking among students in 
the classroom required time. All participants mentioned the concept of time as one of the primary conditions needed to build and implement critical thinking in the classroom. The data showed that six of seven participants felt challenged by time in two ways: (a) content vs breadth, and (b) cognitive dissonance (see Table 13). First, interview data showed that participants struggled with creating a balance between giving students time for content knowledge and learning processing due to length of time, diversity of student population, and amount of geoscience content in introductory courses. Second, interview data indicated how participants experienced cognitive dissonance as a response to student pushback on the use of critical thinking.

\section{Table 13}

Excerpts from Participants' Interviews about the Concept of Time

Content vs Breadth Interview Excerpts Cognitive Dissonance Interview Excerpts

"I mean, we have so many outcomes and objectives that we have to teach to in you know 10 weeks that you know, even if I had a critical thinking activity for every topic in the class, there wouldn't be time to do them all." (Garnet)

"I am left with the choice of either teach really basic stuff here and bore the more advanced students or teach the challenging stuff and just completely leave behind some of the students have less foundation in the dust." (Mica)

"I think is time, you know, we have such limited time to get through so much material...the biggest challenge
"You're really throwing them out of their comfort zone and even if they do, no. I mean, I have I feel like I have anecdotal evidence of students who really do know the concepts, but they're just not used to being assessed in that way." (Garnet)

"...but it is difficult for me to approach a lesson from their perspective and kind of make it a small step for them from where they're at....... it is really hard to use math. In any sort of critical thinking exercise because that in and of itself creates such an enormous stumbling block that i mean literally you see students just shut down.” (Mica)

"You know when you try to teach critical thinking, they kind of push back to and just the knowing that the students coming into 
is how do you both cover all the material you are expected to cover and give them the time to practice critical thinking skills." (Slate)

"Spending time doing these other things, then that means I am not spending as much time on content (Serpentinite)

"It is always different because every single student has different background, different experiences, everything but as a very general statement, there is usually something, especially once you have known the students for a couple of weeks, definitely hard in term system, because they're short, that you can get a feel like how they're asking the question and maybe where they're at, and what things that they tend to struggle with. But that takes time." (Amphibolite)

"In developing is really time. Finding the time to be able to do some deep thinking about things and then implementing them." (Eclogite) the system aren't necessarily set up for it." (Slate)

"...be able to put seemingly separate pieces of information together, into a solution. That takes time to find that time some way, where do you put the content? One more thing I guess I could add is, sometimes I have had some students that I feel are resistant to it. Because they are not used to seeing that in other classes." (Eclogite)

\section{Pedagogy of Hope}

Despite the challenges encountered, it appears that hope was what faculty members to work harder and keep advocating for their students in the end. Interview data showed that hope was a primary driving vehicle for all participants to continue reflecting, creating, and modifying their instruction and curriculum so that their students succeed not just in the course, but in life as well. Participants stated that by teaching critical thinking via active-learning activities, discussions, and/or real-life data analysis, students were 
more inclined to trust science and scientific information. Examples included:

- "I would hope that the act of them engaging with appear makes them more critical than hearing it from me.” (Mica)

- "I hope that critical thinking skills allows students to pick through all that overwhelming information to figure out what's right, not just for them...I hope I know how to do it. I don't really know how to teach it." (Slate)

- “...hopes that they sort of are more inclined to trust science and scientific information right, so I mean I think that's sort of that aspect, particularly in issues of climate change. And so, you know, that is so important for equity issues so important for kind of thinking about their own lives and their quality of life, moving forward." (Serpentinite)

- "Just a skill that you hope, when someone graduates with a college degree has improved their critical thinking, so they can be a contributing member to society." (Eclogite)

- "I try to spend a lot of time having my students interact with real datasets in the hopes that, that insight happens, but it's just a hope." (Peridotite)

\section{Summary of Critical Thinking Themes}

In summary, the findings from survey and interview data about critical thinking centered on five themes. First, faculty members stated that critical thinking has a hierarchy of three conditions: engagement/confidence, active learning strategies/foundation, higher-level thinking. Second, there was a misalignment among these faculty members, departments, and institution understanding of critical thinking due 
to an absence of discussions around critical thinking' definitions, prioritization, training, and support. Third, faculty members taught critical thinking implicitly by personalizing the learning, using think aloud models, and by teaching science as a process. Fourth, teaching critical thinking took a vast amount of time, challenging faculty members with decisions towards content vs breadth and cognitive dissonance. Fifth, faculty members hoped students learn how to use critical thinking so that they can trust science and scientific information. With that said, in the next section, I interpreted the study findings at greater depth using the study's research questions.

\section{Interpretation of Findings}

In this section, I direct the interpretation of the findings using my two research questions (a) what are the geoscience community college faculty members' perceptions of critical thinking? and (b) how do geoscience faculty members' perceptions influence their use of critical thinking instructional strategies? I use the themes mentioned earlier: (a) critical thinking has a hierarchal order, (b) misalignment of how faculty, department, and institutions understand critical thinking, (c) critical thinking embedded in the scientific literacy, (d) critical thinking takes time, and (e) pedagogy of hope to guide me to the answer to the research questions.

\section{What are the Geoscience Community College Faculty Members' Perceptions of Critical Thinking?}

The geoscience community college faculty members' perceptions of critical thinking were: (a) hierarchy, (b) abstract, (c) hidden in the scientific process, (d) process that takes time, (e) hope. In the following paragraphs, I expand on what their perceptions 
mean.

The first perception was the hierarchy of critical thinking. Participants perceived that critical thinking has a hierarchical order of occurrence starting from student engagement, then building confidence, and finally strengthening content foundation. These three conditions allowed for higher levels of critical thinking to occur. Participants argued that before students consider using higher levels of critical thinking, they must be (a) engaged in the material, (b) confident about their own thinking process, and (c) strengthen their content foundation.

Engagement as perceived by participants was present in the classroom when students were interested in learning about the material, participating, and asking questions. Without such engagement with the content, participants found it hard for their students to develop confidence in their thinking processes. They shared sentiments such as: "that they felt like they learned something, not just the content but also about themselves"(Serpentinite) and "if students are just not willing to or have never learned how to put out their own ideas, you know, basically, if they can repeat what they have learned, then they just don't know" (Mica), which emphasized participants' view of the relationship of engagement and confidence. When students did not feel confident or have not taken the risk of sharing their own ideas in the classroom, they relied on memorization of the information rather than understanding the scientific process. Participants' syllabi included words of encouragement for student engagement such as sharing their ideas, observations, and interpretations of the world regardless of their accuracy. 
Once students were engaged and confident in their own thinking, participants argued that content foundation was a third condition needed to properly employ higher levels of critical thinking. Six of the seven participants highlighted this importance of content foundation when using higher levels of critical thinking. Their representative comments included "...you cannot do critical thinking, till you have the foundation and the foundation either is not there, or it is there, but it has not been explicitly connected" (Mica) or "if you're just memorizing rocks and minerals you can't evaluate or like apply that knowledge" (Amphibolite), which indicated that when students did not have that concept foundation or did not understand the relationship among concepts in the larger context, they found it challenging to move beyond lower levels of thinking (i.e., knowledge, comprehension). Additionally, participants' syllabi contained definitions of what it means to build a content foundation; for example, one syllabus included the description "outcomes focus on identify, discuss, describe, and explain which mostly focus on building foundation." (Slate). Thus, once a student could identify, describe, discuss, and explain different geoscience processes, they could potentially use that foundation to do higher levels of thinking (i.e., application, analysis, synthesizing, evaluating). In summary, the findings suggests that critical thinking happens in stages (i.e., engagement, confidence, content foundation). Nevertheless, for each participant, engagement played a big role, making this condition one of the most important propelling conditions for leading students to confidently use critical thinking. First students needed to be engaged in the material, then through engagement students build confidence in their thinking process by sharing their ideas, assessment, synthesis, and evaluations of their 
understanding of the material, and lastly, they strengthen their content foundation. Thus, participants agreed that when students are engaged, confident, and possess a strong content foundation, they are more likely to use higher levels of critical thinking in the geoscience classroom.

The second perception among participants was the abstract nature of critical thinking. They reported that the concept of critical thinking was abstract due to being rarely discussed among faculty, departments, and institutions. This perception led to a misalignment of how institutions, departments, and faculty understand critical thinking, which in turn prompted faculty members to make assumptions about: (a) the concept of critical thinking, (b) the role of critical thinking at the institution and department level, (d) critical thinking in the classroom, and (d) teaching and assessment. Defining critical thinking was challenging and complex; when providing definitions of critical thinking, participants raised two issues: their difficulty remembering the exact moment they learned how to use critical thinking, and the complexity of critical thinking development. Examples of these sentiments were "I cannot even remember specifically being taught how to think critically" (Garnet), and "You know, it's sort of one of the things I said as a joke that I think it required my frontal lobe to be fully developed, and that didn't happen until grad school rounds two" (Serpentinite), which provided insight about the participants' own awareness about how they became critical thinkers themselves. These were important findings because when faculty members have an awareness of their individual understanding of critical thinking development, this awareness might potentially influence how they perceive their students' critical thinking development. 
However, because this concept was abstract to the faculty members themselves, it could make critical thinking difficult to "see" in their students.

Participants also discussed not ever having conversations about the understanding of critical thinking among their peers, department, and institutions. Their responses such as "It is a term that is bounced around with the assumption that everyone has the same definition. Just sitting here reflecting on that, that is a huge assumption, I think" (Eclogite) which implied a misalignment of how the use of critical thinking was happening within different levels of the institution. Misalignment of how various levels within the institution understood critical thinking helped to maintain their perception of critical thinking being an abstract concept. All participants indicated that even though they think critical thinking is a highly important tool, their department did not have definitions of critical thinking; only two of seven participants were aware of their institutions' stance on critical thinking. For example, As one participant shared:

If someone at our institution was to say, hey, we are now all about critical thinking, and we are going to focus on that, and we are going to do it in all our classes, and ideally, they also say: Hey, here is how you do it. Here is our standards that you have to try to accomplish, then I would put more emphasis on it, probably. (Peridotite)

Another participant explained, "I have not had enough interactions with administrators or my dean, who is my supervisor to really say that they support or discouraged me from using those tools" (Garnet). Such commentary suggested an abstract sense of how critical thinking was happening at a collective level, which in turn influenced faculty members' 
assumptions and prioritization of critical thinking in the classroom.

The participants' assumptions about prioritizing critical thinking in the classroom were also evident in their responses about receiving faculty training and support for critical thinking. The absence of institutional prioritization added to the abstraction of how, when, and where participants could look for critical thinking training and support. Their sentiments such as "lack of experience as even having instructed for seven years, nobody ever kind of told me or guided me to that sort of direction" (Slate) suggested that although participants highlighted the importance of critical thinking, they felt unprepared. The absence of definitions, discussions, and prioritization of critical thinking could also be a hindering factor for the teaching and assessment of critical thinking. Although most faculty argued that they felt more comfortable teaching critical thinking, all participants felt unprepared to assess critical thinking due to lack of training, support, and availability of tools to measure critical thinking. Participants' sentiments such as "I don't know. Again, I cannot ... I've definitely never received what I would call formal training in critical thinking, so I guess that's a hard question for me to answer, because I'm not quite sure where it all came from or what I could do better" (Garnet), indicated that the lack of formal training hindered their ability to truly know how to improve implementing critical thinking in their courses. Participants also referred to the uneven support between fulltime and adjunct/part-time faculty when using critical thinking skills in comments such as:

If you compare full time to part time yes, I think full time can feel more comfortable trying new techniques because they have tenured and they are not 
going to lose their job if their students do not like them. It does not matter as much to them because they are just going to get the next class. (Slate).

Moreover, participants revealed the need to reflect on the current tools available for critical thinking assessment:

...how comfortable I feel about assessing it? It is hard, I will just say that it is one of those things where it is... I am going to go back to the fact that it is primarily in written form. And not everybody is a strong writer, or is... I think it does tend to bias a certain population in terms of who is more likely to express themselves in writing... (Serpentinite).

Such comments highlighted both the need for, and complexity of, assessing critical thinking. Serpentinite specifically highlighted the potential bias of assessing a student's capacity for critical thinking primarily through their written expression. This bias could be influenced by culture, language, learning disability, and so on. Clearly, faculty expressed the need for a deeper evaluation of assessment within the pedagogy of critical thinking.

The third perception of critical thinking among participants implied that critical thinking is hidden within the scientific process. In other words, when teaching science as a process, critical thinking was embedded into learning this process. Participant responses such as “...don't know if I explicitly call that out as critical thinking, but it's certainly a theme throughout my class" (Eclogite) suggested that faculty were applying critical thinking in their curriculum, but it was mostly implicit to the students in the classroom. This implicit way of teaching critical thinking was apparent when participants 
personalized the content learning to their student's interest (i.e., using engagement as a precursor of using critical thinking), modeled scientific thinking in the classroom (i.e., think aloud models of solving geoscience problems), and involved students in the process of science. Participants believed that focusing on human elements was a key tool for engaging students with critical thinking. This meant that participants focused on teaching about the local geology, hazards, or societal impacts of human activity. They shared statements such as "...my goal is always the more that I can connect what I am teaching to their lives, the more natural it is going to be for students to engage that critical thinking part of their brain" (Garnet), which supported personalizing the material to engage students into using critical thinking. Although participants did not necessarily use the words "critical thinking" in their classroom, they advocated for modeling how to use critical thinking in the classroom. They also shared sentiments such as, "I kind of also talk to this class as a whole...Here are some things to think about for both the justifications of why I do them. So, that they sort of part probably buy in..." (Serpentinite), which exemplified how participants believed that modeling their thinking process could engage students in using critical thinking in their own way.

In addition, participants believed that students interacting with the scientific process was a fundamental way to learn critical thinking. A representative example was "...it is my belief that you cannot learn about the oceans without touching it and experiencing it first-hand" (Peridotite), which indicated that a personalized connection was felt to be crucial for students to learn how to be critical thinkers. When teaching about the process of science, most participants did not make it explicit to the students that 
they were applying critical thinking in the scientific process. In fact, one participant explained, "I really expect students to almost osmotically learn about critical thinking. I don't force it" (Peridotite), which highlighted how by teaching the process of science students are also learning how to be critical thinkers.

The fourth perception of critical thinking among participants was that the learning process of critical thinking is one that takes time. Participants across all career levels and experiences argued that time is one of the biggest challenges associated with teaching critical thinking. Two factors drove this time constraint: content material and student/faculty preparedness. The content material, including outcomes and objectives, was one of the biggest inhibitors of critical thinking. Although community colleges provided geology courses as a general science elective, participants saw themselves as a gateway to getting students interested in the geosciences; they believed that content plays an important role in curriculum development. They offered sentiments such as "The biggest challenge is how do you both cover all the material you are expected to cover and give them the time to practice critical thinking skills" (Slate) and "In developing is really time. Finding the time to be able to do some deep thinking about things and then implementing them" (Eclogite), which emphasized the complexity of finding the time for students to think deeply regarding a problem. They also indicated that the length of the course was not long enough when building critical thinking into all your topics/activities; there was not enough time to complete them all. Even participants who had almost 25 years of experience and who chose to intentionally focus on teaching critical thinking still struggled with the idea that they were not spending enough time on content. 
Student preparedness was an additional time constraint that hindered critical thinking. One participant described, "I am left with the choice of either teach really basic stuff here and bore the more advanced students or teach the challenging stuff and just completely leave behind some of the students have less foundation in the dust" (Mica). Another participant explained, "You know when you try to teach critical thinking, they kind of push back too and just the knowing that the students coming into the system aren't necessarily set up for it." (Slate), These participants faced challenges in the classroom due to the diversity of student preparation of critical thinking. Therefore, although participants understood that student pushback was simply an absence of student preparation in their earlier experiences, participants felt that the time to get students from lower levels of thinking to higher levels of thinking might not be possible in one course due to their own level preparedness in teaching and assessing critical thinking.

The fifth perception regarding critical thinking among participants was one of hope. In other words, participants' driving force to implementing critical thinking was hope. They shared sentiments such as "We do ourselves a disservice for our students if we're not really getting them to think through some of these more critical aspects of their learning process" (Serpentinite), and "It a skill that you hope, when someone graduates with a college degree, has improved their critical thinking" (Eclogite). Their representative comments suggested that participants perceived critical thinking as a tool needed for student success not only in their college careers, but also in their lives. At the end, regardless of their level of experience, all faculty clearly hoped that critical thinking was a tool that allowed their students to trust the scientific process and engage with 
scientific information.

In summary, findings from my study suggested that participants perceived critical thinking as a tool that occurs in stages. Engagement was the primary condition that leads to higher level of critical thinking. Engagement was what builds students' confidence and strengthens content foundation allowing students to use higher levels of thinking. However, even though participants thought of critical thinking as a hierarchical tool, the concept of critical thinking was notional. In other words, how participants understood critical thinking by themselves, their peers, their departments, and their institutions existed in theory, but was rarely formally discussed between various levels (i.e., facultyfaculty, faculty-department, faculty-institutions). The absence of these conversations suggested that participants are making assumptions about the concept of critical thinking, how critical thinking is occurring in themselves and their students, and how prioritization of critical thinking could occur in the classroom. Additionally, participants viewed critical thinking as a concept hidden within the scientific process. Thus, they assumed that by teaching the process of science they were also teaching critical thinking. This indicates that critical thinking was often implicit in the curriculum and the instruction. Finally, participants explained that for students to fully develop critical thinking, they needed time - time for students to engage in deep thinking and time to implement that thinking into solving problems in nuanced ways. In addition, participants hoped that by the end their course, critical thinking could be a gateway for students to trust science and scientific information so that they could become active contributors in society. 


\section{How do Geoscience Faculty Members' Perceptions Influence Their Use of Critical Thinking Instructional Strategies?}

In this study, geoscience community college faculty members perceived critical thinking as being hierarchical, and an abstract concept, embedded into teaching the scientific process, that took time and was driven by hope. These perceptions influenced the instructional strategies participants used to support students' critical thinking in the classroom. Their responses revealed that (a) Bloom's Taxonomy is the preferred framework, (b) evidence-based active learning is the preferred instructional strategy, (c) training and support varies per individual participant, (d) implementation of critical thinking strategies are based on usability and time, and (e) teaching and assessment of critical thinking is complex.

Findings indicated that regardless of how faculty, departments, and institutions understood critical thinking, Bloom's Taxonomy is the preferred critical thinking framework that faculty feel the most comfortable using for their course curriculum and instruction development (see Figure 4). Participants' sentiments about how they use of Bloom's Taxonomy in their curriculum and instruction included: “...my test questions are kind of two levels. There's the regurgitation level, you know, lower bloomed Bloom's Taxonomy and then there is the application level higher Bloom's Taxonomy" (Mica) and "...try to use verbs that would align with different levels of Bloom's Taxonomy" (Eclogite). These two examples highlighted the use of Bloom's Taxonomy in the curriculum (i.e., exam questions) and in the instruction (i.e., classroom faculty-student interactions). Although participants stated Bloom's Taxonomy as their preferred 
framework for the development of critical thinking, few participants have received formal training by a Bloom's Taxonomy expert. Additionally, participants stated that this framework was primarily used as a guide for curriculum development rather than being taught explicitly to their students. For those participants who selected their comfort using a different framework such as Critical Thinking VALUE framework, they revealed that the use of this framework was at the institutional level (i.e., institutions' strategic plan) and not necessarily at the classroom level. These findings suggested a misalignment of how different institutional levels understand critical thinking. While it seemed that different institutional levels selected frameworks based on need, conversations about those needs were not happening. Thus, from the classroom to the institution, the message of how critical thinking was developed, implemented, and assessed was not necessarily clear to faculty, departments, and institutions. Ultimately, this lack of alignment limited the establishment of a clear pathway on how to develop, strengthen, and enhance critical thinking for the students.

Participants perceived critical thinking as something that has a hierarchy starting with engagement. Engagement built student confidence and content foundation allowing higher levels of critical thinking to occur. Therefore, because participants saw engagement as their primary condition that would eventually lead to higher levels of thinking, they focused on facilitating a classroom environment that was engaging and respectful—where students can learn and debate ideas. This perception influenced participants' selection of classroom strategies. Among the classroom strategies chosen by the participants were think-pair-share, gallery walks, jigsaw puzzles, reflection writing, 
concept maps, concept sketches, class discussions, flipped classroom, TILT, real-data, fieldwork, and hazard teaching activities. The selection of these strategies was based on engagement and personalization. As one participant noted, “...spending some time talking about things that might matter to them and how the science might help them" (Slate), suggesting that participants selected strategies or constructed activities for students to have opportunities to connect with the content by seeing the impact in their lives. According to participants, this connection with the material was key for students to eventually start developing higher levels of thinking.

Participants used a combination of discussions, written reflections and/or real-life database activities as an attempt to get students to dig deeper into the material. An example of personalized discussion was "...discussion topics is the controversy over the Mauna Kea observatories. And sort of how that land is used and who has the right to determine how that land is used" (Garnet), which participant attempted to get students to connect science and society via in-person discussions. Whereas examples of written reflections prompt such as "Why should anybody care about this? And, I might have an actual discussion prompt like, "why do anybody care about this?" so, that it gets them to think a little bit about why it is something that is worth caring about." (Serpentinite) are faculty's attempts for students to engage with science by exploring their own individual learning processes. Lastly, participants gave examples of real-life database activities such as "Complete the table in the excel sheet using data we collected in class on Monday...Now, using Google Earth's distance tool and the depth soundings, create your own profile of the transect labeled Juan de Fuca Ridge" (Peridotite), which prompted 
students to be the scientist, use the data, and create a product for the application of knowledge. In summary, participants showed that getting students engaged in higher levels of thinking was their main goal. However, when asked how much higher level of thinking was really happening in the classroom, most participants indicated that they were not sure how much higher-level thinking was occurring. They indicated this uncertainty was due to their own level of training and their students' preparedness on the exposure to these types of instructional activities.

The training and support pursued by participant varied per their individual interests in critical thinking, faculty appointment, and teaching experience. While participants placed critical thinking as an important tool in the classroom, most participants have not had conversations regarding what it entails to be a critical thinker. However, within their institutions, full-time faculty participants felt that their institutions support to pursue training and other interest. Some areas of support were faculty mentorship, cross-disciplinary workshops, institutional administrative work, and the academic freedom to try new teaching techniques. Yet, even with this support, discussions regarding critical thinking in the classroom seemed to be happening either outside of the institutions (at conferences and workshops) or were not happening at all. In contrast, the comments about training and support from adjunct/part-time faculty participants were quite different. Adjunct/part-time faculty members struggled with feeling unsupported, losing momentum, and being unprepared to use critical thinking curriculum and instructional techniques in the classroom. One reason these participants felt unsupported was absence of instructional guidance by full-time faculty members, 
departments, and institutions. One part-time faculty member lamented:

If you compare full time to part time yes, I think full time can feel more comfortable trying new techniques because they have tenured and they are not going to lose their job if their students do not like them. It does not matter as much to them because they are just going to get the next class. (Slate)

Such comments suggested the discomfort adjunct/part-time faculty experienced when trying new techniques especially if there was a lot of student pushback that could impact their job hiring.

Additionally, the low rates of adjunct/part-time faculty compensation led the adjunct/part-time faculty participants to feel undervalued. As one noted:

...the pay does not really... It is not that you do not want to, it is just, the amount of work, the cost benefit there, to spend those extra couple hours preparing each lecture or really coming up with an impactful activity...I cannot justify it. I know that that is a problem. (Amphibolite)

Their feelings of being undervalued affected their momentum to pursue nuanced ways to improve their curriculum and their instruction as well as to guide students' critical thinking development.

Another critical issue was participants' assessment of curriculum and instructional techniques that prepared students to engage critical thinking. They shared sentiments such as:

I am thinking in my brain where I assess that critical thinking but, the fact of the matter is I think the students that tend to do well with those questions are students 
that come into class with a set of skills that I do not even know where they have gotten. I do not think I am teaching those things in class. (Peridotite)

Participants expressed that if they had more preparation on how, when, and where critical thinking could develop in the classroom, they would be more confident in teaching and assessing it. While all participants were passionate about teaching, the fulltime faculty participants did seek more training and support than adjunct/part-time faculty participants. This was a further indication that other faculty, departments, and institutions play a role in supporting participants' use of critical thinking instructional tools within the classroom.

Participants' implementation of critical thinking instructional strategies depended on usability and time with a primary focus on student engagement. All participants perceived critical thinking as a process that took time, which hindered their use of critical thinking instructional tools in the classroom. Time constraints led participants to select instructional tools that were easy to employ and engage students. They shared thoughts such as "There are certain topics that lend themselves more to some than others... it's more just ease of employment" (Mica) and "My choosing varies depending on topic challenges or engagement and I think usually it's based on trying to fulfill some type of something in the outline or the lab" (Slate). These thoughts exemplified how time forces them to select critical thinking strategies or activities that engage and connect students to the material. As such, it seemed that the development of students' critical thinking was a result of students engaging with the material; however, the issues of how, when, and where the students' critical thinking developed was less clear. 
For participants, teaching and assessment of critical thinking in the classroom was complex. Only one of seven participants stated feeling passionate about teaching and assessing critical thinking. She asserted, “...we do ourselves a disservice for our students if we are not really getting them to think through some of these more critical aspects of their learning process" (Serpentinite). She also reflected on the current tools used for critical thinking assessment in the classroom:

I will just say that it is one of those things where it is... I am going to go back to the fact that if it is primarily written and, not everybody is a strong writer... I think it does tend to bias a certain population in terms of who is more likely to express themselves in writing, and who is...So, it tends to benefit people being white women, and so I think that that is something that I need to think about." (Serpentinite)

She highlighted that using written form assessment (in this case written reflections) as the only type of critical thinking assessment tool was not equitable for all her students. In contrast, the rest of the participants felt mixed, some expressed feeling comfortable teaching critical thinking, but not with assessing critical thinking while others felt uncomfortable doing either. While most of the participants conducted a form of critical thinking assessment during exams or quizzes, the documents they shared focused primarily on understanding the fundamental concepts. Regardless of the critical thinking tools participants used in the classroom, they hoped the development of critical thinking would lead to students' higher levels of thinking so that eventually students strengthened their scientific literacy skills. 
In summary, the findings showed that faculty hoped to fill the absence of conversations regarding the role of critical thinking at various levels by creating an environment of classroom engagement. Thus, participants implied that rather than solely focusing on critical thinking, student engagement was the primary condition participants use to build students' confidence and strengthen content foundation that would ultimately propel students to use higher levels of thinking. Thus, at the introductory course level, when faculty members focused on engaging students in the learning process, most of critical thinking development remained at lower levels of thinking due to the limitations in the faculty members' training, knowledge, and use of instructional tools available for critical thinking.

\section{Limitations of the Study}

My use of qualitative methodology in this study provided me with a deeper understanding of the participants' (community college geoscience faculty members) underlying reasons and motivations towards critical thinking. However, like many research studies, there were notably limitations. In this section, I have identified the limitations encountered in this study and the actions used to address or mitigate them. The limitations related to (a) the sample, (b) data collection, (c) selection of data coding analyses, and (d) researcher bias.

As is the case for many qualitative studies, the size and diversity of the sample of geoscience faculty members participating in my study was a limitation. While I was able to gather data about the perceptions of seven geoscience faculty regarding critical thinking and its use in classrooms, the small sample size limited my ability to generalize 
their experiences. The diversity of the sample was also an issue. All seven participants identified themselves as White/Caucasian, therefore the voices of faculty members of color were absent from this study. (Note: There had been one participant who selected White/Latvian, but this participant was not able to participate after the survey.) Nevertheless, participants in this study did have diverse teaching experiences, academic degrees, physical locations, faculty appointments, training, and discipline specializations. Another limitation related to the specific data collection items used for this study: a survey, two interviews, and documents. The primary use of the survey focused on bounding the research study participant sample, therefore the survey gathered demographic information and research literature knowledge. Thus, I used the survey for interviewee selection. Therefore, this survey did not capture the full range of responses from participants; there was also the possibility that not all participants' responses were accurate. To mitigate this limitation in the survey data, I conducted two interviews with the participants. The interviews also had limitations such as (a) time between each interview, (b) participants' perception of the interview questions, and (c) participants' responses. First, both interviews occurred within a two-week period, which might represent a limitation. I noticed that in general the participants' responses were raw in the first interview, and by the second interview they seemed better prepared. I tried to mitigate this limitation by seeking clarifications and posing follow-up questions. Second, the participants' perceptions of the interview questions might also have been a limitation. At times, I detected the possibility that participants provided responses of what they thought I would want to hear, and at other times, their responses were less articulate or 
clear. I worked to mitigate this limitation by requesting clarifications and asking additional follow-up questions. Moreover, at the beginning of both interviews, I made a clear statement to encourage participants to answer truthfully and assured them that there were no wrong answers. Third, my presence in the interview might have influenced the participant's responses. My role as a former community college geoscience faculty member conducting the interview might have led to bias in the participants' responses. To mitigate this limitation, I focused on the participant by seeking clarifications, using follow-up questions, and redirecting the interview back to the interview questions.

A final limitation might have been my own background as a former community college geoscience faculty. My own experience has been primarily with quantitative methodology, and this study represents my first foray into qualitative research. In addition to my advisor and my doctoral program, I found the following resources particularly helpful: Saldaña (2016), Creswell (2014), Creswell and Poth (2018), Miles et al. (2020), and Merriam and Tisdell (2016). Lastly, to limit the effects of potential bias as a former community college geoscience faculty myself, I conducted voice and written memos throughout the data collection and analysis process whenever possible. 


\section{Chapter 5: Conclusion}

Critical thinking is a multifaceted process that, among other things, involves the analysis of data, problem solving, idea generation, identifies misconceptions, and locates errors. As such, this valuable skill warrants investigation. Conversely, studies investigating critical thinking processes and strategies are scarce and appear primarily within the health care sciences. Furthermore, the research studies in K-12 education focus typically on students rather than on faculty. These studies also focus on factual knowledge acquisition rather than processes and strategies used to achieve critical thinking. Research studies focusing on community college faculty members, especially those that teach non science majors taking introductory geoscience courses are particularly limited. My study addresses this gap by describing and examining the perceptions held by community college geoscience faculty regarding critical thinking and how such perceptions influenced their chosen instructional strategies.

In this chapter, I offer a synthesis of my findings, situate them in the larger context, and conclude with my recommendations. My exploration into the state of critical thinking among geoscience faculty members at community colleges in its current state may potentially foster future meaningful dialogue within this space.

\section{Synthesis of Findings}

The primary finding of my study was that the community college geoscience faculty members perceived and used critical thinking instructional strategies implicitly. This characteristic of implicitness that permeated faculty members, classrooms, departments, and institutions was influenced by their epistemological stances and held 
belief systems. As I found, implicitness also bound the pedagogy of critical thinking within community college faculty members teaching of geoscience. Addressing the issue of implicitness and increasing visibility not only in the classroom but also across all institutional levels, would offer many opportunities to enhance the teaching of critical thinking within this setting.

Specifically, the findings from my study centered around five themes. First, I found that these geoscience faculty perceived critical thinking as having a hierarchical order, such that using and developing critical thinking in the classroom happened in progressive stages: engagement/confidence, foundational knowledge, and higher levels of thinking. Faculty members focused initially on building an environment of engagement and confidence by using active learning strategies. Then, they used these same active learning strategies to strengthen students' content foundation. Once students had a strong content foundation, they were more inclined to use higher-level thinking.

Second, I determined that the absence of explicit discussions regarding critical thinking among faculty members, departments, institutions, largely placed the responsibility onto the faculty on an individual basis. As a result, faculty members felt compelled to define critical thinking, prioritize its teaching, and seek additional training and support in implementing it, largely on their own. In the absence of any explicit understanding of critical thinking, and clear instructional frameworks/methodologies, faculty usually defaulted to their preferred framework, Bloom's Taxonomy (Bloom, 1965), to develop and assess critical thinking.

Third, I found these geoscience faculty often taught critical thinking implicitly by 
personalizing the learning, using think-aloud models, and teaching science as a process, rather than explicitly teaching critical thinking as an isolated strategy. Instead, they viewed themselves as embedding critical thinking into their teaching via personalization of learning, modeled think-aloud strategies, and teaching the process of how to conduct science.

Fourth, I learned that the absence of time dedicated explicitly for teaching critical thinking was problematic. The geoscience faculty often argued that the sheer amount of time needed to teach critical thinking was a constraint in its own right. These time constraints often introduced tough decisions regarding time management and the nature of the content being taught, in terms of depth versus breadth. Many geoscience faculty members noted that implementing critical thinking strategies in the classroom was time consuming, so they often prioritized decisions based on the ease of implementation, availability of materials, and time needed. Subsequently faculty members experienced cognitive dissonance about teaching critical thinking.

Lastly, these geoscience faculty members viewed critical thinking as a means by which students could gain trust in science, scientific literacy, comfort with scientific processes, and ability to digest scientific information. In turn, they hoped that the acquisition of critical thinking would ultimately play a positive role in their students' lives. As such, they viewed critical thinking as an essential tool in teaching the geosciences. Perhaps the word that best defined the complex relationship many of these faculty members had with critical thinking is hope. For multiple participants, on a personal level, they believed in the value of teaching critical thinking, were hopeful yet 
simultaneously uncertain in their success in teaching critical thinking. While most faculty members expressed comfort in the notion of them teaching critical thinking, few were comfortable with the idea of assessing it. Again, many felt that there was an absence of diverse tools available for the assessment of critical thinking. They attributed their own discomfort to the absence of professional training, institutional level discussions, limited availability of diverse instructional tools, and their own lack of experience.

In conclusion, the findings from my study were compelling because these community college geoscience faculty members clearly deemed critical thinking to be an essential and valuable tool, but often felt alone, unsupported, and individually responsible for teaching critical thinking in their classrooms. The absence of explicitly available resources and conversations among faculty, within departments and within institutions, ultimately rendered critical thinking as an abstract concept for many faculty members. They felt that they were on their own in defining critical thinking, teaching critical thinking, and assessing it; yet they continued to remain optimistic because they believed in the inherent value of doing so.

\section{Situated in a Larger Context}

In this section, I discuss my findings from the perspective of my theoretical framework and conceptual model. I show that the sociocultural and conceptual framework supports the notion that communication between different entities is important for cognitive development and growth, and if this communication is primarily implicit, it may limit the effectiveness of teaching critical thinking in the classrooms. Then, I situate my findings with the research literature to compare my findings with previous research 
about critical thinking and the use of critical thinking strategies.

\section{Situating Findings within Theoretical Framework and Conceptual Model}

In Chapter 2, I introduced my theoretical framework, Vygotsky’s (1978) sociocultural theory, in which he postulates that social interaction is essential for cognitive development. In sociocultural theory, Vygotsky emphasized that learning is an active process occurring in cooperative dialogues with more knowledgeable membersfaculty members and/or more capable peers. Because of the incredible value placed on dialogue, the element of implicitness might hinder individuals' growth and development. In my study, the geoscience faculty prioritized fostering student dialogue within their classrooms (interpsychological) as a means to stimulate internal engagement (intrapsychological) of their students. In other words, they prompted critical thinking by stimulating explicit discourse. Faculty members viewed the usage of cooperative dialogue via active learning strategies as a critical first step in their hierarchy of critical thinking, necessary to build students confidence and strengthen their content knowledge.

Within his sociocultural theory, Vygotsky (1978) also advanced his predominant concept: the zone of proximal development. Vygotsky claimed that cognitive development exists in two zones: (a) zone of actual development - the individual's current cognitive development and (b) zone of proximal development - the distance between what an individual can problem-solve independently and the potential deepening of learning that can occur with the assistance of a faculty member or through the collaboration of peers. He asserted that dialogue and communication are critical to growth in the zone of proximal development, whereas reflection in personal activities 
facilitates growth in the zone of actual development. Vygotsky further posited that interpsychological growth is dependent upon social interaction and collaborative learning. In my study, the geoscience faculty used active learning strategies including think-pair-share, discussions, gallery walks, and jigsaw puzzles to enhance social interaction and collaborative learning. These activities depended on the explicit communication that occurred between learners. On the other hand, intrapsychological growth depended on activities in which learning happened primarily within the individual. Previous research on cognitive development showed that when children enter school, their experience of spending time building language, literacy and academic concepts encouraged them to reflect on their own thinking - resulting in advancement of critical thinking (Kozulin, 2003). Examples of activities used by my participantsgeoscience faculty members - which employed this method of learning included reflective writing, muddiest point, exam wrappers, concept sketches, real-life data, and clickers. By employing these strategies, faculty members could maximize their role within the zone of proximal development. These geoscience faculty members seemed to feel that when their students engaged in both collective and individual experiences in the classroom, they could potentially enhance their use of higher levels of thinking such as application, analysis, synthesis, and evaluation.

Yet, when it came to teaching critical thinking within their classrooms, my participants often felt unsupported. They often felt that their institutions, just like they did, valued critical thinking. However, when it came to the actual mechanics of defining, teaching, and assessing critical thinking, they often felt on their own. Viewed from the 
sociocultural lens, the absence of clear definitions and ambiguity in terms of strategies and methodologies in teaching critical thinking were clearly detrimental to growth, both interpsychologically and intrapsychologically. The lack of clarity could help to explain in turn why my participants, although aligned with their institution's valuing of critical thinking, felt uncertain about whether they were succeeding in teaching critical thinking to their students. They experienced the duality of hope- the genuine optimism in striving to impart a valuable skill to their students, while simultaneously remaining doubtful about their ability in achieving this goal. This sentiment of hope could be expanded to the departmental and institutional level potentially as well. Despite seeing the value of critical thinking, the absence of cooperative dialogue, clear definitions, explicit methods for personalization and integration for faculty, departments, and the community colleges seemed to contribute to geoscience faculty members' uncertainty about their own ability to teach critical thinking.

In Chapter 2, I also introduced my own conceptual framework that focused on my view of fostering critical thinking using a sociocultural lens - the development of critical thinking as it occurred within a community (classroom) and individually in a cyclical instructional model, as shown in Figure 1. This conceptual model provided me with a framework to consider and analyze my problem of practice.

My Conceptual Critical Thinking Instructional Model is cyclical, and it has four important steps: clear definitions, language (cooperative dialogues to connect relationships with definitions), integration and personalization (metacognition), and application (i.e., problem solving). The cycle does not have beginning nor end and with 
each use, critical thinking deepens as seen in a funnel type structure representing relationship between depth and use of critical thinking. The model is a useful framework for evaluating the perceptions and use of critical thinking in the classroom among faculty members.

Using my conceptual model as a lens, I found that the element of implicitness went beyond faculty members, departments, and institutions. It also permeated the teaching strategies and methodologies used by the faculty members themselves to teach critical thinking. Rather than explicitly teaching critical thinking within their classrooms, most of my participants chose instead to embed critical thinking into their geoscience curriculum and instruction. They used personalized learning (e.g., connect humans and society), think aloud models (e.g., modeling thinking processes) and teaching science as a process (e.g., real-life data, multiple hypothesis) to implicitly engage students into higher levels of thinking. Although all participants prioritized providing an environment where critical thinking could occur, only one participant made the goal of critical thinking explicit to their students. For example, faculty chose to implicitly use Bloom's Taxonomy (Bloom, 1965) by using Bloom's verbiage and framework rather than explicitly explaining Bloom's Taxonomy to their students. In addition, my findings showed that each faculty member pursued their own versions of definitions for critical thinking, development of language, strategies for integration and personalization, and application of strategies. Most participants prioritized engaging their students using active learning strategies focused on connecting science and human experience. They felt that by doing this, students had the opportunity to clarify definitions, personalize the content, and have 
cooperative dialogues, which subsequently allowed them to build their content foundation. In this hierarchical model, they felt that higher levels of thinking would be achieved, almost as an implicitly assumed final destination. Perhaps on an even deeper level, participants valued critical thinking implicitly, as faculty members, they assumed that their students would recognize that critical thinking was inherently valuable and critical to success in the sciences.

The findings of my study also helped me to update my conceptual model. Revisiting my original conceptual model, I viewed critical thinking as a cyclical process that was also iterative, with each iteration facilitating more depth. However, an important finding of my study was that implicitness bounded the pedagogy of critical thinking.

In Figure 7, I show my revised conceptual model of critical thinking. I visually represent the relationship between explicitness and implicitness by a series of gates. The gates separate both individual steps within a single cycle of critical thinking and also subsequent cycles of critical thinking. When open, faculty/students pass onto the next step; when closed, they are unable to do so. As my study suggests, by addressing the issue of implicitness at each stage, individual obstacles/limitations may be understood and thus potentially overcome, allowing for these gates to be "opened."

\section{Figure 7}

Revised Conceptual Critical Thinking Instructional Model 
Instructional process occurring at each of cycle of critical thinking (CT)

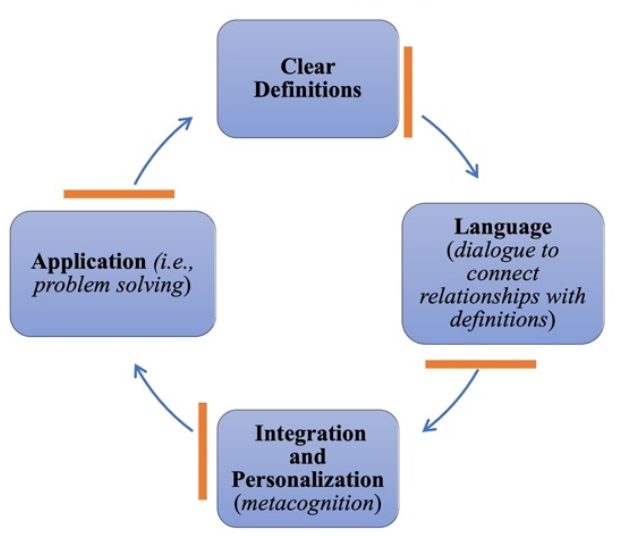

The orange lines represent gates that when open, allow faculty/students to proceed. Gates can be opened once implicit obstacles/limitations are made visible/explicit and are subsequently addressed.
Increase of critical thinking per cycle

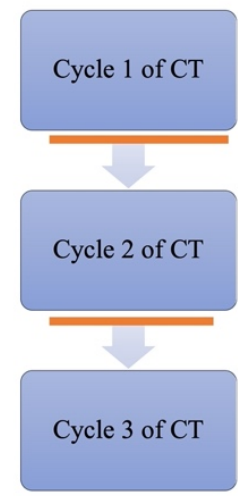

When open, gates also allow for progressive cycles of critical thinking to occur, increasing depth.

\section{Situating Findings within the Research Literature}

Prior research literature illuminates various aspects of implicitness in the fostering of critical thinking. In this section, I show how my work is similar in highlighting the effect of implicitness of critical thinking and unique in highlighting the effects of implicitness in the geosciences. I compare my findings with the work of Paul et al. (1997), Bailin (2002), Choy and Cheah (2009), LaDue and Clark (2012), Nicholas and Labing (2013), and Nicholas and Raider-Ross (2016). Thus, my intention is to add or extend some of the voids in the research literature base.

In their foundational research, Paul et al. (1997) studied 140 faculty in education as well as arts and sciences to understand their critical thinking knowledge and teaching practices. His findings showed that although most faculty members deemed critical thinking as important, many did not clearly articulate the meaning of critical thinking. Some faculty members had vague conceptions of critical thinking (i.e., "critical thinking equates active learning," "critical thinking equates thinking for yourself”) while others 
had developed a notion of critical thinking (i.e., critical thinking a product of multiple theories). Additionally, their study also showed that education faculty members articulated more clearly how they used critical thinking than the faculty members in the arts and sciences. Comparing Paul et al.'s (1997) findings with mine, I found similarities and differences. For example, some of Paul's participants equated critical thinking with active learning like the geoscience faculty in my study. When asked for critical thinking traits in their students, most faculty members equated Bloom's cognitive framework as critical thinking traits just like many of my participants did. However, while some of Paul et al.'s (1997) participants believed that active learning automatically engaged students to critically think, my participants instead clearly stated that engagement alone would not lead students to critical thinking. My participants also asserted that engagement is a first step in fostering critical thinking. Additionally, my findings showed that the geoscience faculty had a clearly articulated concept of critical thinking in contrast to Paul's participants. Lastly, the biggest similarities between my study and Paul et al.'s study were in terms of assessment, and the assumption that critical thinking is taking place in the classroom. In Paul et al.'s study, participants assumed critical thinking was taking place in their instructions without verifying such assumptions; these participants had little understanding of how to assess critical thinking. Conversely, in my study, most of my participants assumed critical thinking was happening or at least they fostered the importance of critical thinking; however, when looking more deeply, most of their instructional efforts focused on student engagement. My participants also expressed discomfort when assessing critical thinking due to an absence of dialogue, training, and 
support. He concluded that teaching training programs were not having conversations about critical thinking. Similarly, my findings revealed that the misalignments regarding the understanding of critical thinking was mostly the result of faculty members not having the space to have conversations among themselves, their colleagues, their departments, and their institutions. Therefore, the comparison between my study and Paul et al.'s study made 24 years ago suggested that these issues have long existed, and little has changed.

In an international study, Choy and Cheah (2009) investigated the critical thinking perspectives of 30 postsecondary faculty members of various disciplines in Malaysia. They reported that faculty perceived that they teach critical thinking in the classroom and that critical thinking provided intellectual stimuli that can facilitate in-depth understanding of the material. However, the faculty focus was for students to understand the material, they did not actually focus on the use of higher levels of critical thinking. Additionally, these faculty members were conflicted when reconciling the tension between fostering critical thinking in the classroom and the course requirements due time constraints. While participants in Choy and Cheah's study perceived themselves as teaching critical thinking in their classroom, the geoscience faculty members in my study stated that critical thinking was one of the main themes within their curriculum. My participants also reported that higher levels of critical thinking in the classroom could be experienced after students met three conditions: engagement, confidence, and content foundation. Contrary to the participants in Choy and Cheah's study who focused only on students' understanding of the material due to their perception of critical thinking as an 
intellectual endeavor, the geoscience faculty members in my study shifted their focus to engaging students, building student confidence, and strengthening student concept foundation. Finally, like the participants in Choy and Cheah's study, the geoscience faculty members in my study had difficulty reconciling the tension between fostering of critical thinking in the classroom and course requirements due to time constraints. Examining critical thinking and science education, Bailin (2002) argued that conceptualization of critical thinking occurred in terms of a process or skill rather than in terms of context. She asserted that critical thinking is contextual and offered explicit examples of science activities that prompt students to use critical thinking to examine complex, scientific problems. Bailin (2003) also reasoned that critical thinking viewed contextually can shift the pedagogical focus on "what does an individual need to understand to reasoned judgement in particular context" (p. 212). When comparing Bailin's arguments with my findings, I found that most of the mid- and late-career geoscience faculty members often conceptualized critical thinking as either a skill or a process, whereas early career geoscience faculty members conceptualized critical thinking in its contextualized nature. Intriguingly, for the mid- and late-career geoscience faculty members, they inadvertently applied critical thinking in context. When they discussed the different resources and strategies used to foster critical thinking in their classrooms, faculty seemed to conceive of critical thinking in terms of what their students needed to effectively generate evidence-based solutions. For example, when these faculty members taught about the impact of natural hazards, the strategies they used focused on guiding their students to make reasoned judgements and generate solutions. Their choices 
suggested that (a) some geoscience faculty members have misconception in their understanding and application of critical thinking, and (b) early career geoscience faculty appear to be shifting conceptualization of critical thinking to be one where critical thinking is contextual.

In a study focused on K-12 Earth science teachers and undergraduate geoscience faculty perceptions, LaDue and Clark (2012) conducted a survey investigating K-12 teacher and faculty perceptions of Earth science literacy (ESS). Their survey investigated (a) the challenges and priorities encountered in ESS, and (b) the important concepts nonscience majors taking ESS courses. In their findings, both teachers and faculty members placed high importance to the understanding of Earth science due to its personal and local relevancy. LaDue and Clark's participants also identified that the K-12 is not teaching Earth science with the same level of rigidity as the other science courses which in turn, lead to public misconceptions in ESS. Results from LaDue and Clark's second survey indicated that geoscience faculty members prefer to teach concepts using systems thinking approach (i.e., disciplines fuse together to understand multiple processes with complex interactions) rather than isolated topics. In the same way, my participants echoed the perceptions of K-12 teachers. Participants from my study felt that the students taking their courses did not have strong content foundation. Strengthening content foundation affected my participants' ability to shift the students to do more higher-level thinking in the classroom right away. Moreover, my participants also preferred to teach a more systems thinking approach rather than isolated topic. Lastly, results from LaDue and Clark's surveys showed that K-12 teachers preferred to teach the connection between 
science and society more than geoscience faculty members did. On the other hand, findings from my study showed that my participants placed immense effort in connecting the impacts of geoscience and society because it yielded higher student engagement.

In a later study conducted in the Midwest United States, Nicholas and Labing (2013) examined how faculty from the humanities, natural, and social sciences assessed students' critical thinking at two different four-year institutions. Their findings showed that (a) faculty members' assessment of critical thinking is implicit and integrated within their specific discipline content, and (b) a misalignment between faculty members and institutions' critical thinking standardized assessment approaches. My findings showed that four of the seven participants had a mental learning process model of what critical thinking looked like in their geoscience classroom. Three of the participants used what they called "three step learning model" which was mental model they went through while observing their students. For example, one participant shared, "First step, very openvery foundational; second step, I explained it to them. Third step, I give them the challenge question that builds on it" (Mica), which provided me with an opportunity to "see" the faculty member's mental assessment process. While three participants used the term three-step learning model, one used a research-based model called self-directed learning model (Lukes \& McConnell, 2014; Zimmerman \& Schunk, 2001). This was the only geoscience faculty member who used a research-based thinking model—a model found explicitly in her syllabus and all forms of assessment (i.e., writing reflections, assignments, and class activities). However, regardless of the mental critical thinking models described by the geoscience faculty members, their assessment of critical thinking 
traits was comparable to the physics, chemistry, and biology faculty members who participated in Nicholas and Labing's study. In their study, they reported that critical thinking encompassed "the processing multiple, complex lines of reason to arrive at a reasonable explanation or resolution to a problem" (Nicholas \& Labing, 2013, p. 309). Further, Nicholas and Labing's findings showed a misalignment between standardized ways of assessing critical thinking by both faculty and their institutions. My findings also showed similar misalignments. While most of the faculty were unaware of the standardized definition or even assessment protocols that their institution used for critical thinking, Bloom's Taxonomy (Bloom, 1965) was the preferred assessment tool. These faculty members used Bloom's Taxonomy in the curriculum and their instruction aligning with studies from McConnell et al. (2003) and Nunn and Braud (2013) that also showed geoscience faculty members use of Bloom's Taxonomy for curriculum and assessment. Whereas for the participants who were familiar with their institutions' critical thinking frameworks, they mentioned their institution used institutional learning outcomes, reasoning, or critical thinking VALUES rubric. Additionally like the faculty members who participated in Nicholas and Labing's study, the geoscience faculty members in my study passionately rejected the idea of multiple-choice tests as a valid measure of critical thinking.

In a more recent study, Nicholas and Raider-Ross (2016) explored humanities, natural, and social sciences faculty members' approaches, assessment, and effectiveness in teaching critical thinking while they taught general science courses. Their findings showed that faculty members definitions of critical thinking varied by discipline, a 
misalignment existed between the faculty and institution's understanding of critical thinking, and faculty members developed a hopeful rather than confident approach to fostering critical thinking in their classroom. When I compared my findings with Nicholas and Raider-Ross's findings, I identified similar as well as different results. First, the definition of critical thinking among my participants was overall comparable to participants in Nicholas and Raider-Ross's study. While most of my participants defined critical thinking using Bloom's Taxonomy terms (Bloom, 1965), others elaborated on their definitions such as assessing multiple hypothesis, analyzing data, synthesizing findings, and self-regulated learning process (i.e., what do I know and what do I need to know). Thus, my findings supported Nicholas and Raider's argument that respective disciplines may have their own definition of critical thinking. My findings also added specifics of how in this case, community college geoscience faculty members, defined critical thinking. Second, my findings also aligned with Nicholas and Raider-Ross's findings regarding misalignment between faculty and their institutions understanding of critical thinking, which in turn, affected the institutions' approach, assessment, and effectiveness of teaching critical thinking. My findings also expanded on the extent of the misalignment. My findings showed a misalignment between full-time faculty members and part-time faculty members, their departments, and their institutions understanding of critical thinking. Lastly, compared to Nicholas and Raider-Ross's study, my findings showed that community college geoscience faculty members possessed a hopeful approach rather than confident approach to teaching and assessing critical thinking due to the absence of institutional level discussions, training, support, availability of diverse 
instructional tools, and the perception of critical thinking as time-consuming.

In the next section, I discuss the implications of my findings and present recommendations for community colleges, undergraduate and graduate programs, and K12 education. I also offer suggestions for future research.

\section{Implications}

Teaching and assessing critical thinking are challenging but important tasks in education. The findings from my study can contribute to the understanding and application of critical thinking by geoscience faculty members, especially those working in community colleges.

While prior studies focused on students and critical thinking within other fields, in Chapter 1, I argued the importance of looking at the perception of critical thinking from the perspective of geoscience faculty within community colleges. Although my study was discipline specific, I believed that the findings from my study offer important insight into the current state of the pedagogy of critical thinking. My primary finding was that in terms of both perceptions and the application of critical thinking within this setting, the element of implicitness was a defining characteristic. The absence of clear definitions, in the institutions and departmental resources, highlighted the absence of explicit support, often requiring faculty members to navigate this journey on their own. Faculty members are in turn compelled to individually synthesize multiple interpretations of critical thinking and apply the strategy that they deem most appropriate to teach critical thinking in the classroom. Furthermore, the duality of institutions appreciating the inherent value of critical thinking, but also without the explicit resources to support its teaching, often 
means confronts faculty members to make difficult decisions regarding prioritization and time management.

The importance of my work is that although it highlights the current state of the pedagogy of critical thinking as one defined by implicitness, it also simultaneously offers a pathway for potential for growth and progress. Specifically, by understanding the specific aspects of implicitness within the geoscience departments in community colleges, it also suggests that by making support more explicit at the faculty/departmental/institutional level, the teaching of critical thinking may progress in this setting. Just as importantly, my work shows the interest is very much present for this support among current faculty, despite the challenges.

In the next section, I provide recommendations for community colleges, geoscience undergraduate and graduate school programs. I also broaden my recommendations to include K-12 education and policy makers. I discuss potential directions for future research and conclude with my final thoughts. In essence, referring to Figure 7 which shows my revised conceptual model of critical thinking, each of the following recommendations represents a potential pragmatic solution on my part to open the gates within a variety of different contexts and environments.

\section{Recommendations for Community Colleges}

Across institutions, great variability exists in terms of defining, understanding, and supporting critical thinking. Cooperative dialogues among faculty, departments, and institutions (e.g., faculty-faculty, faculty-department, faculty-institutions) may provide the opportunity for a collective vision of critical thinking to develop. Such conversations 
may potentially improve the comfort with which faculty feel towards fostering critical thinking in the classroom in an explicit way (Berk, 2018; Kozulin, 2003).

Based on my findings, most of my suggestions focus on trying to limit assumptions and implications, while leaving faculty to clarify and execute the critical thinking process on their own, and instead, focus on providing cooperative dialogues to increase visibility and support in the pedagogy of critical thinking.

To this end, I suggest that leaders with community colleges (e.g., science department chair) take specific steps including:

- First, build a critical thinking community where faculty members can discuss making critical thinking more visible in the classroom. Ideally these discussions could occur during faculty meetings with presentations focused on exploring critical thinking. Faculty can then break into small groups to discuss their own thoughts and suggestions.

- Second, reserve time in a program meeting to allow faculty to exchange ideas and experiences regarding how to implement critical thinking in the classroom, how/when to make critical thinking more explicit to their students.

○ Third, host a session focused specifically on the various successes and challenges encountered by facility as they try to implement critical thinking in the classroom.

- Fourth, develop faculty mentoring programs in teams of two for classroom observations, informal conversations, curriculum development, and instructional practice so that faculty members feel supported and motivated 
when implementing critical thinking.

From my study, I also suggest that community colleges address the inequities regarding part time/adjunct faculty members and full-time faculty members. My findings show a notable disparity in the comfort levels in implementing critical thinking, between full time and part-time/adjunct faculty. The part time/adjunct faculty members seem to be even more isolated than their full-time colleagues. Therefore, I recommend building cooperative dialogues among full-time and part-time/adjunct faculty members to create a communal critical thinking community. Importantly, resources made to support faculty members in terms of teaching critical thinking could be extended to both full time and part-time faculty, such as professional development workshops, and could be compensated similarly for both groups.

\section{Recommendations for Geoscience Undergraduate and Graduate School Programs}

As shown in my study, an opportunity exists to increase the visibility of fostering critical thinking within the classroom itself. I contend that programs have several potential ways to increase the confidence with which faculty members can communicate directly with their students regarding their choices and perspectives on their teaching of critical thinking. I recommend that geoscience departments consider implementing: (a) geoscience educator faculty member appointment and (b) geoscience pedagogy courses for geoscience masters/doctoral graduate students. As demonstrated by prior research, the capability and comfort with which critical thinking can be taught can be augmented by having faculty member who have specific experience and training in the field of education. Faculty members who have dual degrees in the fields of geoscience and 
education and who emphasized geoscience education may bring immense opportunities to the department. The benefits of this include the creation of in-house geoscience faculty development programs, fostering a geoscience education research community, developing geoscience pedagogy courses, as well as serving as liaison among geoscience departments, institutional assessment and strategic planning teams, and geoscience policy makers. In terms of graduate students, they often receive funding in the form of research assistantships or teaching assistantships. Programs could create research and teaching assistantships, specifically focused on the teaching of critical thinking, which would benefit from the input from a geoscience education faculty member. Furthermore, the implementation of workshops for early-career faculty members in geoscience departments are an indicator of an absence of training and support at the geoscience undergraduate and graduate level programs. Having a dual expert in both geoscience and education, especially at geoscience departments without a geoscience education degree, is essential for creating effective pedagogy courses for students pursuing geoscience undergraduate, master, and doctoral degrees.

\section{Recommendations for K-12 Education and Policy Makers}

A key finding of my study is that fostering critical thinking, in its current state, is a complex process largely defined by characteristics of implicitness and as such, demands a lot of time. This inevitably raises the question of how this challenge can be approached even before students enter college. K-12 teachers and geoscience faculty members both view geosciences as a multidisciplinary field that humans experience daily. Yet, in the classroom, a misalignment exists between the 
instructional academic rigor of K-12 teachers and geoscience faculty members (LaDue \& Clark, 2012). Participants of my study echo this misalignment and recommend the vertical articulation of curriculum by K-12 teachers and community colleges geoscience faculty members. Currently, K-12 science curriculum and instruction is guided by states' selection of one of three standards: National Science Based Standards (NSES), Benchmarks for Science Literacy (Benchmarks), or the newest standards, the Next Generation Science Standards (NGSS). Whereas NSES and Benchmarks focus on either inquiry or content in their curriculum, the NGSS focuses on scientific practices (behaviors scientists engage in, such as problem solving, rather than focusing solely on content knowledge). In addition, of all three standards the NGSS contains more geoscience content than their counterparts, NSES and Benchmarks (Wysession, 2014). For this reason, I recommend creating cooperative dialogues between the K-12 and community college communities by assigning a liaison in both communities - a community college geoscience faculty member and a K-12 science (i.e., geoscience/physical science) teacher who can bridge these communities. The liaisons can share what they learn in their faculty and staff meetings. Such cooperative dialogues between K-12 teachers and geoscience faculty members can bring to light the differences between the theory and practice of fostering critical thinking. These conversations can also inform policy by offering an opportunity to create clear and explicit strategies in a broader statewide/national context, to geoscience educators in all settings (i.e., K-12, community colleges, fouryear institutions, and graduate programs). I recommend cooperative dialogues 
between policy makers and geoscience educators to develop a collaborative discipline-specific critical thinking framework. Using a common framework or model for critical thinking in the classrooms, included in course syllabi, can help faculty members and teachers to plan goals for explicitly teaching critical thinking within their regular geoscience instruction. For example, a community college geoscience faculty member can use the framework to make critical thinking visible and explicit to their students (i.e., offering why and how critical thinking is happening) while engaging them in a particular problem-solving strategy. By increasing the visibility of critical thinking in the classroom, this can potentially help students to develop, strengthen, and use such strategies to deepen critical thinking both individually and collaboratively. Additionally, making critical thinking more visible allows students to personalize and integrate what it means for them to be a critical thinker. In addition, students can potentially learn how to apply critical thinking to other problem-solving situations.

\section{Future Research}

Based on my findings, I offer four recommendations for future research studies to further understand the areas of implicitness in the pedagogy of critical thinking. First, I recommend broadening the geographical and institutional context for such studies investigating the perceptions of geoscience faculty members and their use of critical thinking. While my work focused on Pacific Northwest community college geoscience faculty members, I wonder if such perceptions, limitations, and findings are similar in other parts of the United States and globally. 
Similarly, although my work focused on community colleges, would research reveal similar findings among geoscience faculty members at four-year institutions where in general, the priority is often more research heavy and less dedicated to pedagogy?

Second, I suggest researchers further examine the relationship between student engagement and critical thinking. In my own study, I found that participants often viewed student engagement as a key precursor to critical thinking, such that their own models of critical thinking were hierarchical and dependent on this initial engagement. However, in reflection, this too seems to be an assumed causal relationship. What exactly is the relationship between student engagement and critical thinking within introductory geoscience courses? Is the implicit assumption that critical thinking will be achieved once students are engaged the most effective way to teach this skill, or is a more visible and explicit method more effective? In other words, is it possible to reverse the order, and introduce critical thinking first to increase student engagement?

Third, I recommend that researchers conduct a pilot study of how to foster this transition from the implicit to explicit teaching of critical thinking within classrooms. This in turn may develop a more accurate framework/model of critical thinking as an action driven process that can actually be used in the classroom. Given the findings of my study, I recommend community colleges as the ideal setting for such a pilot study. In turn, the results of such a pilot study and subsequent collaboration between researchers and geoscience faculty to develop a framework/model of critical thinking for geoscience introductory courses. 


\section{Final Thoughts}

In a recent study regarding racial diversity in U.S. geoscience undergraduate programs Beane et al. (2021) highlighted the need for more representation. In their study, Beane et al. showed that from 1998-2018 the racial diversity among undergraduate geoscience degree grew over the past 20 years in the following ways (a) $3 \%$ to $10 \%$ increase for Hispanic/Latinx students, (b) 2\% to 3\% increase for Black and Asian Americans, (c) below 1\% increase for Native Hawaiian, other Pacific Islanders, American Indian, Alaska Native students. On the other hand, the racial diversity in graduate school programs over the last 40 years has had no progress at all.

Throughout my own study, I often found myself reflecting on my experiences as a former geoscience faculty member at community colleges in Massachusetts and Oregon. Often, I was the only faculty of color. Given Beane et al.'s (2021) findings, perhaps I was not surprised that within my own post-graduate professional experiences I saw few colleagues of color.

If higher education is committed to equity and diversity, this commitment needs to be comprehensive and not just limited to the student body. Recruiting and retaining students of color is not enough if such students do not see themselves represented by their teachers and mentors. A key finding of my study is that increased visibility has the potential to be transformative within pedagogy. If assumptions and implicit roles/definitions are limiting, then perhaps there is a real opportunity for growth if the opposite is true? If dialogue, collaboration, and increasing visibility are critical to addressing the issue of implicitness within the pedagogy of critical thinking, then perhaps 
there is immense value in also exploring the voices of others who have not traditionally been the focus within in academia? What would geoscience departments find if they included the perspectives of more faculty of color like me? How would the experiences of geoscience faculty members of color compare to those of my own? Would there be additional barriers identified? Alternatively, would there be more effective strategies developed by those who have had to deal with limited societal visibility in all other aspects of their lives? The recruitment, hiring, and retention of faculty of color may broaden the zone of proximal development into an arena of growth accessible by all, rather than some. Recruiting, hiring, and retaining faculty of color with their diverse experiences and perspectives is important because they offer unique voices that may transform and advance the pedagogy of critical thinking. 


\section{References}

Abrami, P. C., Bernard, R. M., Borokhovski, E., Waddington, D. I., Wade, C. A., \& Persson, T. (2015). Strategies for teaching students to think critically: A metaanalysis. Review of Educational Research, 85(2), 275-314. doi:10.3102/0034654314551063

American Association of Community Colleges. (2018). Faculty and staff diversity. https://www.aacc.nche.edu/wpcontent/uploads/2018/06/DataPoints_V6N7.pdf Association of American Colleges and Universities. (n.d.) Value Rubric Development Project. https://www.aacu.org/value/rubrics

American Geoscience Institute. (2018). Geoscience career brochure. https://www.americangeosciences.org/workforce/geoscience-careers-brochure

Anderson, D. L. (2006). Plate tectonics; the general theory: Complex Earth is simpler than you think. In C. A. Manduca \& D. W. Mogk (Eds.), Earth and mind: How geologists think and learn about the Earth (pp. 29-38). The Geological Society of America.

Antonio, A. L., Astin, H. S., \& Cress, C. M. (2000). Community service in higher education: A look at the nation's faculty. The Review of Higher Education, 23(4), 373-397. https://doi.org/10.1353/rhe.2000.0015

Aragón, O. R., Eddy, S. L., \& Graham, M. J. (2018). Faculty beliefs about intelligence are Related to the adoption of active-learning practices. Cell Biology EducationLife Sciences Education, 17(3), 1-9. doi:10.1187/cbe.17-05-0084

Arum, R., \& Roksa, J. (2011). Academically adrift: Limited learning on college 
campuses. Universityof Chicago Press.

Bailin, S. (2002). Critical thinking and science education. Science \& Education, 11, 361375.

Bailin, S. (2003). Education, knowledge, and critical thinking. In D. Carr (Ed), Education, knowledge, and truth: Beyond the postmodern impasse (pp. 204-220). Taylor \& Francis. https://doi.org/10.4324/9780203299128

Bailin, S., \& Battersby, M. (2015). Teaching critical thinking as inquiry. In M. Davies \& R. Barnett (Eds.), The Palgrave handbook of critical thinking in higher education (pp. 123-138). Palgrave Macmillan.

Bandura, A. (1986). Social foundations of thought and action: A social cognitive theory. Prentice Hall.

Bandura, A. (2001). Social cognitive theory: An agentic perspective. Annual Review of Psychology, 52(1), 1-26. doi:10.1146/annurev.psych.52.1.1

Beane, R. J., Baer, E. M. D., Lockwood, R., Macdonald, R. H., McDaris, J. R., Morris, V. R., Villalobos, I. J., \& White, L. D. (2021). Uneven increases in racial diversity of US geoscience undergraduates. Communications Earth \& Environment, 2(1), 126. https://doi.org/10.1038/s43247-021-00196-6

Behar-Horenstein, L. S., \& Niu, L. (2011). Teaching critical thinking skills in Higher Education: A review of the literature. Journal of College Teaching \& Learning, $8(2), 25-41$.

Berk, L. E. (2018). Development throughout the lifespan ( $7^{\text {th }}$ ed.). Pearson Education Bers, T. (2005). Assessing critical thinking in community colleges. New Directions for 
Community Colleges, 2005(130), 15-25. doi.org/10.1002/cc.192

Bezuijen, X. M., van Dam, K., van den Berg, P. T., \& Thierry, H. (2010). How leaders stimulate employee learning: A leader-member exchange approach. Journal of Occupational and Organizational Psychology, 83(3), 673-693.

doi.org/10.1348/096317909X468099

Black, M. (1946). Critical thinking. Prentice Hall.

Bloom, B. S. (1965). Taxonomy of educational objectives: The classification of educational goals. David McKay.

Bloom, B. S., Englehart, M. D., Furst, E. J., Hill, W. H., \& Krathwohl, D. R. (1956). Taxonomy of educational objectives. The classification of educational goals, handbook I: Cognitive domain. David McKay.

BoarerPitchford, J. K. (2010). An examination of the assessment practices of community college instructors (Publication No. 3397237) [Doctoral dissertation]. ProQuest Dissertations \& Theses Global.

Burroughs, L. A. (1999). The knowledge and use of critical thinking teaching strategies of faculty in associate degree nursing education programs (Publication No. 9938873) [Doctoral dissertation]. ProQuest Dissertations \& Theses Global.

Caelli, K., Ray, L., \& Mill, J. (2003). 'Clear as mud': Toward greater clarity in generic qualitative research. International Journal of Qualitative Methods, 2(2), 1-13. https://doi.org/10.1177/160940690300200201

Cai, W., \& Sankaran, G. (2015). Promoting critical thinking through an interdisciplinary study abroad program. Journal of International Students, 5(1), 38-49. 
Chirgwin, S. K., \& Huijser, H. (2015). Cultural variance, critical thinking, and indigenous knowledges: Exploring a both-ways approach. In M. Davies \& R. Barnett (Eds.), The Palgrave handbook of critical thinking in higher education (pp. 335-350). Palgrave Macmillan.

Choy, S. (2002). Nontraditional undergraduates (NCES 2002-012). National Center for Education Statistics, U.S. Department of Education.

Choy, S. C., \& Cheah, P. K. (2009). Teacher perceptions of critical thinking among students and its influence on higher education. International Journal of Teaching and Learning in Higher Education, 20(2), 198-206.

Conley, V. M., Leslie, D. W., \& Zimbler, L. J. (2002). 1993 national study of postsecondary faculty (NSOPF:93), Part-time instructional faculty and staff: Who they are, what they do, and what they think (610732011-012) [Data set]. U.S. Department of Education, National Center for Education Statistics. https://doi.org/10.1037/e610732011-012

Creswell, J. W. (2014). Research design: Qualitative, quantitative, and mixed methods approaches ( $2^{\text {nd }}$ ed.). SAGE

Creswell, J. W., \& Poth, C. N. (2018). Qualitative inquiry \& research design: Choosing among five approaches ( $4^{\text {th }}$ ed.). SAGE.

Crowe, A., Dirks, C., Wenderoth, M. P., \& Sundberg, M. (2008). Biology in Bloom: Implementing Bloom's Taxonomy to enhance student learning in biology. $C B E-$ Life Sciences Education, 7(4), 368-381. doi:10.1187/cbe.08-05-0024

Daiute, C. (2014). Narrative inquiry: A dynamic approach. SAGE. 
Dewey, J. (1910). How we think. Heath \& Co.

Ennis, R. H. (2015). Critical thinking: A streamline conception. In M. Davies \& R. Barnett (Eds.), The Palgrave handbook of critical thinking in higher education (pp. 31-48). Palgrave Macmillan.

Facione, P. A. (1990). Critical thinking: A statement of expert consensus for purposes of educational assessment and instruction. Research findings and recommendations (ED315423). ERIC. https://files.eric.ed.gov/fulltext/ED315423.pdf

Facione, P. A. (2015). Critical thinking: What it is and why it counts. Insight Assessment, 9, 1-30. www.insightassessment.com/Resources/Tools-For-Teaching-For-andAbout-Thinking/Critical-Thinking-What-It-Is-and-Why-It-Counts/CriticalThinking-What-It-Is-and-Why-It-Counts-PDF

Flavell, J. H. (1979). Metacognition and cognitive monitoring: A new area of cognitivedevelopmental inquiry. American Psychologist, 34(10), 906-911. doi:10.1037/0003-066X.34.10.906

Forawi, S. A. (2016). Standard-based science education and critical thinking. Thinking Skills and Creativity, 20, 52-62.

Freire, P. (2000). Pedagogy of the oppressed (30 ${ }^{\text {th }}$ anniversary ed.). Continuum. Kindle Edition.

Fuhrman, M. (1996). Developing good multiple-choice tests and test questions. Journal of Geoscience Education, 44, 379-384.

Glaser, E. M. (1941). An experiment in the development of critical thinking. AMS Press. Glesne, C. (2011). Becoming qualitative researchers: An introduction (4 ${ }^{\text {th }}$ ed.). Pearson. 
Glesne, C. (2015). Becoming qualitative researchers: An introduction (5 $5^{\text {th }}$ ed.). Pearson. Kindle Edition.

Graff, G. (2003). Clueless in academe: How schooling obscures the life of the mind. Yale University Press.

Green, S. (2018, October). Explore our colleges. Washington State Board of Community and Technical Colleges. https://www.sbctc.edu/our-colleges/explorecolleges/default.aspx

Gronlund, N. E. (1955). Social perception and teaching effectiveness. The School Review, 63(5), 277-283.

Haas, P. F., \& Keeley, S. M. (1998). Coping with faculty resistance to teaching critical thinking. College Teaching, 46(2), 63-67.

Halpern, D. F. (1999). Teaching for critical thinking: helping college students develop the skills and dispositions of a critical thinker. New Directions for Teaching and Learning, 1999(80), 69-74. doi:10.1002/t1.8005

Halpern, D. F. (2014). Thought and knowledge: An introduction to critical thinking. Psychology Press.

Hobaugh, C. F. (2010). Critical thinking skills: Do we have any? Critical thinking skills of faculty teaching medical subjects in a military environment. U.S. Army Medical Department Journal, Oct-Dec, 48-62.

Horn, L., \& Radwin, D. (2012). The completion arch: Measuring community college student success-2012. College Board Advocacy \& Policy Center. http://media.collegeboard.com/digitalServices/pdf/advocacy/arch/10b- 
3074_Completion_Arch_Web_120410.pdf

Ivanitskaya, L., Clark, D., Montgomery, G., \& Primeau, R. (2002). Interdisciplinary learning: Process and outcomes. Innovative Higher Education, 27(2), 95-111. https://doi.org/10.1023/A:1021105309984

Jaramillo, J. A. (1996). Vygotsky's sociocultural theory and contributions to the development of constructivist curricula. Education, 117(1), 133-140.

Kahlke, R. M. (2014). Generic qualitative approaches: Pitfalls and benefits of methodological mixology. International Journal of Qualitative Methods, 13(1), 37-52. https://doi.org/10.1177/160940691401300119

Keane, C. M. (2018, May). The current and mid-21st century geoscience workforce [Webinar]. American Geophysical Union/American Geophysical Institute Heads and Chairs. https://www.americangeosciences.org/workforce/webinars/currentand-mid-21st-century-geoscience-workforce

Kelley-Quon, L. I. (2018). Surveys: Merging qualitative and quantitative research methods. Seminars in Pediatric Surgery, 27(6), 361-366. doi.org/10.1053/j.sempedsurg.2018.10.007

Kim, K., Sharma, P., Land, S. M., \& Furlong, K. P. (2013). Effects of active learning on enhancing student critical thinking in an undergraduate general science course. Innovative Higher Education, 38(3), 223-235. doi:10.1007/s10755-012-9236-x

King, A. (1995). Designing the instructional process to enhance critical thinking across the curriculum. Teaching of Psychology, 22(1), 13-17. doi:10.1207/s15328023top2201_5 
Kozulin, A. (2003). Vygotsky's educational theory in cultural context. Cambridge University Press.

Krathwohl, D. R. (2002). A revision of Bloom's Taxonomy: An overview. Theory Into Practice, 41(4), 212-218. doi:10.1207/s15430421tip4104_2

LaDue, N. D., \& Clark, S. K. (2012). Educator perspectives on Earth system science literacy: Challenges and priorities. Journal of Geoscience Education, 60(4), 372383.

Lloyd, M., \& Bahr, N. (2010). Thinking critically about critical thinking in higher education. International Journal for the Scholarship of Teaching and Learning, 4(2), 1-16. https://doi.org/10.20429/ijsotl.2010.040209

Lukes, L. A., \& McConnell, D. A. (2014). What motivates introductory geology students to study for an exam? Journal of Geoscience Education, 62(4), 725-735. https://doi.org/10.5408/13-110.1

Manduca, C. A., \& Kastens, K. A. (2012). Geoscience and geoscientist: Uniquely equipped to study Earth. In K. A. Kastens \& C. A. Manduca (Eds.), Earth and mind II: A synthesis of research on thinking and learning in the geosciences (pp. 1-12). The Geological Society of America.

Maxwell, J. A. (2002). Realism and the role of the researcher in qualitative psychology. In M. Kiegelmann (Ed.), The role of the researcher in qualitative psychology (pp. 11-30). Verlag Ingeborg Huber.

Maxwell, J. A. (2013). Qualitative research design: An interactive approach ( $\left.3^{\text {rd }} \mathrm{ed}.\right)$. SAGE. 
Merriam, S. B., \& Tisdell, E. J. (2016). Qualitative research: A guide to design and implementation. Jossey-Bass.

McConnell, D. A., Steer, D. N., \& Owens, K. D. (2003). Assessment and active learning strategies for introductory geology courses. Journal of Geoscience Education, 51(2), 205-216. doi:10.5408/1089-9995-51.2.205

Miles, M. B., Huberman, A. M., \& Saldaña, J. (2020). Qualitative data analysis: A methods sourcebook ( $4^{\text {th }}$ ed.). SAGE.

Morgan, D. L. (1997). Focus groups as qualitative research (2 ${ }^{\text {nd }}$ ed.). SAGE.

National Research Council. (1996). The national science educational standards. The National Academy Press.

https://www.csun.edu/science/ref/curriculum/reforms/nses/nses-complete.pdf

National Research Council. (2011). Assessing 21st century skills: Summary of a workshop. National Academies Press.

Nicholas, M. C., \& Labig, C. E., Jr. (2013). Faculty approaches to assessing critical thinking in the humanities and the natural and social sciences: Implications for general education. The Journal of General Education, 62(4), 297-319. doi.org/10.1353/jge.2013.0022

Nicholas, M. C., \& Raider-Roth, M. (2016). A hopeful pedagogy to critical thinking. International Journal for the Scholarship of Teaching \& Learning, 10(2), 1-10.

Nuhfer, E. B. (1996). The place of formative evaluations in assessment and ways to reap their benefits, Journal of Geoscience Education, 44, 385-394.

Nunn, J. A., \& Braud, J. (2013). A service-learning project on volcanoes to promote 
critical thinking and the earth science literacy initiative. Journal of Geoscience Education, 61(1), 28-36.

Paris, D., \& Alim, H. S. (2017). Culturally sustaining pedagogies: Teaching and learning for justice in a changing world. Teachers College Press.

Pearlman, S. J. (2020). America's critical thinking crisis: The failure and promise of education. Steven Pearlman.

Piaget, J. (1968). Piaget's point of view. International Journal of Psychology, 3(4), 281299. doi.org/10.1080/00207596808246651

Obama, B. (2014). State of the Union 2014 [Speech]. http://www.whitehouse.gov/thepress-office/2014/01/28/president-barack-obamas-state-union-address

Oregon Higher Education Coordinating Commission. (n.d.) Oregon's 17 Community colleges. https://www.oregon.gov/highered/institutionsprograms/ccwd/Pages/community-colleges.aspx

Paul, R. (1992). Critical thinking: What every person needs to survive in a rapidly changing world (Rev. $2^{\text {nd }}$ ed.). Foundation for Critical Thinking.

Paul, R. W., Elder, L., \& Bartell, T. (1997). California teacher preparation for instruction in critical thinking: Research findings and policy recommendations (ED437379). ERIC. https://files.eric.ed.gov/fulltext/ED437379.pdf

Perry, W. G., Jr. (1981). Cognitive and ethical growth: The making of meaning. In A. W. Chickering (Ed.), The modern American college (pp. 76-116). Jossey-Bass.

Provasnik, S., \& Planty, M. (2008). Community colleges: Special supplement to The Condition of Education 2008 (NCES 2008-033). National Center for Education 
Statistics, Institute of Education Sciences, U.S. Department of Education.

Richardson, J. C., \& Ice, P. (2010). Investigating students' level of critical thinking across instructional strategies in online discussions. The Internet and Higher Education, 13(1-2), 52-59. doi:10.1016/j.iheduc.2009.10.009

Rowe, M. P., Gillespie, B. M., Harris, K. R., Steven, D. K., Shannon, L. Y., \& Rose, L. A. (2015). Redesigning a general education science course to promote critical thinking. CBE—Life Science Education, 14(3), 1-12.

Rowles, J., Morgan, C., Burns, S., \& Merchant, C. (2014). Faculty perceptions of critical thinking at a health sciences university. Journal of the Scholarship of Teaching and Learning, 13(4), 21-35.

Sainn, G., \& Ugwuegbu, D. C. E. (1980). Education psychology in a changing world. Unwin Hyman.

Saldaña, J. (2016). The coding manual for qualitative researchers (3 ${ }^{\text {rd }}$ ed.). SAGE.

Seidman, I. (2013). Interviewing as qualitative research: A guide for researchers in the social sciences ( $4^{\text {th }}$ ed.). Teachers College Press.

Shute, R. H., \& Slee, P. T. (2015). Mechanism: The whole is equal to the sum of its parts. In R. H. Shute \& P. T. Slee (Eds.), Child development: Theories and critical perspectives ( $2^{\text {nd }}$ ed., pp. 107-25). Routledge.

Stassen, M. L. A., Herrington, A., \& Henderson, L. (2011). Defining critical thinking in higher education. To Improve the Academy, 30(1), 126-141. https://doi.org/10.1002/j.2334-4822.2011.tb00653.x

Stedman, N. L. R., \& Adams, B. L. (2012). Identifying faculty's knowledge of critical 
thinking concepts and perceptions of critical thinking instruction in higher education. NACTA Journal, 56(2), 9-14.

Tsui, L. (1999). Courses and instruction affecting critical thinking. Research in Higher Education, 40(2), 185-200. doi:10.1023/A:1018734630124

Tudge, J. R. H., \& Winterhoff, P. A. (1993). Vygotsky, Piaget, and Bandura: Perspectives on the relations between the social world and cognitive development. Human Development, 36(2), 61-81. doi.org/10.1159/000277297

Van Der Stuyf, R. R. (2002). Scaffolding as a teaching strategy. Adolescent Learning and Development, 52(3), 5-18.

Van Gelder, T. (2005). Teaching critical thinking: Some lessons from cognitive science. College Teaching, 53(1), 41-48. doi:10.3200/CTCH.53.1.41-48

Vaughan, G. B. (2006). The community college story ( $3^{\text {rd }}$ ed.). American Association of Community Colleges.

Vygotsky, L. (1978). Mind and society: The development of higher psychological processes. Harvard University Press

Wass, R., Harland, T., \& Mercer, A. (2011). Scaffolding critical thinking in the zone of proximal development. Higher Education Research \& Development, 30(3), 317328. doi.org/10.1080/07294360.2010.489237

Wolcott, H. F. (1999). Ethnography: A way of seeing. AltaMira Press.

Wysession, M. E. (2014). The Next Generation Science Standards: A potential revolution for geoscience education. Earth's Future, 2(5), 299-302. doi: $10.1002 / 2014 \mathrm{EF} 000237$ 
Zimmerman, B. J., \& Schunk, D. H. (Eds.). (2001). Self-regulated learning and academic achievement: Theoretical perspectives ( $2^{\text {nd }}$ ed.). Lawrence Erlbaum Associates. 


\section{Appendix A: Recruitment Email}

To: Geoscience Faculty

From: Mariela Bao

Date: [add date]

Subject: Invitation to Participate: Community College Geoscience Faculty Perspectives on Critical Thinking Instructional Tools

Dear [Name],

My name is Mariela Salas Bao; I am a doctoral student at Portland State University in the Department of Curriculum and Instruction. I am also a former community college geoscience faculty member.

I am contacting you about your participation in a research study, "Community College Geoscience Faculty Perspectives on Critical Thinking Instructional Tools." I am inviting you to participate because you are a geoscience faculty member teaching introductory geoscience course(s) at a community college in the Pacific Northwest.

This research study is part of my doctoral dissertation. The purposes of my research are to study (a) the perceptions of community college geoscience faculty toward critical thinking, and (b) how these faculty perceptions play a role (or not) in their chosen instructional tool used to teach geoscience concepts to nontraditional students in the classroom. The possible benefits of your participation include having your voice heard, reflecting on your teaching practice, and expanding your pedagogical knowledge.

I hope you will consider participating in my important study!

Please reply to this email indicating your choice: I am in interested in participating in this study

_ I am not interested in participating in this study.

Thank you in advance for considering my invitation to participate in "Community College Geoscience Faculty Perspectives on Critical Thinking Instructional Tools." 
PSU HUMAN RESEARCH

PROTECTION PROGRAM HRPP \#: 196417-18

\title{
Appendix B: Participant Consent Form
}

\author{
The Portland State University \\ Consent to Participate in Research \\ Community college geoscience faculty perspectives on critical thinking instructional \\ tools
}

January 2019

Introduction

You are being asked to participate in a research study because you are a geoscience faculty member currently teaching introductory geoscience course(s) at a community college in the Pacific Northwest. This research study is being conducted by Mariela Salas Bao, a graduate student under the instruction of Dr. Micki Caskey (Principal Investigator), from the Department of Curriculum and Instruction, at Portland State University in Portland, Oregon. This research study is part of my doctoral dissertation. This research is studying community college geoscience faculty perceptions towards critical thinking and how that plays a role (or not) in their chosen instructional tool used to teach geoscience concepts to nontraditional students in the classroom.

This form will explain the research study and will also explain the possible risks as well as the possible benefits to you. We encourage you to talk with your family and friends before you decide to take part in this research study. If you have any questions, please ask one of the study investigators.

What will happen if I decide to participate?

If you agree to participate, the following things will happen:

You will participate in one question survey (sent via email), one in person audio recorded interview and two classroom observations.

How long will I be in this study?

Participation in this study will involve a 5-10-minute question survey, 90 minutes in person interview and two classroom observations (time will vary depending on your class length) over a period of two weeks.

What are the risks or side effects of being in this study?

There are no major risks associated with participation in this study. The questions that will be asked as a part of the survey and interview will focus your pedagogical experience as faculty, and the degree of discomfort, or the level of risk should not exceed that of regular day-to-day. Participation in this study will not influence employment status in any way. For more information about risks and discomforts, ask the investigator. 
What are the benefits to being in this study?

Current academic goals among postsecondary institutions is to increase our students critical thinking yet, very little information or training has been provided to faculty in order to achieve this goal. As a former geoscience faculty, I would like to learn from you about your perceptions and the teaching methods you have been using to support your students in achieving their use of critical thinking. Additionally, I would like to learn what are the needs of faculty within geoscience to continue strengthen their pedagogical knowledge in order to strengthen their students use of critical thinking. Your voice is an important and valuable part of this study.

How will my information be kept confidential?

I will take measures to protect the security of all your personal information, but we cannot guarantee confidentiality of all study data (please read below for more on this). To protect your personal information, I will not include your name or other identifying information in the final written analysis or any published reports about this study. Additionally, at the end of this study I will destroy any audio recording of the interview session, and classroom observation notes.

Information contained in your study records is used by study staff and, in some cases, it will be shared with the sponsor of the study. The Portland State University Institutional Review Board (IRB) that oversees human subject research and/or other entities may be permitted to access your records, and there may be times when we are required by law to share your information. It is the investigator's legal obligation to report child abuse, child neglect, elder abuse, harm to self or others or any life-threatening situation to the appropriate authorities, and; therefore, your confidentiality will not be maintained.

Will I be paid for taking part in this study?

No

Can I stop being in the study once I begin?

Your participation in this study is completely voluntary. You have the right to choose not to participate or to withdraw your participation at any point in this study without penalty or loss of benefits to which you are otherwise entitled.

Whom can I call with questions or complaints about this study?

If you have any questions, concerns or complaints at any time about the research study, please contact myself, Mariela Salas Bao, at (503) 750-3646, or my advisor, Dr. Micki Caskey at (503) 725-4749. Either of us will be glad to answer them.

Whom can I call with questions about my rights as a research participant?

If you have questions regarding your rights as a research participant, you may call the PSU Office for Research Integrity at (503) 725-2227 or 1(877) 480-4400. The ORI is the office that supports the PSU Institutional Review Board (IRB). The IRB is a group of 
people from PSU and the community who provide independent oversight of safety and ethical issues related to research involving human participants. For more information, you may also access the IRB website at https://sites.google.com/a/pdx.edu/research/integrity.

\section{CONSENT}

You are making a decision whether to participate in this study. Your signature below indicates that you have read the information provided (or the information was read to you). By signing this consent form, you are not waiving any of your legal rights as a research participant.

You have had an opportunity to ask questions and all questions have been answered to your satisfaction. By signing this consent form, you agree to participate in this study. A copy of this consent form will be provided to you.

Name of Adult Subject (print) Signature of Adult Subject Date

INVESTIGATOR SIGNATURE

This research study has been explained to the participant and all of his/her questions have been answered. The participant understands the information described in this consent form and freely consents to participate.

$\overline{\text { Name of Investigator/ Research Team Member (type or print) }}$

(Signature of Investigator/ Research Team Member) Date




\section{Appendix C: Critical Thinking Survey for Geoscience Faculty}

What is this project studying?

You are being asked to participate in a research study because you are a geoscience faculty member currently teaching introductory geoscience course(s) at a community college in the Pacific Northwest. This research study is being conducted by Mariela Salas Bao, a graduate student under the instruction of Dr. Micki Caskey (Principal Investigator), from the Department of Curriculum and Instruction, at Portland State University in Portland, Oregon. This research study is part of my doctoral dissertation. This research is studying community college geoscience faculty perceptions towards critical thinking and how that plays a role (or not) in their chosen instructional tool used to teach geoscience concepts to nontraditional students in the classroom.

What will happen if I decide to participate in this survey?

If you agree to participate, you will be asked to complete a 5-10 minute question survey online via Qualtrics. A link will be provided to you via email. Some of these questions will be about you, about your career path, and any professional development training. Please know this is completely voluntary so if at any point you feel uncomfortable you may skip or stop doing the survey at any time.

How will my information be kept confidential?

To protect your privacy this survey will not request any personal information.

Can I stop being in the study once I begin?

Your participation in this study is completely voluntary. You have the right to choose not to participate or to withdraw your participation at any point in this study without penalty or loss of benefits to which you are otherwise entitled.

Whom can I call with questions or complaints about this study?

If you have any questions, concerns or complaints at any time about the research study, please contact myself, Mariela Salas Bao, at (503) 750-3646, or my advisor, Dr. Micki Caskey at (503) 725-4749. Either of us will be glad to answer them.

Whom can I call with questions about my rights as a research participant?

If you have questions regarding your rights as a research participant, you may call the PSU Office for Research Integrity at (503) 725-2227 or 1(877) 480-4400. The ORI is the office that supports the PSU Institutional Review Board (IRB). The IRB is a group of people from PSU and the community who provide independent oversight of safety and ethical issues related to research involving human participants. For more information, you may also access the IRB website at https://sites.google.com/a/pdx.edu/research/integrity. 
Do you wish to participate?

o Yes

- No

Survey Items

Q1. What are the names of the introductory geoscience courses you teach at the community college?

Q2. How many years have you taught at the community college?

Q3. What is the name of your department/division at the community college you are working?

Q4. Do you teach at more than one community college?

○ No.

○ Yes. If Yes, how many community colleges do you teach?

Q5. What is your area of specialization?

○ Geological Sciences

- Earth Science

○ Volcanology

- Seismology

○ Geophysics

○ Geomorphology

- Hydrology

- Environmental Sciences

○ Geo-biology

○ Other: 
Q6. When you think about critical thinking, which terms come to mind?
○ Reflective Thinking
- Metacognition
- Self Regulation
○ Problem Solving
○ Higher-order learning
○ Bloom's Taxonomy
O Other:

Q7. Which critical thinking frameworks do you know? Select all that apply.

I am familiar with this framework and feel comfortable using it in my classroom.
I am familiar with this framework but have not use it in my classroom.
I am not familiar with this framework.

\section{Bloom's Taxonomy \\ Critical Thinking \\ VALUE Rubrics \\ Paul-Elder Critical \\ Thinking \\ Framework}

Q8. Please indicate your agreement with the statement: The enhancing, strengthening, and deepening of critical thinking within the geosciences involves the interaction among students and faculty

○ Strongly Disagree

- Disagree 
- Neither Agree nor Disagree

$\circ$ Agree

- Strongly Agree

Q9. Have you ever had training on how to teach critical thinking for geosciences courses? Select all that apply.

- I have done formal training on how to teach critical thinking for the geosciences.

- I occasionally read about how to teach critical thinking from articles and/or books.

- I constantly read about how to teach critical thinking from articles and/or books constantly.

I have not had any training.

Q10. Have you ever had training on how to assess critical thinking for geosciences courses? Select all that apply.

I have done formal training on how to assess critical thinking within the geosciences.

- I occasionally read about critical thinking assessment tools from articles and/or books.

- I constantly read about critical thinking assessment tools from articles and/or books.

I have not had any training.

Q11. What is your current position at the community college? 
○ Part-Time Faculty

$\bigcirc$ Adjunct Faculty

○ Instructor

- Assistant Professor

○ Associate Professor

○ Professor

Q12. What is your educational background?

○ Bachelor's degree

- Master's degree

- Doctoral degree (PhD or EdD)

○ Other:

Q13. What gender do you identify as?

○ I identify as:

I prefer not to answer

Q14. What is your ethnicity?

- My ethnicity is:

I prefer not to answer 


\section{Appendix D: First Interview Questions}

Thank you for allowing me to interview you today regarding your experiences with critical thinking and critical thinking instructional tools. I designed these questions to gather information about your experiences with critical thinking. The interview will be 45-minute audiotaped for accuracy of all your answers to the interview questions. There are no right or wrong answers to these questions. If a question makes you uncomfortable you may choose not to answer. Additionally, you may also choose to withdraw from this interview and/or research study at any times with no penalty or consequences.

Although you are currently teaching remotely due to the world addressing COVID19, I would like for you to answer these questions as in light of you past teaching experiences.

What is the format of this interview?

This is a semi-structured interview, which means that I may ask you follow-up questions in between to gather more understanding.

What happens after the interview?

I will provide you with a written transcript of this interview. This will provide you with an opportunity to review your responses and make changes that clarify or correct meaning.

Lastly, everything you say in this interview will be confidential. Your name and institution will not appear in any of the documents or reports.

This first interview will focus on your experiences with critical thinking as the instructor:

Interview Questions:

1. In your own words, please explain what "critical thinking" means to you.

2. How does the geoscience department as a whole in your institution define "critical thinking"?

3. How does the community college where you work define critical thinking?

4. What importance do you place on critical thinking instruction within geoscience curriculum? Why?

5. Reflecting on your prior experiences with critical thinking in high school, college, and graduate school, how did you learn to be a critical thinker? 
6. What is the role of the faculty in the geoscience classroom?

7. What is the practical value in teaching critical thinking within the geosciences?

8. How do you emphasize the practical aspect of critical thinking in connection to the geosciences with your students?

9. What do you believe that your prior knowledge about critical thinking instruction helps your lessons?

10. What do you believe that your prior knowledge about critical thinking instruction hinders your lessons?

Notes for researcher:

Community College:

Date:

Participant Name: Participant number/email:

Interview Location: Duration of Interview: 


\section{Appendix E: Second Interview Questions}

Thank you for allowing me to interview you today regarding your experiences with critical thinking and critical thinking instructional tools. I designed these questions to gather information about your experiences with critical thinking. The interview will be 45-minute audiotaped for accuracy of all your answers to the interview questions. There are no right or wrong answers to these questions. If a question makes you uncomfortable you may choose not to answer. Additionally, you may also choose to withdraw from this interview and/or research study at any times with no penalty or consequences.

Although you are currently teaching remotely due to the world addressing COVID19, I would like for you to answer these questions as if you were teaching face to face. Therefore, please reflect on your experiences during previous term/semester.

What is the format of this interview?

This is a semi-structured interview, which means that I may ask you follow-up questions in between to gather more understanding.

What happens after the interview?

I will provide you with a written transcript of this interview. This will provide you with an opportunity to review your responses and make changes that clarify or correct meaning.

Lastly, everything you say in this interview will be confidential. Your name and institution will not appear in any of the documents or reports.

This second interview will focus on your experiences with critical thinking instructional tools with your students.

Interview Questions:

1. In what way(s) you model critical thinking in your own teaching?

2. Please describe which instructional tools you use to support critical thinking is the classroom?

3. How do you choose which instructional tools you want to use in the classroom?

4. Reflecting on your decision to use a particular critical thinking instructional tool, how do you gauge when your students are critically thinking? Please share some examples. 
5. How do you facilitate for your students to continue on paths of new thinking from yours? Why do you accomplish this?

6. What are the strengths you have experienced while implementing critical thinking in community college geoscience curriculum?

7. What are the challenges you have experienced while implementing critical thinking in community college geoscience curriculum?

8. In what ways do you think your institution support the use of critical thinking instructional tools in the geoscience classroom?

9. Please describe how comfortable you feel about teaching critical thinking in the geosciences.

10. Please describe how comfortable you feel about assessing critical thinking in the geosciences.

Notes for researcher:

Community College:

Date:

Participant Name:

Participant number/email:

Interview Location: Duration of Interview: 